NBER WORKING PAPER SERIES

\title{
THE IMPACT OF GLOBAL WARMING ON RURAL-URBAN MIGRATIONS: EVIDENCE FROM GLOBAL BIG DATA
}

\author{
Giovanni Peri \\ Akira Sasahara \\ Working Paper 25728 \\ http://www.nber.org/papers/w25728 \\ NATIONAL BUREAU OF ECONOMIC RESEARCH \\ 1050 Massachusetts Avenue \\ Cambridge, MA 02138 \\ April 2019
}

The authors would like to thank Brock Smith for his guidance in the construction of the dataset and Justin Wiltshire for his very competent research assistance. The views expressed herein are those of the authors and do not necessarily reflect the views of the National Bureau of Economic Research.

NBER working papers are circulated for discussion and comment purposes. They have not been peer-reviewed or been subject to the review by the NBER Board of Directors that accompanies official NBER publications.

(C) 2019 by Giovanni Peri and Akira Sasahara. All rights reserved. Short sections of text, not to exceed two paragraphs, may be quoted without explicit permission provided that full credit, including $(\odot$ notice, is given to the source. 
The Impact of Global Warming on Rural-Urban Migrations: Evidence from Global Big Data

Giovanni Peri and Akira Sasahara

NBER Working Paper No. 25728

April 2019

JEL No. J61,O13,R23

\begin{abstract}
$\underline{\text { ABSTRACT }}$
This paper examines the impact of temperature changes on rural-urban migration using a $56 \mathrm{~km} \times 56 \mathrm{~km}$ grid cell level dataset covering the whole world at 10 -year frequency during the period 1970-2000. We find that rising temperatures reduce rural-urban migration in poor countries and increase such migration in middle-income countries. These asymmetric migration responses are consistent with a simple model where rural-urban earnings differentials and liquidity constraints interact to determine rural-to-urban migration flows. We also confirm these temperature effects using country-level observations constructed by aggregating the grid cell level data. We project that expected warming in the next century will encourage further urbanization in middle-income countries such as Argentina, but it will slow down urban transition in poor countries like Malawi and Niger.
\end{abstract}

Giovanni Peri

Department of Economics

University of California, Davis

One Shields Avenue

Davis, CA 95616

and NBER

gperi@ucdavis.edu

Akira Sasahara

College of Business and Economics

University of Idaho

875 Perimeter Drive MS 3161

Moscow, ID 83844

sasahara@uidaho.edu 


\section{Introduction}

Internal and international migrations are crucial ways for individuals to pursue better economic opportunities. In aggregate, rural-urban mobility is an important channel through which structural transformation occurs. Internal migration leads to urbanization, which in turn induces economic growth (e.g., $\mathrm{Au}$ and Henderson, 2006). Within this industrialization process some migrants move to other countries, but it is much more common to observe internal migration due to limits and regulations on international migration. Economic development that has deeply transformed countries in recent decades is often associated with heavy internal migration, especially movements from rural areas to urban areas of a country. Examples include the massive rural-to-urban migrations in China (see Chen et al., 2010 and Baum-Snow et al., 2017) and the urbanization of Africa (see Cobbinah et al., 2015). ${ }^{1}$

Within the context of economically driven internal migration, we analyze the effect of temperature changes on this process. Temperature increases (predicted for the future decades) may affect agricultural productivity and income potential, especially in the poor rural areas of developing countries (see, for example, Dell et al., 2012). ${ }^{2}$ While productivity in urban areas is not immune to the effects of warming, it is likely to be less vulnerable than rural productivity because rural areas are more dependent on resource extraction and agriculture. Hence global warming may have important consequences on migration flows from rural to urban areas. On the one hand, global warming may increase incentives to leave rural areas by making them less productive, which may speed up internal migration flows toward urban areas. On the other hand, if a country is still in poverty and rural populations have limited migration opportunities due to a lack of resources, deteriorating agricultural productivity may lower their income, which works to make it harder for them to pay migration costs. As a result, migration flows from rural to urban areas decrease, perpetuating a poverty trap.

This paper is the first to assess the impact of temperatures on countries' internal migration patterns using data on net migration rates from an extremely fine and comprehensive grid of cells covering the whole world. Each cell constituting an observation in our data is a $0.5 \times 0.5$ square degrees (approximately $56 \mathrm{~km} \times 56 \mathrm{~km}$ at the equator) and their aggregate covers the total surface area of Earth. The data are available for the period between 1970 and 2000 at 10 year intervals. We combine these migration data with data on population, temperatures and precipitation at the same level of geographical detail and with national GDP level data to study the impact of temperature on net migration at this very detailed geographical level.

We first document some general patterns of net migration, showing that individuals in a country move, on average, out of rural into urban areas. Importantly, we find that the intensity of rural-tourban migration differs across country groups. We group countries by GDP per capita into a "bin" of

\footnotetext{
${ }^{1}$ Chen et al. (2010) describe that 34.1 million, 67 million, and 140 million individuals migrated to urban China in 1990 , 1999, and 2008, respectively, by referencing prior studies (Cai, 1996; Huang and Pieke, 2003; and China's National Bureau of Statistics Reports). Baum-Snow et al. (2017) report that China's urban population was $29 \%$ of the total population in 1990, and the figure rose to $50 \%$ by 2010 . Cobbinah et al. (2015) document that the urban population in Africa was $14 \%$ in 1950 , increasing to $40 \%$ by 2010 .

${ }^{2}$ According to IPCC (2014), observed global warming from 1850-1990 to 1986-2005 was $0.62^{\circ} \mathrm{C}$. Estimated average annual temperatures in 2050 are higher than the 1990 level by about $4^{\circ} \mathrm{C}$ under a pessimistic scenario (World Bank, 2018). Herring (2012) also note that results from many climate models suggest that global mean temperature could be between 1.1 to $5.4^{\circ} \mathrm{C}$ higher in 2100 than the current level. Lastly, according to IPCC (2013), the mean global mean temperature is expected to rise by 2.6 to $4.8^{\circ} \mathrm{C}$ under the most extreme scenario for 2081-2100, relative to 1986-2005.
} 
poor countries (the bottom $25 \%$ of the world income per capita distribution), a "bin" of middle-income countries (between the $25^{t h}$ and $75^{t h}$ income per capita percentiles), and one of rich countries (above the $75^{\text {th }}$ percentile). The data show that the middle-income group has the greatest rate of rural-to-urban migration.

This empirical observation is consistent with a simple model of economic incentives and costs of migration. Middle-income countries are those where the process of industrialization and economic growth has started. Therefore, individuals' income levels in rural areas are high enough to pay migration costs. In addition, large rural-urban income differentials induce them to move to urban areas. On the other hand, in poor countries, a fewer people have high enough income to pay migration due to rural poverty. Rich countries, finally, have smaller rural-to-urban migration as rural-urban income differentials are smaller and rural populations, which constitute a small group, have little incentive to move to urban areas.

We employ this model to predict the effects of higher temperatures on migration rates from rural to urban areas, assuming that global warming mainly hurts rural areas, which rely on agriculture productivity. In such a context, an increase in temperatures reduces out-migration from rural areas in poor countries because it deteriorates rural productivity, worsening the liquidity constraint and making migration infeasible. On the other hand, rising temperatures increase out-migration from rural areas in middle-income countries because temperature shocks widen the rural-urban income gaps, which work to strengthen individuals' incentives to migrate, once they can pay for migration costs.

These simple predictions of asymmetric responses to weather shocks across countries are also consistent with a collection of previous empirical findings. A large number of studies document that adverse weather shocks increase out-migration from affected areas (e.g., Kleemans and Magruder, 2018, Bohra-Mishra et al., 2014, for Indonesia). On the other hand, studies on extremely poor countries such as Malawi (e.g. Suckall et al., 2017), find that negative climate shocks represented by droughts and sudden flooding reduce internal migration because these decrease individuals' capabilities and livelihood to move to other areas. Kubik and Maurel (2016) show that, using the data from Tanzania, negative weather shocks work to increase or decrease internal migration depending upon the households' initial income because people decide to migrate only if they have high enough income to pay migration costs.

While these results from prior studies are suggestive of heterogeneous migration responses to weather shocks, possibly depending upon income levels of countries, this paper is the first to test a general theory using a grid cell level dataset covering the whole world. We find robust evidence that higher temperatures reduce out-migration from rural areas in poor countries, and increase out-migration from rural areas in middle-income countries. The temperature effects on migration are insignificant in rich countries, as these countries tend to be less agriculture-based and employ advanced technologies that are less sensitively affected by climate.

The results of our grid cell level analysis are then confirmed using country-level observations constructed by aggregating the grid cell level data. Our results are robust to a wide range of different sample selection criteria and specifications. They suggest that global warming will increase the speed of transition to urban economies in countries where structural transformation has already started, but will slow down such transformation in countries where the transition has not yet started. As a result, global warming may accentuate polarization (and reduce convergence) of countries in the world in terms of the level of economic development. 
This paper contributes to the literature on the impact of weather shocks on migration patterns. ${ }^{3}$ Previous studies find that an increase in temperatures in a location induces out-migration from the location (e.g., Zhou, 2011, for China; Joseph and Wodon, 2013, for Yemen; Marchiori et al., 2012, for Sub-Saharan Africa; and Bohra-Mishra et al., 2014, for Indonesia) and rainfall shortages also have similar effects (e.g., Kleemans and Magruder, 2018, for Indonesia; Nawrotzki et al., 2013, for Mexico; Barrios et al., 2006, and Au and Henderson, 2006, for Sub-Saharan Africa; Strobl and Valfort, 2015, for Uganda; and Viswanathan and Kumar, 2015, for India). Catastrophic weather shocks such as Typhoons are also shown to induce internal migrations in Vietnam (Gröger and Zylberberg, 2016). While these studies show that negative weather shocks increase internal migration, other studies (e.g. Suckall et al., 2017) show that negative climate shocks in Malawi, a very poor country, reduced internal migration because those shocks reduced individuals' capacity to migrate.

While country-specific evidence exists, there are only a few studies analyzing data from many countries to find a systematic relationship between the level of economic development and the economic or demographic responses to weather shocks. ${ }^{4}$ Existing articles investigate the impact of weather shocks on the GDP growth rate (Dell et al., 2012), agricultural productivity (Garcia-Verdu et al., 2019), local conflicts (Bosetti et al., 2018), urbanization (Henderson et al., 2017), and international migrations (Cattaneo and Peri, 2016). These last two studies are those most closely related with our paper. Henderson et al. (2017) show that, in Sub-Saharan Africa, drier conditions induced urbanization as they worked as an 'escape' from negative shocks in agriculture-based regions but there are smaller migration responses in industrialized regions. Cattaneo and Peri (2016) find that a higher temperature increases international emigration from middle-income countries and reduces emigration from poor countries. Using much finer geographical units and much more highly detailed data on net migration, our paper shows there are significant internal migration responses to weather shocks that depend on the income level of the country.

The remainder of the paper is organized as follows. The next section presents data sources and descriptive statistics. Section 3 proposes a simple model explaining the asymmetric temperature impacts on internal migrations across countries. Sections 4 and 5 test empirically the relation between temperature and net migration using the grid cell level data and the country-level data, respectively. Section 6 offers some concluding remarks.

\section{Data and Descriptive Statistics}

\subsection{Definition and Sources for the Net Migration Variables}

Our dataset is constructed using data from several sources. The data on net migration come from the Global Estimated Net Migration Grids By Decade, v1 (1970-2000) (de Sherbinin et al., 2015). These data

\footnotetext{
${ }^{3}$ The effects of weather changes, especially in the long-run, are channelled through their impact on agriculture-based economies. Some studies directly test the linkages between climate change and agricultural output or income per capita (e.g., Kleemans and Magruder, 2018; Strobl and Valfort, 2015; and Viswanathan and Kumar, 2015). Burgess et al. (2014) find that, using the district-level data from India between 1957 and 2000, a greater number of high temperature days in a year decreases agricultural yields and wages by $12.6 \%$ and $9.8 \%$, respectively, and increases annual mortality by $7.3 \%$ in rural areas. Jayachandran (2006) finds that rainfall increases agricultural wages in India.

${ }^{4}$ Other related studies employing data on a large number of countries include Beine and Parsons (2015). By working with the data on 137 origin countries and 166 destination countries, Beine and Parsons (2015) find that international migrations are induced by natural disasters. However, these studies not focus on asymmetric reactions to weather shocks across countries.
} 
provide estimates of net migration (in-migration minus out-migration) per $1 \mathrm{~km}^{2}$ grid cell for the $1970 \mathrm{~s}$, 1980s and 1990s. While we provide a detailed description of how the data are produced in the Appendix A, the main procedure is as follows. The data start with a very fine, census-based grid distribution of population in year 2000, from the Global Rural-Urban Mapping Project, Version 1. Data on population growth during the previous decades for the same cross-sectional units, from the History Database of the Global Environment, Version 3.1, are then used to calculate population totals in 1970, 1980, 1990. In the next step, nativity and mortality rates from national/ethnicity/decades specific tables are applied to each grid cell to estimate decennial births and deaths. Lastly, the fact that "births minus deaths plus net migration equals net population growth", is used to find net migrations in each grid cell. ${ }^{5}$ We aggregate this highly detailed data to a $0.5 \times 0.5$ degree resolution. One grid cell used in the analysis in the current paper contains $56 \times 56=3,136$ of original grid cells. This aggregation reduces data volatility from small cells and leads to geographical units whose size is roughly comparable with the size of cities and labor markets.

We match the data on net migrations with the population data obtained from Yamagata and Murakami (2015) at the same level of aggregation. Using these data, we construct net migration rates for grid cell (location) $l$ of country $c$ during the decade ending in year $t$ as follows:

$$
\text { NetMigRate } e_{l, c, t}=100 \times \frac{\text { NetMig } g_{l, c, t}}{\text { Pop }_{l, c, t}-N e t M i g_{l, c, t}}
$$

where $N e t M i g_{l, c, t}$ denotes net migration (a positive or negative number of people) at location $l$ of country $c$ during the period between year $t-10$ and year $t$. As we do not have population data in 1970 but do observe net migration in the 1970-80 period, the initial population in year $t-10$ is inferred as Pop $_{l, c, t}-$ Net Mig $g_{l, c, t}$ and this is inserted in the denominator. By dividing by the initial population, equation (1) provides a standardized measure of net migration. This migration rate is a percentage change in population due to mobility. ${ }^{6}$

We also construct country-level measures of internal migration by aggregating grid cell level observations. The first measure of aggregate internal migration is constructed as follows:

$$
A g g M i g_{c, t}^{\text {Total }}=\frac{1}{2} \sum_{l \in L_{c}}\left|N e t M i g_{l, c, t}\right|
$$

where $L_{c}$ is a set of all locations in country $c$. It shows that absolute values of net migration rates from all grid cells in country $c$ are aggregated, and the sum is divided by two. If one individual migrates from a grid cell to another in the same country, net migration in the source location is -1 and in the destination location is +1 . As a result, the sum of absolute values of these is two. However, since there is only one individual who internally moved in this example, the sum is divided by two to find the total number of internal migrations in a country. This variable is indicated with superscript "Total" because it captures total internal migrations in a country.

We are particularly interested in emigration from rural areas of a country because rural areas are

\footnotetext{
${ }^{5}$ Appendix A describes the procedure in detail

${ }^{6}$ In the initial computation we include all cells in the world. Some of them may have zero population in some decades. When calculating the net migration rates in percent, we trim the values at or above $100 \%$ and at or below $-100 \%$. They are fewer than $0.1 \%$ of all cells and include those areas that go from zero to positive values and vice-versa
} 
expected to be more sensitive to climate change. We therefore also construct different variables capturing this type of emigration. First, a set of grid cells in a country is divided into four groups-rural, middlerural, middle-urban, and urban-based on the levels of population density in the (0-25th], (25th-50th], (50th-75th] and (75th-100th] percentiles within each country. ${ }^{7}$ Then, net out-migration from these grid cells is aggregated as follows:

$$
\begin{aligned}
\operatorname{AggMig}_{c, t}^{\text {Rural Middle-rural }} & =\sum_{l \in L_{c}^{\text {Rural Mid-Rural }}} \mid \text { NetMig } g_{l, c, t} \mid \times \mathbf{1}_{\left(\text {NetMig }_{l, c, t}<0\right)}, \\
\text { AgMMig }_{c, t}^{\text {Rural }} & =\sum_{l \in L_{c}^{\text {Rural }}} \mid \text { NetMig } g_{l, c, t} \mid \times \mathbf{1}_{\left(\text {NetMig }_{l, c, t}<0\right)} .
\end{aligned}
$$

where in the first measure we aggregate grid cells in the rural and middle-rural areas in country $c$, and in the second measure we only aggregate grid cells in rural areas. $\left.\mathbf{1}_{\left(N_{e t M i g}, c, t\right.}<0\right)$ denotes an indicator variable taking unity if the net migration rate $N e t M i g_{l, c, t}$ is negative, and zero otherwise. Because these variables collect only negative net migration rates, these are a good approximation of out-migration from rural areas. Measure (3) captures out-migration from the rural and middle-rural and measure (4) quantifies that from rural areas only. ${ }^{8}$

Using each of these measures of total internal and rural out-migration, we construct the corresponding migration rates by dividing each by the country's population at the beginning of the decade as follows:

$$
\text { AggMigRate } e_{c, t}^{s}=100 \times \frac{A g g M i g_{c, t}^{s}}{\operatorname{Pop}_{c, t-10}},
$$

for $s=$ 'Total', 'Rural Mid-Rural', and 'Rural'. Pop $p_{c, t-10}$ denotes the total population in country $c$ in year $t-10$. Because country-level total population data are available from 1970, we can use the initial population level for the country-level internal migration measures in (5) unlike the grid cell level counterpart (1).

\subsection{Definition and Sources for Climate Data and Country-level Data}

We obtain data on temperatures and precipitation from the Terrestrial Air Temperature and Precipitation: 1900-2006 Gridded Monthly Time Series, Version 1.01 (Matsuura and Willmott, 2007), and construct variables which capture their decennial change:

$$
\begin{aligned}
\Delta T \operatorname{emp}_{l, c, t} & =\overline{\operatorname{Temp}}_{l, c, t}-\overline{\operatorname{Temp}}_{l, c, t-10}, \\
\Delta \operatorname{Prec}_{l, c, t} & =\overline{\operatorname{Prec}}_{l, c, t}-\overline{\operatorname{Prec}}_{l, c, t-10} .
\end{aligned}
$$

\footnotetext{
${ }^{7}$ It is conventional to use population density to define rural/urban areas. According to Ratcliffe et al. (2016), for example, in the case of the U.S., it order to be classified as "urban", a location must have a density of 1,000 people per square mile. Although there are several other classification rules such as land use, we simply employ population density to define rural/urban areas within a country. Alternatively, we use grid cell level GDP to define rural/urban areas to test robustness of our results. See Appendix F.1 for the robustness checks.

${ }^{8}$ An alternative would be to sum all net migration from rural and semi-rural cells, including positive values. That variable is similar to the one constructed here, as rural and mid-rural cells have a large majority of negative net migration
} 
The average terms, $\overline{\operatorname{Temp}}_{l, c, t}$ and $\overline{\operatorname{Prec}}_{l, c, t}$, are defined as follows:

$$
\overline{\operatorname{Temp}}_{l, c, t}=\frac{1}{3} \sum_{k=1}^{3} \operatorname{Temp}_{l, c, t+1-k} \quad \text { and } \quad \overline{\operatorname{Prec}}_{l, c, t}=\frac{1}{3} \sum_{k=1}^{3} \operatorname{Prec}_{l, c, t+1-k},
$$

where $\operatorname{Temp}_{l, c, t}$ and $\operatorname{Prec}_{l, c, t}$ indicate the annual average temperature and the annual average precipitation at location $l$ of country $c$ in year $t$. These are three-year averages of annual average temperatures and precipitations. As a result, equations (6) and (7) measure changes in average temperatures and average precipitations over a decade as these are differences between year $t$ and $t-10$. These variables capture long-run changes in climate, attenuating year-to-year fluctuations and only isolating a decennial trend.

This grid cell level dataset is matched with country-level data using grid cell level country identifiers obtained from the Global Rural-Urban Mapping Project, Version 1 (GRUMPv1): National Identifier Grid (van Donkelaar et al., 2015). The country-level variables are obtained from the World Development Indicators (World Bank, 2018, hereafter WDI).

\subsection{Descriptive Statistics}

This section discusses descriptive statistics from grid cell data shown in Table $1 .{ }^{9}$ We report mean, standard deviation, minimum, and maximum for net migration rates for the full sample, and separately for each of four country groups: poor, lower-middle income, upper-middle income, and rich, based on the 25th, 50th, and 75th percentile of the income per capita distribution in the world. ${ }^{10}$ The first row of the table shows that the average net migration rate is $-6.52 \%$. This negative value implies that net emigration rates are, on average, greater than net immigration rates, which is explained by the fact that people tend to emigrate from low-population-density cells (hence larger negative values of the net migration rate) and immigrate to high density cells (hence lower positive value of the net migration rate).

The table also shows that lower-middle income countries have the largest (in absolute value) negative average net migration rate among all groups. The level of rural-to-urban migrations is highest for these countries at intermediate level of development. A similar relationship between economic development and international emigration is documented by several studies such as Dao et al. (2018) and Clemens (2014). The table also shows average temperatures and their average decennial changes, revealing an average warming of almost half a degree over three decades for most country groups. Precipitations are more stable and their decennial variations are small. ${ }^{11}$

We present some interesting empirical facts using the grid cell level data. First, the four scatter plots in Figure 2 show the relationship between net migration rates for rural locations and temperature changes during the more recent 1990-2000 decade. The red line in each chart is the regression line, and each chart includes countries from one income-level group. We observe that, for poor (and to some extent for lowermiddle income) countries, an increase in temperatures is associated with greater but still negative net migration rates in rural areas, suggesting that a higher temperature reduces out-migration from rural areas of poor countries. In contrast, in upper-middle income countries, rural out-migration rates increase in absolute value (and are negative) with increasing temperatures, implying that rising temperatures

\footnotetext{
${ }^{9}$ See Appendix A.2 for summary statistics of country-level variables.

${ }^{10}$ See Appendix B for a list of countries in each of the four groups.

${ }^{11}$ It also shows population growth rates. These are not at the grid cell level, but rather at the country-level.
} 
induce out-migration from rural areas. In rich countries, a rather flat slope implies only minor effects. Figure 3 shows the migration rates calculated using equation (5) for the three different definitions of aggregate internal migration in a country, by country group and decade. All of the three measures (each represented in a different panel) show that the level of internal migration was largest for lower-middle income countries. This pattern was particularly strong in the '70s and '80s.

Lastly, Figure 4 shows similar correlations to Figure 2, using country-level data. In particular we show the correlation between temperature changes and out-migration from rural areas, defined as

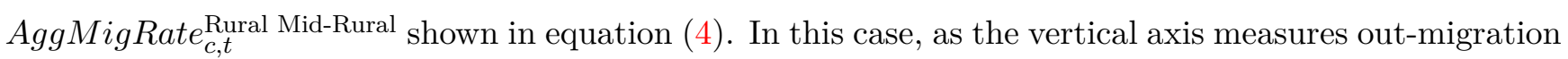
(negative net migration), the slopes of the lines are opposite to those in 2 but the finding is the same. Specifically, there is a negative correlation between temperature change and rural out-migration in poor countries, while the relationship turns positive in lower-middle income countries, and even more positive in upper-middle income countries. These results suggest that a higher temperature reduces rural out-migration in poor countries while it increases such migration in middle-income countries.

\section{A Simple Model}

We consider a simple theoretical framework with agents who have costs and incentives to migrate within a country. The goal is to explain some of the above stylized facts and to offer a prediction of the impact of temperature on rural to urban migration. Once we have shown the qualitative implications of the model, we choose particular parameter values based on empirical observations. We then conduct numerical simulations to understand the effect of economic development and temperature shocks on ruralto-urban migration.

\subsection{The model}

The model includes a country with two regions, "urban" and "rural", indicated by superscripts $U$ and $R$, respectively, each of which differs in productivity. Urban productivity realizations follow a stochastic process. Specifically, the productivity level in the urban region in period $t, A_{t}^{U}$, is as follows:

$$
\ln \left(A_{t}^{U}\right)=\alpha_{0}+\alpha_{1} \ln \left(A_{t-1}^{U}\right)+\epsilon_{t}
$$

where $\alpha_{0}$ is the average productivity growth rate and $\alpha_{1}$ is the degree of persistence of productivity over time. The term $\epsilon_{t}$ denotes a random innovation and is distributed with zero mean and positive variance. On the other hand, rural productivity is determined by the initial rural productivity and urban productivity. Specifically, as in Desmet and Rossi-Hansberg (2009), rural productivity is given by:

$$
A_{t}^{R}=\rho A_{t}^{U}+(1-\rho) A_{t-1}^{R}
$$

which shows that rural productivity is a weighted average of urban productivity and past rural productivity. The parameter $\rho<1$ captures the speed of technology diffusion from the urban to the rural region. A greater $\rho$ leads to a higher speed of technology diffusion and therefore a faster convergence of rural productivity to urban productivity. The initial productivity in the two regions, $A_{1}^{U}$ and $A_{1}^{R}$, is endogenously given and the urban area is more productive than the rural area in the initial period, $A_{1}^{U}>A_{1}^{R}$. 
The wage rate for an individual $i$ in region $J, w_{i, t}^{J}$, is equivalent to labor productivity of the individual in that region and is given by:

$$
w_{i, t}^{J}=A_{i, t}^{J} \delta^{J}\left(T_{t}\right)+\beta^{J} \epsilon_{i}
$$

where $A_{t}^{J}$ is the productivity of the region, $\delta^{J}\left(T_{t}\right)$ is a term capturing the potential productivity effect of temperature, and $\beta^{J}$ indicates the location-specific return to skills. The term $\epsilon_{i}$ indicates human capital that is specific to individual $i$ and transferable to other regions. It follows a normal distribution with a zero mean and a standard deviation of unity. We assume that $\beta^{U}>\beta^{R}$, meaning that returns to skills are greater in the urban region than in the rural region for all workers. ${ }^{12}$ Given productivity in the two regions, $A_{t}^{R}$ and $A_{t}^{U}$, the urban region offers a higher wage than the rural region. This income differential generate incentives for rural-to-urban migration. Given the same price levels across regions for simplicity, income differentials are the only source of incentive to migrate.

An increase in temperature reduces GDP and especially stunts agricultural productivity in poor countries as shown in Dell et al. (2012) and Garcia-Verdu et al. (2019). We use the term $\delta^{J}\left(T_{t}\right)$ to capture the negative effects of an increase in temperatures. In particular, rural productivity decreases if temperatures rise above a certain threshold. On the other hand, urban productivity is not affected by an increase in temperatures. ${ }^{13}$ Specifically, the productivity terms $\delta^{J}\left(T_{t}\right)$ are:

$$
\delta^{U}\left(T_{t}\right)=1 \text { for all } T_{t}
$$

and

$$
\delta^{R}\left(T_{t}\right)= \begin{cases}1 & \text { if } T_{t} \leq T^{*} \\ \gamma_{t} & \text { otherwise }\end{cases}
$$

where $T_{t}$ denotes temperature at time $t ; T^{*}$ is a threshold above which an increase in temperature reduces productivity; and $\gamma_{t} \in(0,1)$ is a parameter capturing the reduced productivity due to high temperatures in the rural economy.

Consider an individual living for two periods. In the first period, she is in the rural region and works to earn income. At the end of the first period, she makes a decision to either migrate to the urban region or remain in the rural region. If she decides to move, she uses a part of her income to pay migration costs. Migration costs are denoted by $C>0$, which includes costs for relocating, traveling, and searching for a job. In the second period, she works and earns in the location she chose. She needs to pay these costs in the first period in order to work in the urban region in the second period.

Therefore, an individual makes a migration decision based on the wage she will receive in the second period at the current location-the expected wage in the urban region (i.e., post-migration)-and the costs of migration $C$. Individual $i$ migrates from the rural region to the urban region at the beginning of period

\footnotetext{
${ }^{12}$ The assumption is supported by a number of studies estimating the spatial difference in the return to observable skills. See, for example, Moretti (2013) and Diamond (2016) for the evidence from the U.S and see Lucas (1997) and Lagakos et al. (2016) for the evidence from developing countries.

${ }^{13}$ Dell et al. (2012) and Garcia-Verdu et al. (2019) find significant impacts of weather shocks in poorer countries only. Mendelsohn et al. (2001) and Mendelsohn et al. (2006) argue that economic development makes countries less sensitive to weather shocks because more developed countries use technologies that are less sensitive to climate as they are more capital-intensive and sophisticated.
} 
$t$ if

$$
A_{t}^{U}+\beta^{U} \epsilon_{i}-C>A_{t}^{R} \delta^{R}\left(T_{t}\right)+\beta^{R} \epsilon_{i}
$$

or simply

$$
\epsilon_{i}>\frac{A_{t}^{R} \delta^{R}\left(T_{t}\right)-A_{t}^{U}+C}{\beta^{U}-\beta^{R}} .
$$

This condition is similar to what would arise in a Roy-Borjas model as the "selection equation". A parameter restriction $\beta^{U}>\beta^{R}$ implies that only individuals with high enough value of $\epsilon_{i}$ (proxy for skills) have an incentive to migrate. One can interpret this equation as an incentive-compatibility condition, which identifies individuals for which migration is compatible with their economic incentives.

The second condition identifies individuals who are able to migrate; thus we call this condition the feasibility constraint. An individual $i$ needs enough income to pay the costs of migration at the end of the first period. Individual $i$ migrates only if the cost of migration is not greater than savings at the end of the first period, which are $w_{i}^{R}=A_{t-1}^{R} \delta^{R}\left(T_{t-1}\right)+\beta^{R} \epsilon_{i}$. The "feasibility constraint" is therefore written as

$$
A_{t-1}^{R} \delta^{R}\left(T_{t-1}\right)+\beta^{R} \epsilon_{i}>C
$$

or

$$
\epsilon_{i}>\frac{C-A_{t-1}^{R} \delta^{R}\left(T_{t-1}\right)}{\beta^{R}}
$$

Individual $i$ migrates from the rural region to the urban region if both of the two conditions, (12) and (13), are satisfied.

Given the distribution of $\epsilon_{i}$ and using equation (12), the fraction of people who have an incentive to migrate from the rural to the urban region is

$$
S_{\text {Selection }, t}^{R}=1-\Phi\left(\frac{A_{t}^{R} \delta^{R}\left(T_{t}\right)-A_{t}^{U}+C}{\beta^{U}-\beta^{R}}\right),
$$

where $\Phi$ denotes the cumulative distribution function of the standard normal distribution. The fraction of people whose feasibility constraint is not binding is, using equation (13),

$$
S_{\text {Feasibility }, t}^{R}=1-\Phi\left(\frac{C-A_{t-1}^{R} \delta^{R}\left(T_{t-1}\right)}{\beta^{R}}\right) .
$$

While the selection equation depends on the current temperature $T_{t}$, the "feasibility constraint" depends on temperature from the previous period $T_{t-1} \cdot{ }^{14}$

The share of individuals who migrate from the rural region to the urban region is

$$
S_{\text {Migration }, t}^{R}= \begin{cases}S_{\text {Feasibility }, t}^{R} & \text { if } S_{\text {Selection }, t}^{R}>S_{\text {Feasibility }, t}^{R} \\ S_{\text {Selection }, t}^{R} & \text { otherwise. }\end{cases}
$$

\footnotetext{
${ }^{14}$ Even though there is a time lag between the two conditions, we consider a case of slow and permanent changes-long-run decennial changes in the average temperatures are used in our empirical analysis. Such decennial change in temperatures will affect subsequent generations' migration through both effects. Both conditions have to be satisfied in order for individual $i$ to be willing and able to migrate.
} 
In the first case where $S_{\text {Selection }, t}^{R}>S_{\text {Feasibility, } t}^{R}$, there are some individuals who have incentives to migrate but whose feasibility constraints are binding. Thus the share of individuals who migrate is given by $S_{\text {Feasibility, } t}^{R}$. If $S_{\text {Selection, } t}^{R}<S_{\text {Feasibility }, t}^{R}$, instead, the overall income level is high enough that the feasibility constraint is not binding anymore. As a result, the share of individuals who migrate is given by $S_{\text {Selection, } t}^{R}$.

\subsection{Numerical Exercise: The Evolution of Rural-Urban Migration}

In order to illustrate how the model works, we simulate a number of hypothetical transition paths of a country from poor to middle-income. Alternatively we can interpret the graph as representing an ordered set of identical countries at different levels of economic development.

\subsubsection{Parameterization}

We choose key parameter values to match the summary statistics from a representative poor economy that has grown significantly in the considered decades, namely Vietnam. We use industrial and agricultural value-added per worker as a rural and an urban productivity, respectively, taken from the WDI (World Bank, 2018). Vietnam's industry-to-agriculture productivity ratio equals 6 in the earliest available year in the dataset, 1991. We therefore set our initial urban-to-rural productivity gap to 6 . The process of productivity growth is specified as $\ln \left(A_{t}^{U}\right)=0.17+0.90 \ln \left(A_{t-1}^{U}\right)+\epsilon_{t}$ where $\epsilon_{t}$ follows a normal distribution with zero mean and a standard deviation of 0.028 . The initial $\log$ productivity is $\ln \left(A_{1}^{U}\right)=1.5$, therefore $A_{1}^{U} \approx 4.48$. The parameter determining the speed of technology diffusion is $\rho=0.025$. A temperature rise is assumed to generate a $10 \%$ decline in rural productivity (i.e. assuming $\delta^{R}=\gamma=0.9$ ), and we analyze the new growth path with lower rural productivity.

The total costs of rural-to-urban migration is set to be 0.6 times the value of urban income, which is a reasonable assumption given that international migration costs are 1-6 times greater than urban income according to Grogger and Hanson (2011). We set returns from skills in the rural region to be $\beta^{R}=1.6$. Herrendorf and Schoellman (2018) estimate returns to schooling in agriculture and industry using data from poor countries and find that returns to schooling are about 1.5 times greater in industry than agriculture. Therefore returns from skills in the urban region is set to $\beta^{U}=1.6 \times 1.5=2.4$. See Appendix $\mathrm{C}$ for more justification for these assumptions.

\subsubsection{Description of Numerical Simulation}

Equipped with the model and with the parameter values, we simulate 1,000 hypothetical paths of urban productivity. Given realized urban productivity in each period, all other endogenous variables are obtained from the model. The stochastic component of a simulation only comes from the error term in equation (8). Figure 5 shows the average path of urban and rural productivity-indicated by dashed and solid lines, respectively-and their one standard deviation bands obtained from the 1,000 simulations. In earlier periods, the rural region has lower productivity but it grows faster than the urban region. As middle-income countries have lower urban-rural productivity gaps, this productivity evolution is considered a transition from a poor country to a middle-income country. ${ }^{15}$ Alternatively, the horizontal

\footnotetext{
${ }^{15}$ The fact that the rural-urban productivity gap declines with development (average GDP per person) is shown in Figure A1 in Appendix D. Furthermore, a number of studies document a time-series declining trend in regional income differentials, so-called convergence (see Sala-i-Martin, 1996, for evidence from the U.S. and Japan).
} 
axis can be interpreted as a set of otherwise identical countries ranked from left to right in ascending level of development-or equivalently, descending order of urban-rural productivity gaps.

Figure 6 shows the averages of the selection equation and of the feasibility condition from the 1,000 simulations. The thinner solid line, representing the selection condition, shows that incentives for ruralurban migration is the greatest at earlier periods because the urban-rural productivity gap is the highest. These incentives decline as the country grows. On the other hand, the thicker solid line, indicating the feasibility constraint, shows that the share of individuals who can afford to migrate is lowest at earlier stages of development and becomes larger at later stages. Lower rural income in earlier periods makes it difficult to migrate. However, as rural productivity rises, a greater share of people have enough income to pay migration costs. Interactions between these two conditions determine the share of individuals who are able and willing to migrate. The share of such individuals first increases, as determined by the feasibility constraint, and then decreases, as determined by the selection equation. The thick solid line in Panel A of Figure 7 shows that the net migration rate has a hump-shaped curve, reaching its maximum around period $t=22$ of our simulation.

Given these results, we now describe the effect of negative temperature shocks on migration. Figure 6 shows the incentive and feasibility conditions when higher temperatures led to a $10 \%$ loss of rural productivity. Such negative shocks shift the feasibility constraint down and move the selection equation up. These shifts imply that the share of individuals who are able to migrate declines while the share of individuals who are willing to migrate increases. A dashed line in Panel A of Figure 7 shows new net migration rates with negative temperature shocks. Panel B describes differences between the net migration rates with temperature shocks and the ones without such shocks. It summarizes the model's main predictions and provides the main hypothesis for our empirical results. An increase in temperatures reduces rural-to-urban migration in countries at lower levels of development. This effect is explained by the fact that the feasibility constraint prevails in these countries and negative temperature effects reduce individuals' income levels and therefore the capacity to migrate. However, for countries at intermediate levels of development a negative temperature shock increases rural-to-urban migrations because it widens the urban-rural productivity gaps, providing stronger incentives to move to the urban region.

Numerical results are summarized as follows:

1 The highest level of rural-to-urban migration is observed when a country is at an intermediate level of economic development.

2 An increase in temperatures decreases rural-to-urban migrations in poor countries while increasing such migration in middle-income countries.

In Figure 8 we represent these results in a space with the vertical axis measuring the net migration rate and the horizontal axis measuring the level of population density (rural areas in the left and urban areas in the right). Plotting average net migration rates in this space should lead to an upward-sloping net migration line crossing the zero horizontal line, because the net migration rates are negative in rural regions and positive in urban regions. We call this upward-sloping line the 'net migration line'.

The first result of our model implies that the net migration line is flatter for poor and rich countries and steeper for middle-income countries, as shown in Figure 8. The second result is also described in the figure. The dashed lines in the graph represent net migration rates before the temperature increase, 
while the solid line represents the migration line after the temperature increase. The temperature increase reduces, in absolute value, the net migration rates in poor countries because fewer people emigrate from rural areas due to the negative productivity shock. This causes a clockwise rotation of the red line in Figure 8 from the dashed to the solid one. To the contrary, the temperature increase would steepen the net migration line of middle-income countries, producing a rotation of the blue line, from the dashed to the solid one, because it leads to larger emigration (negative net migration) from rural areas and larger positive net migration in urban areas.

\section{Empirical Analysis using Grid Cell Level Observations}

Guided by the theoretical predictions in the previous section, we first estimate the slope of the net migration line for each of the four country groups. We then examine whether an increase in temperature affects net migration rates, and if temperature effects differ depending upon the income levels of countries.

\subsection{Estimating the Slope of the Net Migration Lines}

The first set of regressions address the following two questions. (1) What is the direction of internal migration? (2) Do we observe different levels of internal migration across countries? To answer these questions, we calculate average net migration rates over the period 1970-2000 in rural, middle-rural, middle-urban, and urban areas of each country, where these are defined by population density in the earliest available year, 1980, as described in section 2.1. Countries are divided into four groups: poor, lower-middle, upper-middle, and rich, as described in section 2.3.

Panel A of Figure 9 shows the estimated simple average net migration relative to the world average in each of the four areas and for each of the four groups of countries. The horizontal axis measures relative population density. The $95 \%$ confidence intervals associated with those averages are also shown. Panel B of Figure 9 shows average net migration rates, controlling for country and grid cell specific characteristics, obtained by estimating the following regression:

$$
\text { NetMigRate }_{c, l, t}=\alpha_{1} \Delta \text { Temp }_{l, c, t}+\alpha_{2} \Delta \operatorname{Prec}_{l, c, t}+\sum_{g \in G} \alpha_{3}^{g} D_{l, c}^{g}+\mathbf{X}_{l, c, t} \alpha_{4}+u_{l, c, t} .
$$

The dependent variable NetMigRate $_{c, l, t}$ denotes the net migration rate in location (grid cell) $l$ of country $c$ during the decade from year $t-10$ to year $t . \Delta T e m p_{l, c, t}$ and $\Delta \operatorname{Prec}_{l, c, t}$ are decennial changes in average temperatures and precipitation, respectively. The variables $D_{l, c}^{g}$ are three dummy variables taking value one if location $l$ is in area $g$ for $g=$ rural, middle-rural, middle-urban, and urban in country $c$, and $G$ is the set of the four areas. We drop an intercept from the regression so that we can include all of the four dummies. The $\mathbf{X}_{l, c, t}$ is a vector of control variables including grid cell level population growth rate, and country fixed effects. $u_{l, c, t}$ denotes an error term. We estimate equation (16) separately for the four groups of countries.

Panels A and B of Figure 9 show similar net migration averages with or without controls, and with a different standardization. We observe an upward-sloping relation of net migration rates in each country group with relative density. Cells in urban and middle-urban areas have positive net migration rates (i.e., receiving people on net). On the other hand, cells in rural and middle-rural areas have negative 
net migration rates on average (i.e., sending people on net). These suggest that internal migrations are directed from rural areas to urban areas.

The figure also shows a clear across-group difference in net internal migration. Poor and rich countries exhibit a flatter net migration line, and middle-income countries have the steepest net migration rate. ${ }^{16}$ These patterns of internal migration are consistent with our model's prediction that rural-to-urban migration is highest at intermediate levels of development. We note that this relationship between internal migration and economic development is similar to that between international migration and economic development documented in Dao et al. (2018) and Clemens (2014). Those studies show that emigration from a country increases as the country becomes richer, but after a certain development level further development reduces emigration from the same country. Our data show that economic development has a similar effect on internal migration.

\subsection{Effects of a Temperature Increase}

\subsubsection{Regression Model to Estimate the Temperature Effect with Grid Cell Level Data}

We now investigate temperature affects on the net migration rates. Guided by the theoretical prediction, we allow for different migration responses to temperature shocks across areas of different population density and across income groups of countries. Specifically, our regression equation introduces interaction terms between the three dummies capturing relative population density within a country and temperature changes. It is specified as follows: ${ }^{17}$

$$
\begin{aligned}
\text { NetMigRate }_{c, l, t}= & \alpha_{0}+\alpha_{1} \Delta \text { Temp }_{l, c, t}+\sum_{g \in G \backslash\{\mathrm{Urban}\}} \alpha_{1}^{g} D_{l, c}^{g} \Delta T e m p_{l, c, t}+\alpha_{2} \Delta \text { Prec }_{l, c, t} \\
& +\sum_{g \in G \backslash\{\mathrm{Urban}\}} \alpha_{2}^{g} D_{l, c}^{g} \Delta \operatorname{Prec}_{l, c, t}+\sum_{g \in G \backslash\{\mathrm{Urban}\}} \alpha_{3}^{g} D_{l, c}^{g} D_{t}+\mathbf{X}_{l, c, t} \alpha_{4}+e_{l, c, t},
\end{aligned}
$$

where $D_{l, c}^{g}$ are the dummies taking unity for area $g=$ rural, middle-rural, and middle-urban within country $c$. $D_{t}$ denotes a time (decade) dummy. The 'urban area' dummy $D_{l, c}^{\text {Urban }}$ is excluded from the interaction terms, as indicated in the expression. As a result, the main coefficient of temperature changes $\alpha_{1}$ measures the impact of temperature shocks in the urban area. The coefficients for the interaction terms capture differences in temperature effects on the net migration rates relative to the effect for urban regions. For example, $\alpha_{1}^{\text {Rural }}$ captures the difference between the temperature effects in the urban area and that in the rural area. A linear combination of coefficients, $\alpha_{1}+\alpha_{1}^{\text {Rural }}$, measures the temperature effects in the poor area. We estimate regression (17) separately for countries in the poor, lower-middle income, upper-middle income, and rich groups of the world distribution of GDP per capita.

\footnotetext{
${ }^{16}$ The parameter estimates imply that rural and middle-rural areas of lower-middle income countries experience emigration that reduces their population by $15-20 \%$ every decade. Emigration from rural and mid-rural areas of poor countries is, instead, $5-15 \%$ of the population in each decade. That same rate is down to $0-5 \%$ of the population in rich and middle-rich countries. The urban regions of each country, considering the simple average chart, receive immigration in the order of $5-7 \%$ of their population in each decade.

${ }^{17}$ In the baseline estimation, standard errors are clustered at the grid cell level. We consider possible spatial correlation of the error term because one grid cell is fairly small (about $50 \mathrm{~km} \times 50 \mathrm{~km}$ ) and climatic conditions are correlated across space, which may lead to standard errors which are smaller than they are supposed to be. In order to correct for possible spatial error correlations, in Appendix F.3, we show three other sets of standard errors clustered at more aggregated grid cells. We find that our baseline results remain qualitatively unchanged.
} 
Estimating equation (17) makes it possible to test the implications described in Figure 8. One of them is that, in poor countries, higher temperatures reduce the slope of the net migration line. In other words, rising temperatures reduce out-migration from rural areas and have little effect on urban areas. Therefore we expect the following:

Temperature effects in poor countries: $\alpha_{1}^{\text {Rural }}>\alpha_{1}^{\text {Middle-rural }}>\alpha_{1}^{\text {Middle-urban }}>\approx 0$.

The coefficient $\alpha_{1}^{\text {Rural }}$ is positive because rising temperatures induce a fewer people to emigrate from the rural area, increasing the net migration rate (e.g., if the number of individuals who emigrate decreases by $50 \%$, keeping population constant, the net migration rate changes from $-6 \%$ to $-3 \%$ ). Because the temperature effects are expected to be greatest in rural areas, the coefficient is largest for rural areas and the ones for urban areas are smaller.

On the other hand, in middle-income countries an increase in temperatures would increase the slope of the net migration line. Hence, we expect the following results:

Temp. effects in middle-income countries: $\alpha_{1}^{\text {Rural }}<\alpha_{1}^{\text {Middle-rural }}<\alpha_{1}^{\text {Middle-urban }}<0$.

Contrary to the case of poor countries, the coefficient $\alpha_{1}^{\text {Rural }}$ is negative because increasing temperatures induce more people to emigrate, reducing the net migration rate (e.g., if the number of individuals who emigrate increases by $50 \%$, keeping population constant, the net migration rate changes from $-6 \%$ to $-12 \%$ ). The absolute value of the coefficient declines as moving towards urban areas as these areas are less affected by temperature shocks. Lastly, if rich countries exhibit limited rural-urban migration as income differentials are small and once economic and urbanization transition has fully taken place, we expect the following:

Temp. effects in rich countries: $\alpha_{1}^{g} \approx 0$ for $g=$ Rural, Middle-rural and Middle-urban.

Armed with these conjectures, we show the temperature effects implied from equation (17), estimated separately for each income group of countries.

\subsubsection{Baseline Results on the Temperature Effect with Grid Cell Level Data}

Table 2 summarizes our baseline results and Figure 10 plots the linear combinations of the estimated coefficients that gives the effect of temperature on net migration in each density area. The four graphs in Panel A show the effect of a $1^{\circ} \mathrm{C}$ rise in temperatures on the net migration rate, in percentage points, with $95 \%$ confidence intervals, for rural, middle-rural, middle-urban and urban areas. ${ }^{18}$ It shows two important results. First, rural areas of a country are more affected by temperatures than urban areas. Second, there are clear cross-country differences in line with the prediction of the model-higher temperatures have a positive effect on the net rural migration rate in poor countries, and have a negative effect on rural

\footnotetext{
${ }^{18}$ We only show the coefficients on temperature change. While we also include in every regression the precipitation changes interacted with the same dummies, those coefficients turn out to be small and usually not significant, so we do not show them. Table 2 shows results separating country groups between poor, lower-middle income, and upper-middle income countriesleaving out rich countries-for which effects are always very small. Figure 10 plots temperature effects from rich countries as reference.
} 
migration in upper-middle income countries.

In order to see more clearly how the effect of temperature works to change net migration rates, Panel B of Figure 10 shows average net migration rates with and without the estimated temperature effects. The dashed lines show the average net migration rates before the increase in temperature, while the solid lines indicates those which include the effect of increasing temperature, shown in Panel A. The solid lines are obtained by calculating the effect of a significant rise in temperatures - defined as the 90th percentile of historical changes in the average temperature over the period 1970-2000 - on net migration rates.

Several interesting patterns emerge. First, rising temperatures work to reduce rural out-migration in poor countries. The positive temperature effects are particularly significant in the rural regions of poor countries-a $1^{\circ} \mathrm{C}$ rise in temperatures increases the net migration rate by 4.7 percentage points. The temperature effects are positive in middle-rural areas although these are insignificant. In contrast, temperature effects turn to be negative in urban areas. These results imply that a rise in temperature flattens (or attenuates) the net migration line of poor countries because it reduces rural-to-urban migration. On the other hand, a rise in temperature increases rural-to-urban migration in upper-middle income countries. The temperature effects on net migration rates are negative and most significant in rural areas, while they are close to zero in urban areas. This implies that a higher temperature works to steepen the slope of the net migration line in the upper-middle income countries, especially by increasing emigration from rural areas.

Third, for rich countries, temperature effects are small in magnitude and generally non-significant. In rich countries, rural productivity may be less affected by temperature, as documented in prior studies (e.g., Dell et al., 2012). Moreover income inequality is smaller, and the scope for rural-to-urban migration more limited, as most of the population is in urban areas. Thus these insignificant results are not surprising. Lastly, in lower-middle income countries, a higher temperature reduces the net migration rate in the urban regions and it has an insignificant effect in the rural regions. These effects are somewhat different from the theoretical predictions. This is presumably due to the fact that this group includes countries in the middle of a transition from being a poor country to being a middle-income country, making it difficult to observe a clear-cut temperature effect. In the next section, we show that the temperature effects on this group turn to be consistent with the theory once non-linearity of temperature effects are taken into consideration.

\subsubsection{Robustness Checks on the Temperature Effect with Grid Cell Level Data}

This section addresses a number of potential critiques to our baseline results. First, prior studies show that temperatures have non-linear effects, meaning that rising temperatures have a negative impact on economic variables above a certain threshold (e.g., Burke et al., 2015; Schlenker and Roberts, 2009; Bohra-Mishra et al., 2014). ${ }^{19}$ In order to respond to this potential critique, we interact temperature changes with a dummy variable taking unity if average temperatures are above the 75 th percentile of the

\footnotetext{
${ }^{19}$ Burke et al. (2015) show that global productivity is maximized when the annual average temperature is at $13^{\circ} \mathrm{C}$ and a further increase in temperatures reduces world production. Schlenker and Roberts (2009) focuses on the effect of temperatures on crop yield and finds that crop production increases up to $29-30^{\circ} \mathrm{C}$ before declining once temperatures pass the threshold. Bohra-Mishra et al. (2014) show that the migration likelihood is also a non-linear function of temperature using the householdlevel data from Indonesia. Therefore, some previous studies include the level of temperatures, its square term, and even higher order polynomials to allow non-linearity (e.g., Burke et al., 2015; Bohra-Mishra et al., 2014) or introduce a step damage function of temperatures by introducing dummies (e.g., Schlenker and Roberts, 2009; Garcia-Verdu et al., 2019).
} 
world temperature distribution. This makes it possible to examine whether there is an additional effect of temperature changes in grid cells that are already hotter than most.

Figure 11 presents estimated temperature effects, separately in hot grid cells and other grid cells. The temperature effects in poor countries are not very different between hot and less hot areas. On the other hand, temperature effects are different across hot and less hot areas in lower-middle income countries. Interestingly, less hot areas react to a higher temperature in the same way as poor countries, while hot areas respond to it as in upper-middle income countries. Our explanation for these results are as follows. First, in less hot areas, rising temperatures probably work to increase agricultural productivity because temperatures have a non-linear effect on agricultural production. As a result, a higher temperature improves economic conditions, inducing fewer people to emigrate from those areas. Therefore negative net migration rates increase. Second, in hot areas, rising temperatures reduce agricultural productivity, which induces emigration from those areas as in upper-middle income countries. The third panel shows that, in upper-middle income countries, rising temperatures have greater effects in hot areas, which increases emigration from rural areas more significantly than in less hot areas.

Results from a series of other robustness checks are summarized in Figure 12. Panels A, B, and C show results from poor, lower-middle income, and upper-middle income countries, respectively. Each of of these panels includes four charts for rural, middle-rural, middle-urban, and urban, from left to right. Each chart shows point estimates and associated $95 \%$ confidence intervals for six different specifications as indicated in the chart for the rural area. Specification (1) drops observations with extreme temperature changes where these are defined as $\Delta T e m p_{l, c, t}$ above the 95 th percentile and below the 5 th percentile of the distribution in the data used in the regression. Specification (2) omits observations with extreme precipitation, $\Delta \operatorname{Prec}_{l, c, t}$, greater than the 95 th or less than the 5 th percentiles. Specification (3) excludes both extreme temperature changes and precipitation changes. Specification (4) drops extreme net migration observation changes, defined as the top $1 \%$ and bottom $1 \%$ of the net migration rates in the baseline sample. Specification (5) excludes observations from Sub-Saharan Africa, as previous studies argue that countries in the region are different in terms of the impact of weather shocks. ${ }^{20}$ If so, our results may be driven by countries in the region. Lastly, in specification (6), we drop highly urbanized countries (with urban population above the 75th percentile of the distribution) as they may have small impacts from agricultural productivity. Overall, the results show that these additional considerations do not change much the baseline results. Estimates from the cell-level analysis are quite robust and stable.

\section{$5 \quad$ Analysis using Country-level Data}

We examine the impact of temperatures on rural-to-urban migration using aggregate data at the country-level. We first discuss our regression model and then present estimation results. The estimated coefficients from these regressions and the anticipated temperature changes in the next 80 years are then used to predict current and future internal migration rates.

\footnotetext{
${ }^{20}$ For example, Barrios et al. (2010) show that rainfall shortages in Sub-Saharan Africa during 1960-2000 are responsible for lower income levels in the region today. They also argue that the significant rainfall impacts are observed in poor SubSaharan African countries but not in other countries. Barrios et al. (2006) find that rainfall shortages induced urbanization in Sub-Saharan African countries and argue that the climate-induced urbanization is not observed elsewhere.
} 


\subsection{Empirical Framework for Country-level Analysis}

To analyze the impact of temperatures on rural-urban migration with country-level data, we estimate the following equation:

$$
\text { AggMigRate }_{c, t}^{s}=\gamma_{0}+\gamma_{1} \Delta \operatorname{Temp}_{c, t}+\sum_{h \in H \backslash\{\text { Rich, Up-mid }\}} \gamma_{1}^{h} D_{c}^{h} \Delta T e m p_{c, t}+\mathbf{X}_{c, t} \gamma_{3}+\epsilon_{c, t},
$$

for $s=$ "Total" and "Rural Mid-rural", and these dependent variables are defined in section 2.1. We use a sample excluding rich countries because these countries exhibit little rural-to-urban migration, and temperature effects are mostly insignificant in those countries. $\Delta T e m p_{c, t}$ denotes changes in countrylevel long-run average temperatures. $H$ is a set of groups of countries including poor, lower-middle, upper-middle, and rich. $D_{c}^{h}$ indicates a dummy variable taking unity if country $c$ is in group $h$ and zero otherwise.

Because we exclude observations from rich countries from the sample and the regression equation introduces interaction terms with a poor country dummy $D_{c}^{\text {Poor }}$ and a lower-middle country dummy

$D_{c}^{\text {Lower-middle }}$, the coefficient for $\Delta T e m p_{c, t} \gamma_{1}$ quantifies temperature effects in upper-middle countries. A linear combination of two coefficients produces the effect on lower middle-income and poor countries. For instance, $\gamma_{1}+\gamma_{1}^{\text {Poor }}$, measures temperature effects on poor countries. The term $\mathbf{X}_{c, t}$ denotes a vector of country-level controls. Our baseline model includes the GDP population growth rates where these are long-run rates of change from the beginning of the decade to the end of the decade. Then we introduce precipitation, the log of initial population, the log of initial GDP, the initial agricultural and manufacturing value-added as a share of GDP, and their decennial changes as controls. $\epsilon_{c, t}$ is the error term.

Because we construct these measures from grid cell level observations, our sample includes more than 160 countries. However, we omit several small countries and islands where measurement errors in aggregation can be large, and we include countries for which we have some basic control variables (such as GDP) going back to 1970. These reduce the sample size substantially. ${ }^{21}$ We also exclude rich countries from the regressions. As a result, the total number of countries in the sample is 77 .

\subsection{Country-level Results}

Baseline results are summarized in Table 3. Panel A shows the effects of a $1^{\circ} \mathrm{C}$ rise in temperatures on the total internal migration rate constructed using formula (2). Panel B shows the effect of the same rise in temperature on the rural out-migration rates defined in formula (3). Each panel shows estimated coefficients for the dummies and linear combinations of the coefficients indicating temperature effects on the country-level migration rates. Column (1) includes only temperature changes without introducing any interaction term with income-level dummies. The two panels show a small insignificant temperature effect. However, it does not allow different responses to temperatures across income groups of countries, which is an important distinction as suggested by the grid cell level analysis.

Column (2) adds interaction terms between temperatures and income-level dummies, making it possible to estimate heterogeneous migration responses to temperatures depending on the income-level of countries. This specification shows that, in upper-middle income countries, higher temperatures increase

\footnotetext{
${ }^{21}$ See Appendix B for the list of the countries.
} 
total internal migration rates by around 2 percentage points and rural out-migration rates by 0.6 percentage points. On the other hand, in poor countries the same increase in temperatures reduces these two measures of internal migration rates by about 3 and about 2 percentage points, respectively.

Columns (3), (4) and (5) introduce additional controls. Column (3) adds precipitation. The levels of population and GDP are controlled for in column (4). Industrial structures of the countries are controlled for in column (5). In columns (4) and (5) of Panel A, the negative temperature effects in poor countries lose statistical significance, presumably due to the fact that total internal migration rates employed in the regressions include all internal migrations in addition to rural out-migrations. However, as shown in Panel B, the temperature effects on the rural out-migration rates are significant in all columns. The fact that only the effects on rural out-migration rates remain significant in all columns is consistent with the model's theoretical explanation. Coefficients from lower-middle income countries are insignificant. These insignificant effects in lower-middle income countries are consistent with the grid cell level results that, in this group of countries, rising temperatures have limited effects in less hot areas and we observe poor-country-like effects in hot areas only. Overall, the results from the country-level data confirm our grid cell level evidence.

\subsection{Robustness Checks for Country-level Results}

We conduct a set of robustness and present results in Figure 13. Panels A and B show estimated temperature effects on the total internal migration rates and the rural out-migration rates, respectively. Each of the two panels shows point estimates for poor, lower-middle, and upper-middle countries, from the left to the right. Vertical bars indicate $95 \%$ confidence intervals. The first four plotted bars describe the results from columns (2)-(5) in Table 3. Subsequent bars show results from additional robustness checks. The fifth bar in the chart drops observations with extreme temperature changes, which is defined as temperature changes above the 95th percentile of the distribution. The sixth bar includes a dummy to control for countries whose average temperature is above the 75 th percentile. The seventh bar omits observations with extreme precipitation changes, defined using the 95th percentile of the distribution of precipitation changes. The eighth bar omits observations with extreme internal migration rates, defined as top $1 \%$ and bottom $1 \%$ of the migration rate observations for each measure. All of these are to check weather outliers are drivers of our results. Results from these robustness checks are similar to our baseline results.

The ninth bar omits urban countries defined as those with urban populations greater than the 75 th percentile of the observations in 1970. The tenth bar excludes less agriculture-based countries, defined as those with agricultural value-added as a share of GDP less than the 25 th percentile in $1990 .{ }^{22}$ Prior studies show that agricultural sectors are more sensitively affected by weather shocks (e.g., Mendelsohn et al., 2001; Mendelsohn et al., 2006; and Schlenker and Roberts, 2009). Therefore, these excluded countries are less suited to the model's underlying mechanisms leading to migratory responses to rising temperatures. Therefore these are expected to magnify the temperature effects on the internal migration rates. Indeed, in Panel B the temperature effects on poor countries become about 0.2 percentage points greater and the

\footnotetext{
${ }^{22}$ The data on urban population come from 1970 while the data on agricultural value-added share come from 1990 . This inconsistency in the year that data were retrieved is due to a difference in availability of a large enough sample. The data are obtained from the WDI (World Bank, 2018).
} 
effects on upper-middle income countries also become about 0.35 points greater in absolute values due to exclusions of less suited countries. Overall, Figure 13 shows that our results are robust to dropping outliers and excluding some sub-sets of the baseline sample.

Lastly, we acknowledge that the temperature effects on the total migration rates are not robust as shown in Panel A. While these are significant in all columns except for the one considering extreme precipitation changes for upper-middle income countries, those on poor countries are insignificant in all specifications for robustness checks. As we discussed already, this is probably due to the fact that temperatures affect rural-to-urban migrations only. The dependent variable employed in Panel A includes all internal migrations. Therefore, insignificant temperature effects are not surprising as this measure does not accurately capture rural-to-urban migration.

\subsection{Projecting Internal Migration Rates for 2020-2100}

This section predicts the expected migration responses to temperature changes for the period 2020 2080 using the estimated coefficients in regression (18) and projected temperature changes in the decades spanning 2020-2100 obtained from the Climate Change Knowledge Portal (World Bank, 2018). It provides projections under a pessimistic scenario called A2, based on a forecast of higher carbon emissions and therefore higher increase in average temperatures, and an optimistic scenario called B1, based on a lower emission forecast. Projected average temperatures are shown in Figure 14 where the lines in the middle are the median projection and an associated band indicates a range of 10th and 90th percentiles of projections. The left and right panels show projections under A2 and B1 scenarios, respectively. All groups of countries-poor, lower-middle, and upper-middle-are expected to experience an increase in temperatures of about $4^{\circ} \mathrm{C}$ and of $2.3^{\circ} \mathrm{C}$ by the year 2100 under the A2 and B1 scenarios, respectively.

Expected internal migration rates are obtained by using the estimated coefficients from the countrylevel regression (18), with all variables kept constant at the level in 2000, and only the temperature changing to its projected values in the coming decades $t=2020-40,2040-60,2060-80$, and 2080-2100, as follows:

$$
\operatorname{AggM\operatorname {igRat}_{c,2000,t}^{s}}=\hat{\gamma}_{0}+\hat{\gamma}_{1} \Delta T e m p_{c, t}^{\text {Projection }}+\sum_{g \in G} \hat{\gamma}_{1}^{g} D_{c}^{g} \Delta T e m p_{c, t}^{\text {Projection }}+\mathbf{X}_{c, 2000} \hat{\gamma}_{3}+\hat{\epsilon}_{c, 2000}
$$

where AggM $\widehat{\text { gRat }_{c}^{s}}{ }_{c, 2000, t}$ denotes the predicted internal migration rates in country $c$ during the decade between year $t-10$ and year $t$, including all internal migration if $s=$ 'Total' and only rural out-migration if $s=$ 'Rural Mid-Rural'. It includes subscript 2000 because it uses control variables, other than the temperature, taken from the period 1990-2000. $\hat{\gamma}_{0}, \hat{\gamma}_{1}, \hat{\gamma}_{1}^{g}$, and $\hat{\gamma}_{3}$ denote estimated coefficients and $\hat{\epsilon}_{c, t}$ are the estimated residuals. We use estimated coefficients from column (3) of Table 3 to perform this exercise. $\Delta T e m p_{c, t}^{\text {Projection }}$ are projected temperature changes in every two decades, 2020-2040, 2040-2060, 20602080, and 2080-2100, compared with a control period of 1961-1999. In order to match with our regression specifications exploiting historical decennial changes in the average temperatures, we divide these projected changes by two to find the decennial migration relative to the average temperature level during the period 1961-1999. As a result, computed migration rates are the ones expected when temperature levels rise to the projected levels relative to the average temperatures during 1961-1999. Variations in these predicted variables come from cross-sectional and time-series variations in $\Delta T e m p_{c, t}^{\text {Projection }}$ as predicted for future 
decades.

Figure 15 summarizes results from this exercise. ${ }^{23}$ Panel A shows the expected total internal migration rates while Panel B presents the rural out-migration rates. Both panels show poor countries are expected to experience a decline of internal migrations. Panel A shows that the average total internal migration rate in poor countries was $7.10 \%$ in 2000 . This figure is expected to decline to $5.03 \%$ and $5.48 \%$ by 2080-2100 under A2 and B1 scenarios, respectively. Panel B shows that the average rural out-migration rate was $1.92 \%$ in 2000 . This number is expected to decline to $1.37 \%$ and $1.89 \%$ by $2080-2100$ under the two scenarios, respectively.

In contrast with poor countries, upper-middle income countries are expected to see an increase in internal migration rates. Panel A indicates that the average total internal migration rate was $6.99 \%$ in 2000, and this figure is expected to increase to $7.80 \%$ and $7.05 \%$ under scenarios A2 and B1, respectively. The rural out-migration rate in this group was $1.22 \%$ in 2000 , and would increase to $1.44 \%$ and $1.24 \%$ under the two scenarios, respectively. The temperature effects on lower-middle income countries are between those on the poor and upper-middle countries. Therefore, the internal migration rate for this group is expected to remain rather stable or decline slightly. The wide confidence intervals for lower-middle countries are due to greater standard errors in the regressions.

This exercise produces the expected internal migrations for individual countries. We discuss results for a couple of representative countries. First, in Malawi, a country squarely in the group of "poor economies", the total internal migration rate was $4.63 \%$ per decade as of 2000 . This figure is expected to decline to $1.9 \%$ or $2.4 \%$ by $2080-2100$ under A2 and B1 scenarios, respectively. This is a drastic reduction in internal migration by almost half. Using this rate and the population in the country in 2000, 11.3 million, we obtain that the total number of internal migrants was 527 thousand in 2000. This number, in our predictions, is expected to decline to 216 or 271 thousand under the more or less pessimistic scenario, respectively. This would imply that 255-310 thousand people per decade, who would have migrated, would instead remain in rural poverty as a consequence of lower agricultural income. On the other hand, in Argentina, an upper-middle income country, the total internal migration rate was $8.8 \%$ per decade in 2000 . According to our calculations this number is expected to increase to $10.1 \%$ or $9.4 \%$ by $2080-2100$ under A2 and B1 scenarios, respectively. By using Argentina's population in 2000, 37 million, the total number of internal migrants in 2000 was 3.2 million, and this will grow to to 3.7 million or 3.5 million under the two scenarios, respectively. This calculation suggests that rising temperatures would drive 300,000-500,000 more people per decade to move from sparsely populated areas to more urban environments in Argentina. These examples show that climate changes may affect the mobility of a large number of people in each country.

There are two reasons for taking the simulations above with caution. First, we employ a linear model to project the effect of temperatures, but migration responses may not be linear, especially as adaptation may imply different effects in the long-run. Second, predicted temperature are subject to error and these predictions are beyond the historical experience and their increase is outside the range analyzed for the 1970-2000 period, so out of sample prediction may be inaccurate. ${ }^{24}$ Nonetheless, this exercise gives us a

\footnotetext{
${ }^{23}$ See Tables A11 and A12 in Appendix E for data associated with this figure. The average internal migration rates in 2000 shown in Figure 15 are slightly different from the ones in Figure G and Table A2 because some countries are dropped from the analysis in this section because of missing control variables for these countries. See Appendix G for more details.

${ }^{24}$ The predicted temperature increases $-4^{\circ} \mathrm{C}$ rise and $2.5^{\circ} \mathrm{C}$ rise under $\mathrm{A} 2$ and $\mathrm{B} 1$ scenarios, respectively-are greater than
} 
good sense of how severe the temperature effects could be in the coming decades.

To summarize, the results from this section establish two facts regarding the most important effects likely to generate consequential changes in the next decades. First, rising temperatures will significantly reduce rural-to-urban migrations in poor countries. Second, for countries on their way to industrialization, in the upper-middle part of world income, an increase in temperatures may work to increase rural-tourban migration. As a result, global warming may increase polarization of countries in the world in terms of the levels of economic development by further hurting development in countries at the lower tail of income per person distribution and encouraging it in the upper-middle part.

\section{Conclusions}

In this study we have examined the impact of rising temperatures on internal migration using a $56 \mathrm{~km} \times 56 \mathrm{~km}$ grid cell level dataset on net migration rates at the 10 -year frequency during the period 1970-2000. The results show that, within poor countries, rising temperatures reduced emigrations out of rural areas. This is consistent with the well-established observation that increases in temperatures reduce rural income and exacerbate the poverty of rural residents, making costs of migration prohibitive. On the other hand, in middle-income countries, higher temperatures increased migrations out of rural areas into cities because they increased urban-rural income differentials and hence the incentive to migrate for a population that could afford to do so. The results also show that temperature effects on internal migration are insignificant in rich countries.

These asymmetric migration responses are confirmed by regressions with country-level data constructed by aggregating the grid cell level data. The results imply that a $1^{\circ} \mathrm{C}$ increase in long-run average temperatures reduces the net migration rate by about 2 percentage points in poor countries. On the other hand, the same rise in temperatures increases the internal migration rate by $0.5-1$ percentage points in upper-middle income countries. We find particularly significant results when we employ rural out-migration rates as the dependent variable, suggesting that out-migration from rural areas responds most strongly to temperatures. These results on internal migration reinforce the country-level evidence on international migration documented in Cattaneo and Peri (2016). Our results suggest that rising temperatures help urbanization in middle-income countries. On the other hand, a higher temperature works to exacerbate economic conditions worsening the rural poverty trap in poor countries.

We project future temperature increases to show that poor countries will suffer a consequent significant decline in emigration from their rural areas, which implies an increase of people stuck in rural poverty. We should interpret these results with caution. First, our analysis is based on the data for 10-year long-run migrations and decennial changes in average temperatures and precipitation. The estimated coefficients measure long-run effects and they differ from the ones estimated using year-to-year shortrun variations in weather. Second, we employ estimated coefficients to predict out-of-sample internal migration rates. The expected rise in temperatures in the next decades is beyond what it has been in the sample period in the regressions, hence the predictive ability of our simple linear model may be limited. These considerations suggest that our predicted internal migration rates maybe be over-estimated because

temperature changes during the sample period. According to Table 1, the average decennial rise in average temperatures during $1970-2000$ was $0.15^{\circ} \mathrm{C}$ and its three standard deviation range was $[-0.96,1.26]$. Clearly, the predicted increase in temperatures is outside this range. 
of possible adaptation and non-linearity of response. Nevertheless, given the very limited evidence on the relation between climate change and internal migration, the present paper opens up a line of inquiry based on a simple model and very detailed and large amount of data, which we think can be pursued further.

\section{References}

Au, Chun-Chung and J. Vernon Henderson (2006). "How Migration Restrictions Limit Agglomeration and Productivity in China". In: Journal of Development Economics 80 (2), pp. 350-388.

Barrios, Salvador, Luisito Bertinelli, and Eric Strobl (2006). "Climatic Change and Rural-Urban Migration: The Case of Sub-Saharan Africa". In: Journal of Urban Economics 26 (6), pp. 656-673.

- (2010). "Trends in Rainfall and Economic Growth in Africa: A Neglected Cause of the African Growth Tragedy". In: Review of Economics and Statistics 92.2, pp. 350-366.

Baum-Snow, Nathaniel, Loren Brandt, J. Vernon Henderson, Matthew A. Turner, and Qinghua Zhang (2017). "Roads, Railroads, and Decentralization of Chinese Cities". In: Review of Economics and Statistics 99.3, pp. 435-448.

Beine, Michel and Christopher Parsons (2015). "Climatic Factors as Determinants of International Migration". In: Scandinavian Journal of Economics 117 (2), pp. 723-767.

Bohra-Mishra, Pratikshya, Michael Oppenheimer, and Solomon M. Hsiang (2014). "Nonlinear Permanent Migration Responses to Climatic Variations but Minimal Responses to Disasters". In: Proceedings of the National Academy of Sciences of the United States of America 111 (27), pp. 9780-9785.

Bosetti, Valentina, Cristina Cattaneo, and Giovanni Peri (2018). "Should They Stay or Should They Go? Climate Migrants and Local Conflicts". NBER Working Paper No. 24447.

Burgess, Robin, Olivier Deschênes, Dave Donaldson, and Michael Greenstone (2014). "The Unequal Effects of Weather and Climate Change: Evidence from Mortality in India". Unpublished manuscript, MIT, CIFAR, LSE, and UCSB.

Burke, Marshall, Solomon M. Hsiang, and Edward Miguel (2015). "Global Non-Linear Effect of Temperature on Economic Production". In: Nature 527.November 2015, pp. 235-239.

Cai, Fang (1996). "An Economic Analysis for Labor Migration and Mobility". In: Social Sciences in China Spring, pp. 120-135.

Cattaneo, Cristina and Giovanni Peri (2016). "The Migration Response to Increasing Temperatures". In: Journal of Development Economics 122.(September 2016), pp. 127-146.

Chen, Yuyu, Ginger Zhe Jin, and Yang Yue (2010). "Peer Miration in China". NBER Working Paper No. 15671.

Clemens, Michael A. (2014). "Does Development Reduce Migration?" In: International Handbook on Migration and Economic Development. Ed. by R.E.B. Lucas. Cheltenham, United Kingdom: Edward Elgar. Chap. 6, pp. 152-174.

Cobbinah, Patrick B., Michael O. Erdiaw-Kwasie, and Paul Amoateng (2015). "Africa's Urbanisation: Implications for Sustainable Development". In: Cities 47.September 2015, pp. 62-72.

Dao, Thu Hien, Frédéric Docquier, Chris Parsons, and Giovanni Peri (2018). "Migration and Development: Dissecting the Anatomy of the Mobility Transition". In: Journal of Development Economics 132.May 2018, pp. 88-101. 
de Sherbinin, Alex, M. Levy, S. Adamo, K. MacManus, G. Yetman, V. Mara, L. Razafindrazay, B. Goodrich, T. Srebotnjak, C. Aichele, and L. Pistolesi (2012). "Migration and Risk: Net Migration in Marginal Ecosystems and Hazardous Areas". In: Environment Research Letters 7, pp. 1-14.

- (2015). Global Estimated Net Migration Grids by Decade: 1970-2000. Palisades, NY: NASA Socioeconomic Data and Applications Center (SEDAC).

Dell, Melissa, Benjamin F. Jones, and Benjamin A. Olken (2012). "Temperature Shocks and Economic Growth: Evidence from the Last Half Century". In: American Economic Journal: Macroeconomics 4.3 , pp. 66-95.

Desmet, Klaus and Esteban Rossi-Hansberg (2009). "Spatial Growth and Industry Age". In: Journal of Economic Theory 144.6, pp. 2477-2502.

Diamond, Rebecca (2016). "The Determinants and Welfare Implications of US Workers' Diverging Location Choices by Skill: 1980-2000". In: American Economic Review 106 (3), pp. 479-524.

Garcia-Verdu, Rodrigo, Alexis Meyer-Cirkel, Akira Sasahara, and Hans Weisfeld (2019). "Importing Inputs for Climate Change Mitigation: The Case of Agricultural Productivity". IMF Working Paper No. $19 / 26$.

Gröger, André and Yanos Zylberberg (2016). "Internal Labor Migration as a Shock Coping Strategy: Evidence from a Typhoon". In: American Economic Journal: Applied Economics 8 (2), pp. 123-53.

Grogger, Jeffrey and Gordon H. Hanson (2011). "Income maximization and the selection and sorting of international migrants". In: Journal of Development Economics 95.1, pp. 42-57.

Henderson, J. Vernon, Adam Storeygard, and Uwe Deichmann (2017). "Has Climate Change Driven Urbanization in Africa?" In: Journal of Development Economics 124 (January 2017), pp. 60-82.

Herrendorf, Berthold and Todd Schoellman (2018). "Wages, Human Capital, and Barriers to Structural Transformation". In: American Economic Journal: Macroeconomics 10 (2), pp. 1-23.

Herring, David (2012). "Climate Change: Global Temperature Projections". Climate.gov: Science \& Information for a Climate-Smart Nation.

Huang, Ping and Frank N. Pieke (2003). "China Migration Country Study". aper presented at the Regional Conference on Migration, Development and Pro-Poor Policy Choices in Asia, Dhaka.

IPCC (2013). "Climate Change 2013: The Physical Science Basis". Working Group I Contribution to the Fifth Assessment of the International Panel on Climate Change.

- (2014). "Climate Change 2014: Impacts, Adaptation, and Vulnerability, Summary for Policymakers". Working Group II Contribution to the Fifth Assessment of the International Panel on Climate Change. Jayachandran, Seema (2006). "Selling Labor Low: Wage Responses to Productivity Shocks in Developing Countries". In: Journal of Political Economy 114 (3), pp. 538-575.

Joseph, George and Quentin Wodon (2013). "Is Internal Migration in Yemen Driven by Climate or Socioeconomic Factors?" In: Review of International Economics 21 (2), pp. 295-310.

Kleemans, Marieke and Jeremy Magruder (2018). "Labour Market Responses To Immigration: Evidence From Internal Migration Driven By Weather Shocks". In: The Economic Journal 128 (613), pp. 20322065.

Kubik, Zaneta and Mathilde Maurel (2016). "Weather Shocks, Agricultural Production and Migration: Evidence from Tanzania”. In: Journal of Development Studies 52.5, pp. 665-680. 
Lagakos, David, Mushfiq Mobarak, and Michael E. Wauch (2016). "Urban-Rural Wage Gap in Developing Countries: Spatial Misallocation or Efficient Sorting?" Unpublished manuscript, UC San Diego, Yale, and NYU.

Lucas, Robert E. B. (1997). "Internal Migration in Developing Countries". In: Handbook of Population and Family Economics 1.Part B, pp. 721-798.

Marchiori, Luca, Jean-Francois Maystadt, and Ingmar Schumacher (2012). "The Impact of Weather Anomalies on Migration in Sub-Saharan Africa". In: Journal of Environmental Economics and Management 63 (3), pp. 355-374.

Matsuura, Kenji and Cort Willmott (2007). Terrestrial Air Temperature and Precipitation: 1900-2006 Gridded Monthly Time Series, Version 1.01. University of Delaware.

Mendelsohn, Robert, Ariel Dinar, and Apurva Sanghi (2001). "The Effect of Development on the Climate Sensitivity of Agriculture". In: Environment and Development Economics 6 (1), pp. 85-101.

Mendelsohn, Robert, Ariel Dinar, and Larry Williams (2006). "The Distributional Impact of Climate Change on Rich and Poor Countries". In: Environment and Development Economics 11 (2), pp. 159 178.

Moretti, Enrico (2013). "Real Wage Inequality". In: American Economic Journal: Applied Economics 5 (1), pp. 65-103.

Murakami, Daisuke and Yoshiki Yamagata (2017). "Estimation of Gridded Population and GDP Scenarios with Spatially Explicit Statistical Downscaling". arXiv:1610.09041.

Nawrotzki, Raphael J., Fernando Riosmena, and Lori M. Hunter (2013). "Do Rainfall Deficits Predict U.S.Bound Migration from Rural Mexico? Evidence from the Mexican Census". In: Population Research and Policy Review 32 (1), pp. 129-158.

Ratcliffe, Michael, Charlynn Burd, Kelly Holder, and Alison Fields (2016). "Defining Rural at the U.S. Census Bureau". U.S. Department of Commerce, U.S. Census Bureau.

Restuccia, Diego, Dennis Tao Yang, and Xiaodong Zhu (2008). "Agriculture and Aggregate Productivity: A Quantitative Cross-Country Analysis". In: Journal of Monetary Economics 55 (2), pp. 234-250.

Sala-i-Martin, X. Xavier (1996). "The Classical Approach to Convergence Analysis". In: Economic Journal 106.437, pp. 1019-1036.

Schlenker, Wolfram and Michael J. Roberts (2009). "Nonlinear Temperature Effects Indicate Severe Damages to U.S. Crop Yields under Climate Change". In: Proceedings of the National Academy of Sciences of the United States of America 106 (37), pp. 15594-15598.

Strobl, Eric and Marie-Anne Valfort (2015). "The Effect of Weather-Induced Internal Migration on Local Labor Markets. Evidence from Uganda". In: World Bank Economic Review 29 (2), pp. 385-412.

Suckall, Natalie, Evan Fraser, and Piers Forster (2017). "Reduced Migration under Climate Change: Evidence from Malawi using an Aspirations and Capabilities Framework". In: Climate and Development 9 (4), pp. 298-312.

van Donkelaar, A., R.V. Martin, M. Brauer, and B.L. Boys (2015). Global Annual PM2.5 Grids from MODIS, MISR and SeaWiFS Aerosol Optical Depth (AOD), 1998-2012. Palisades, NY: NASA Socioeconomic Data and Applications Center (SEDAC). 
Viswanathan, Brinda and K.S. Kavi Kumar (2015). "Weather, Agriculture and Rural Migration: Evidence from State and District level Migration in India". In: Environment and Development Economics 20 (4), pp. 469-492.

World Bank (2018a). Climate Change Knowledge Portal: Ensemble Projections. Washington D.C.

- (2018b). World Development Indicators. Washington D.C.

Yamagata, Yoshiki and Daisuke Murakami (2015). Global Dataset of Gridded Population and GDP Scenarios. Center for Global Environmental Research, Tsukuba International Office, Global Carbon Project. Zhou, Jingkui (2011). "Climate Change, Health and Migration in Urban China". In: Frontiers of Economics in China 6 (4), pp. 592-615. 


\section{Tables and Figures}

Figure 1: Net Migrations, Europe, 1990-2000

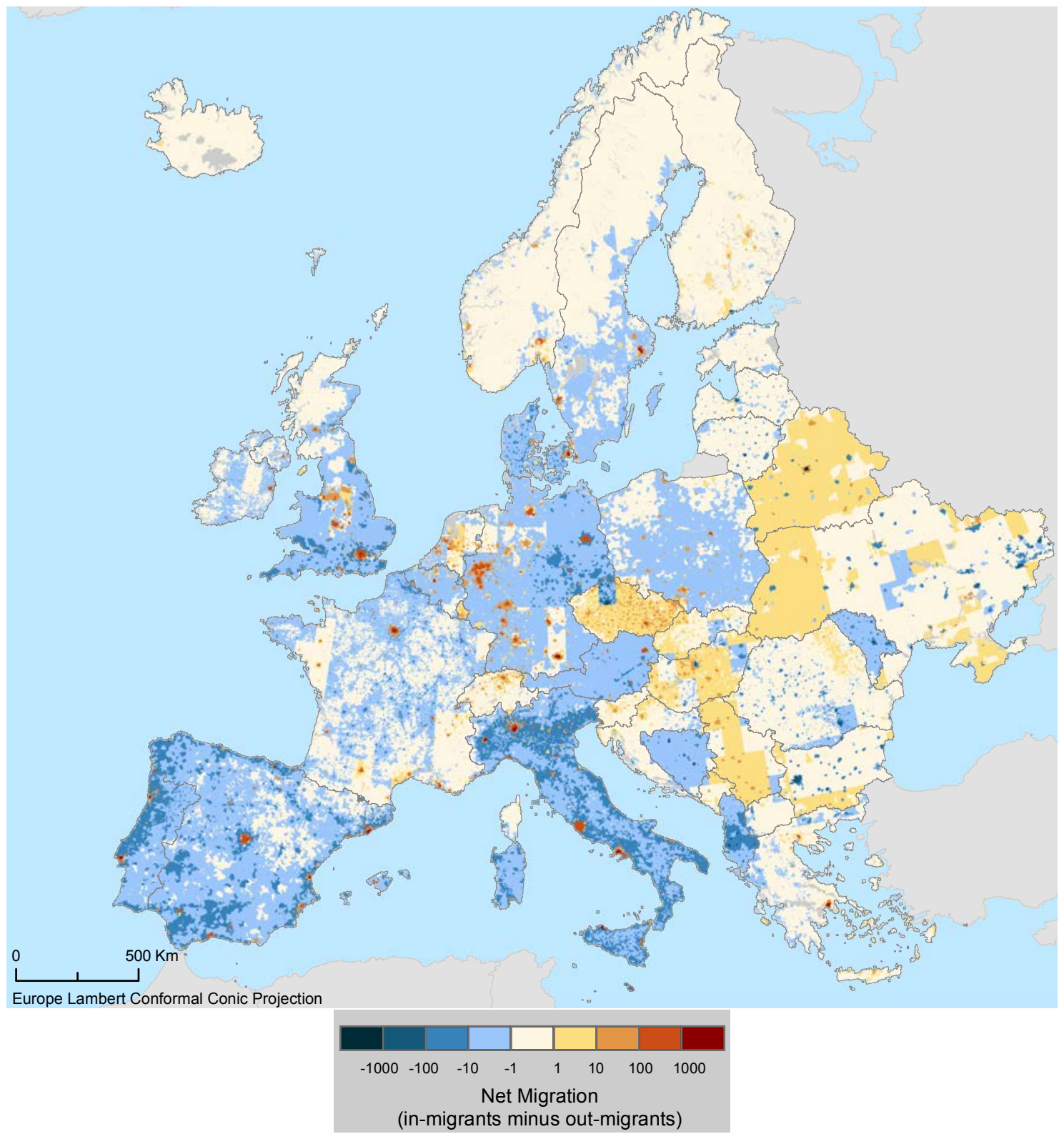

Notes: The map comes from de Sherbinin et al. (2015). 
Table 1: Summary Statistics of the Data for Grid Cell Level Regressions

\begin{tabular}{|c|c|c|c|c|c|}
\hline & Obs. & Mean & St. dev. & Min & Max \\
\hline \multicolumn{6}{|l|}{ Net migration rates } \\
\hline Full sample & 96,792 & -6.52 & 19.54 & -98.51 & 88.85 \\
\hline Poor countries & 24,236 & -8.25 & 20.02 & -98.51 & 87.93 \\
\hline Lower-middle income countries & 12,703 & -14.38 & 27.27 & -98.19 & 88.31 \\
\hline Upper-middle income countries & 33,695 & -5.34 & 18.32 & -97.63 & 88.85 \\
\hline Rich countries & 26,158 & -2.62 & 14.06 & -96.39 & 88.74 \\
\hline \multicolumn{6}{|c|}{ Net migration rates (relative to the world average) } \\
\hline Full sample & 96,792 & 0.00 & 19.51 & -92.38 & 95.74 \\
\hline Poor countries & 24,236 & -1.73 & 20.00 & -92.38 & 94.89 \\
\hline Lower-middle income countries & 12,703 & -7.87 & 27.26 & -91.62 & 93.78 \\
\hline Upper-middle income countries & 33,695 & 1.18 & 18.27 & -92.04 & 95.74 \\
\hline Rich countries & 26,158 & 3.90 & 14.04 & -90.19 & 94.21 \\
\hline \multicolumn{6}{|c|}{ Long-run average temperatures (degree Celsius) } \\
\hline Full sample & 88,855 & 14.61 & 9.88 & -19.86 & 35.21 \\
\hline Poor countries & 23,191 & 18.62 & 9.33 & -12.48 & 31.97 \\
\hline Lower-middle income countries & 10,984 & 19.32 & 9.54 & -13.26 & 30.52 \\
\hline Upper-middle income countries & 31,787 & 13.63 & 9.80 & -13.85 & 35.21 \\
\hline Rich countries & 22,893 & 9.63 & 7.77 & -19.86 & 31.36 \\
\hline \multicolumn{6}{|c|}{ Changes in the long-run average temperatures } \\
\hline Full sample & 88,855 & 0.15 & 0.37 & -4.94 & 4.79 \\
\hline Poor countries & 23,191 & 0.14 & 0.27 & -1.96 & 1.77 \\
\hline Lower-middle income countries & 10,984 & 0.13 & 0.38 & -2.77 & 2.06 \\
\hline Upper-middle income countries & 31,787 & 0.16 & 0.41 & -4.94 & 4.79 \\
\hline Rich countries & 22,893 & 0.15 & 0.40 & -3.77 & 3.62 \\
\hline \multicolumn{6}{|c|}{ Long-run average precipitation ( $\mathrm{mm}$, at monthly scale) } \\
\hline Full sample & 88,855 & 73.86 & 58.47 & 0.02 & 979.00 \\
\hline Poor countries & 23,191 & 77.73 & 53.86 & 0.10 & 457.20 \\
\hline Lower-middle income countries & 10,984 & 98.56 & 76.07 & 0.02 & 666.97 \\
\hline Upper-middle income countries & 31,787 & 70.10 & 63.18 & 0.07 & 979.00 \\
\hline Rich countries & 22,893 & 63.33 & 39.67 & 2.13 & 426.02 \\
\hline \multicolumn{6}{|c|}{ Changes in the long-run average precipitation ( $\mathrm{mm}$, at monthly scale) } \\
\hline Full sample & 88,855 & -0.43 & 9.78 & -194.89 & 261.21 \\
\hline Poor countries & 23,191 & -0.80 & 10.04 & -110.04 & 88.26 \\
\hline Lower-middle income countries & 10,984 & -2.88 & 15.03 & -128.14 & 115.59 \\
\hline Upper-middle income countries & 31,787 & 0.07 & 9.10 & -194.89 & 261.21 \\
\hline Rich countries & 22,893 & 0.43 & 6.44 & -59.77 & 62.86 \\
\hline \multicolumn{6}{|l|}{ Population growth rates } \\
\hline Full sample & 96,704 & 1.68 & 1.00 & -1.83 & 5.17 \\
\hline Poor countries & 24,236 & 2.17 & 0.76 & -1.83 & 5.14 \\
\hline Lower-middle income countries & 12,615 & 2.35 & 0.74 & -1.70 & 4.59 \\
\hline Upper-middle income countries & 33,695 & 1.52 & 1.03 & -1.18 & 4.67 \\
\hline Rich countries & 26,158 & 1.11 & 0.84 & 0.02 & 5.17 \\
\hline
\end{tabular}

Notes: The table shows summary statistics of variables used for regressions using grid cell level observations. Summary statistics for the full sample as well as for each of the four groups of countries are shown. The country groups are based on the 25th, 50th, 75 th percentiles of the world distribution of GDP per capita. Observations vary across grid cells except the population growth rate, which is the country-level data. 
Figure 2: Net Migration Rates from Rural Locations and Changes in Temperatures, 19902000
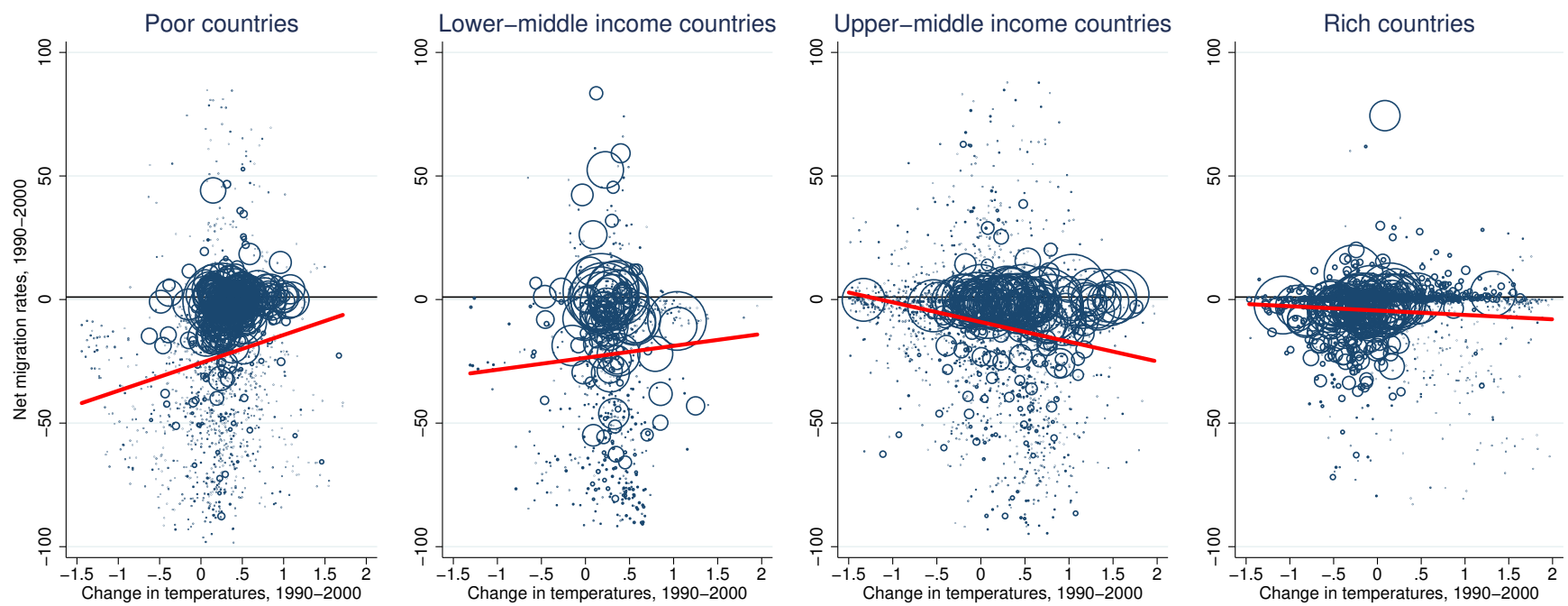

Notes: The figure shows the relationship between the net migration rates from rural locations only in the decade $1990-2000$ and changes in temperatures in the same period. Each panel includes a different set of countries. The size of bubbles measures population size of grid cells.

Figure 3: Country-level Aggregate Internal Migration Rates, 1970-2000
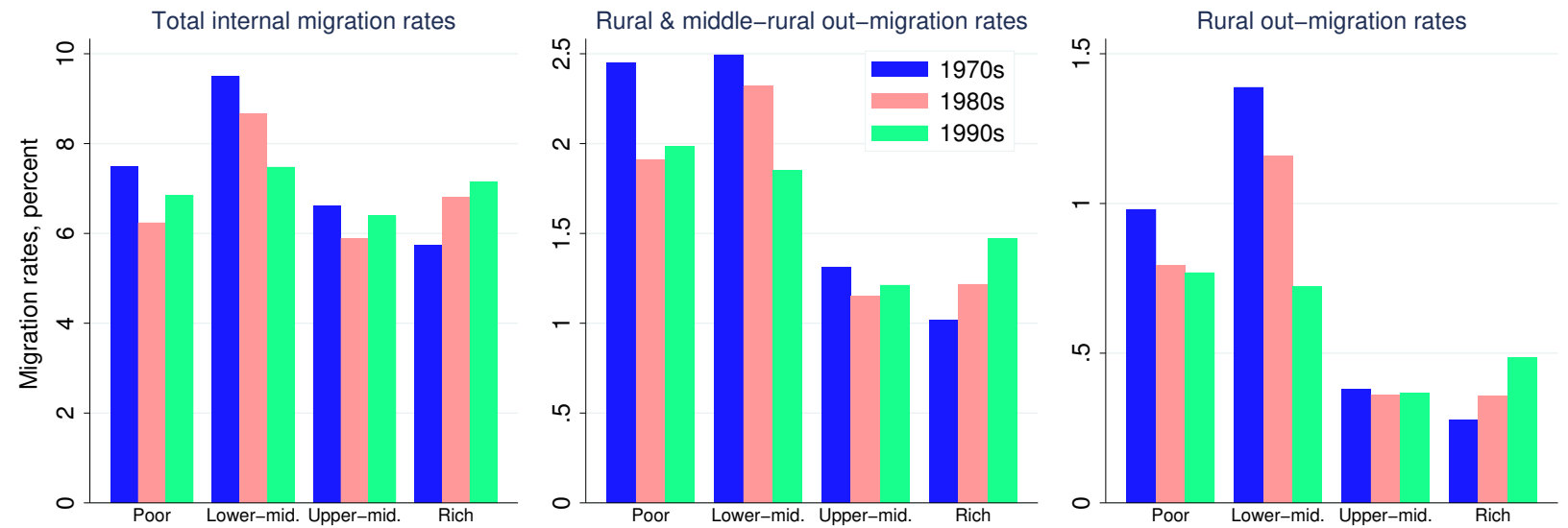

Notes: The figure shows country-level aggregate rural to urban migration rates, for three decades and four country groups, during 1970-2000. The left panel shows the total measure and the middle one shows the out-migration from rural and middle-rural, the left panel shows the out-migration from rural areas only 
Figure 4: Rural Out-Migration Rates and Changes in Temperatures, 1990-2000
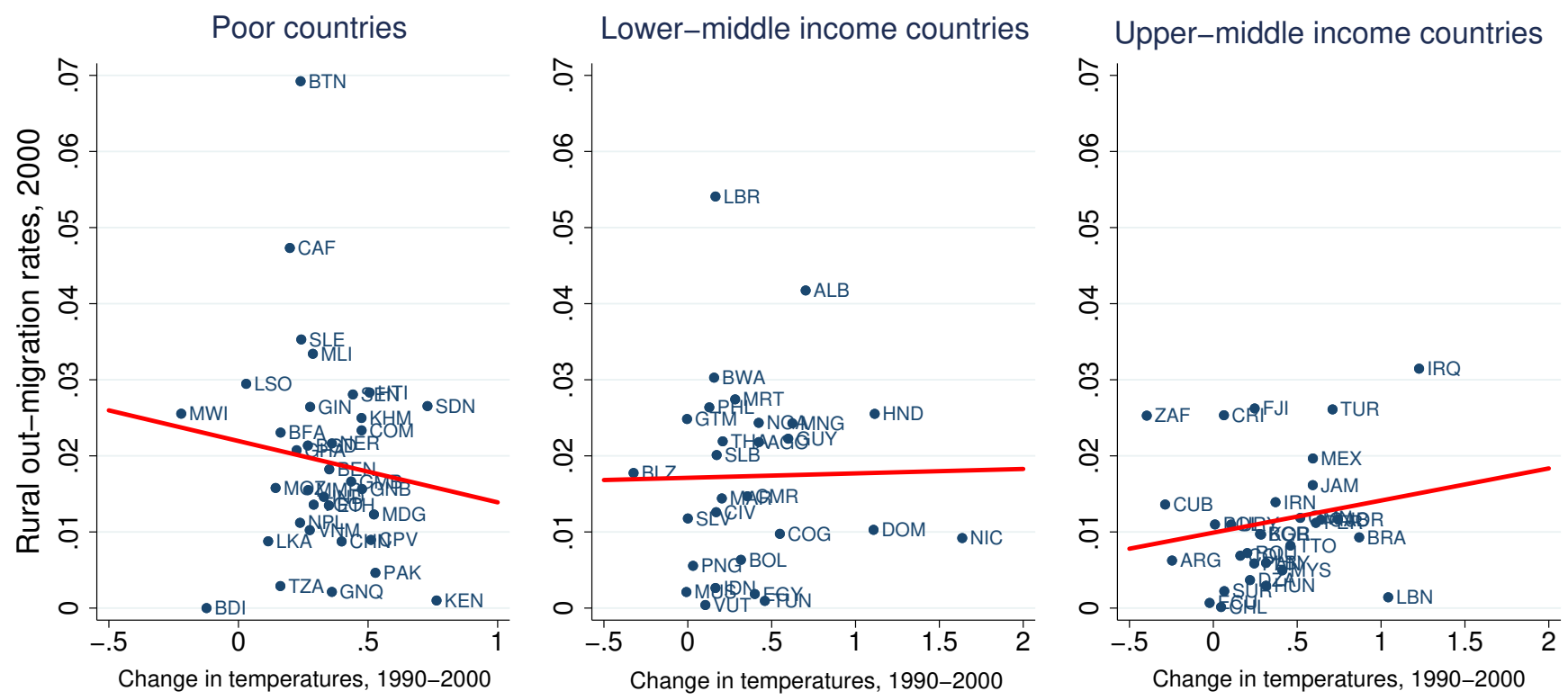

Notes: The figure shows the relationship between the net migration rates in the decade 1990-2000 and changes in temperatures in the same period.

Figure 5: Urban and Rural Productivities

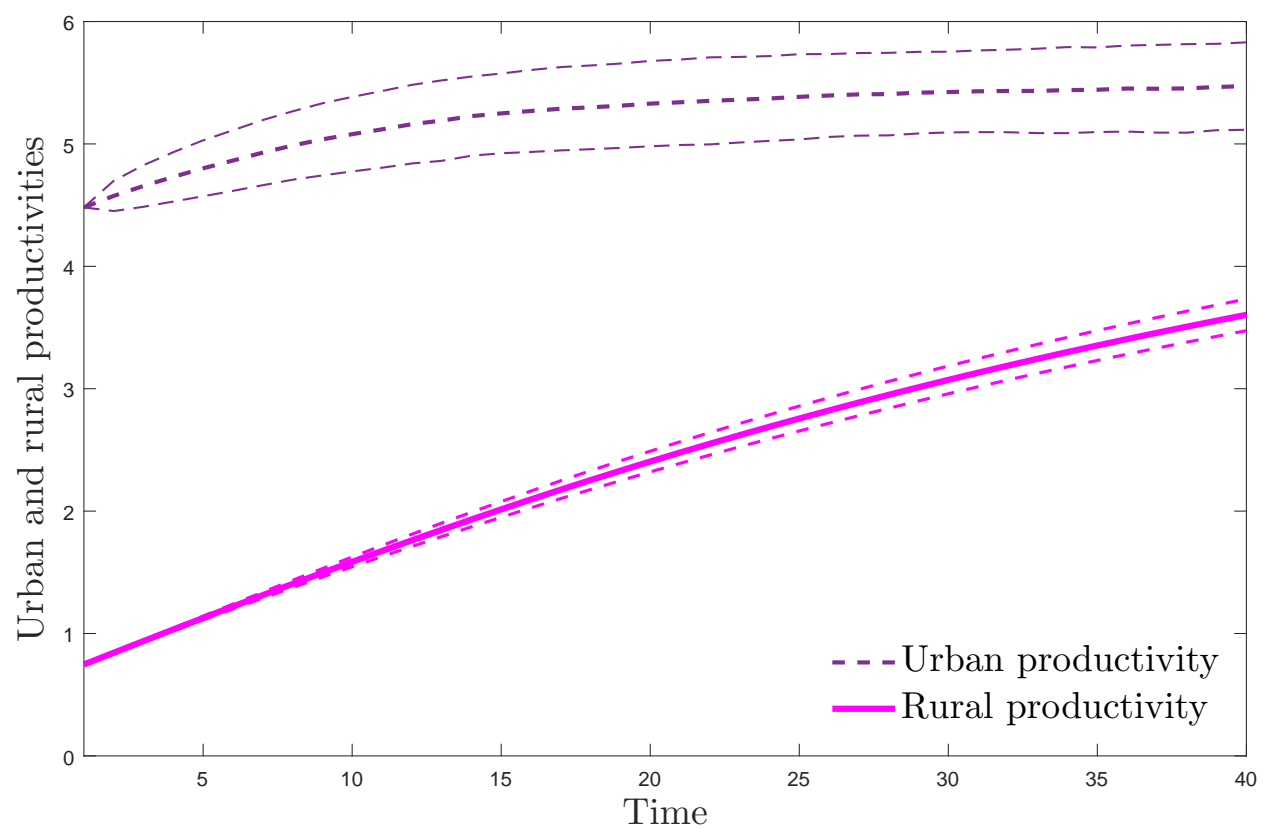

Notes: The figure describes urban and rural productivities. 
Figure 6: The Impact of Temperature Shocks on Internal Migrations

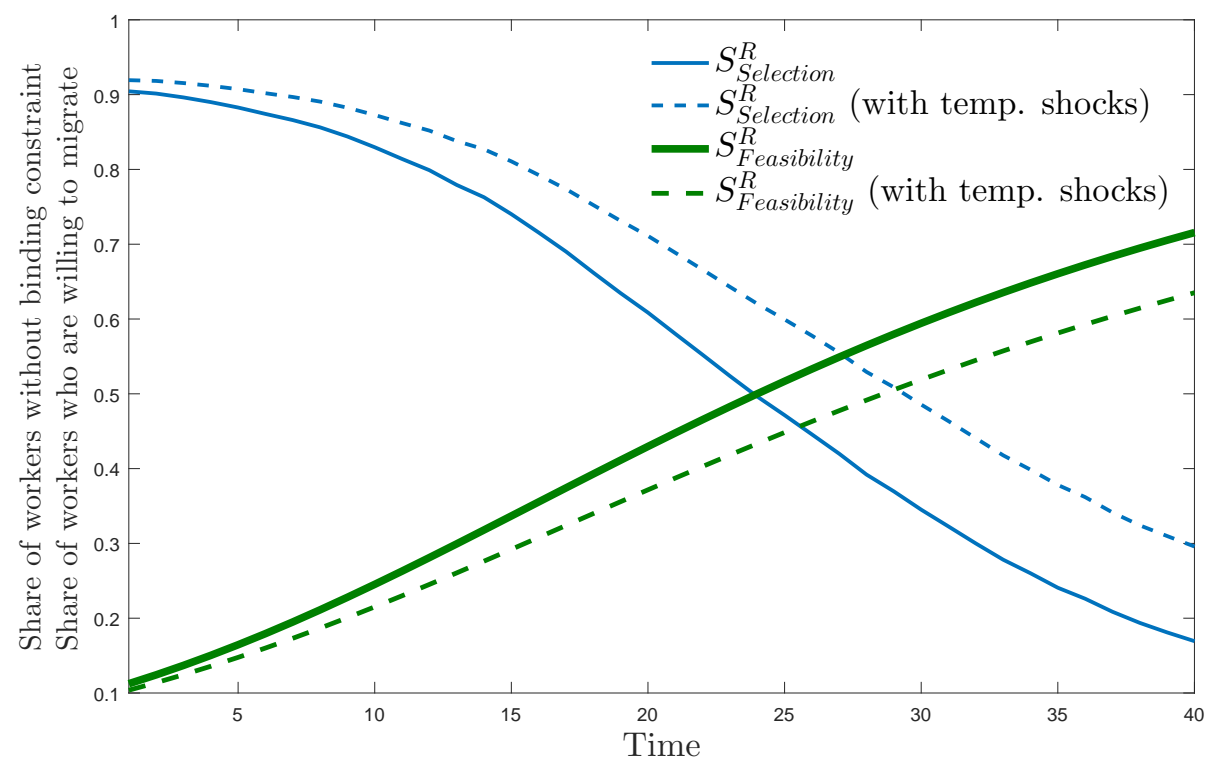

Notes: The figure describes urban and rural productivities. The solid lines indicate the mean of 1,000 growth paths from 1,000 simulations. The dashed lines indicate the ones with temperature shocks reducing rural productivity. See Table A3 for parameter values.

Figure 7: The Impact of Temperature Shocks on Internal Migrations
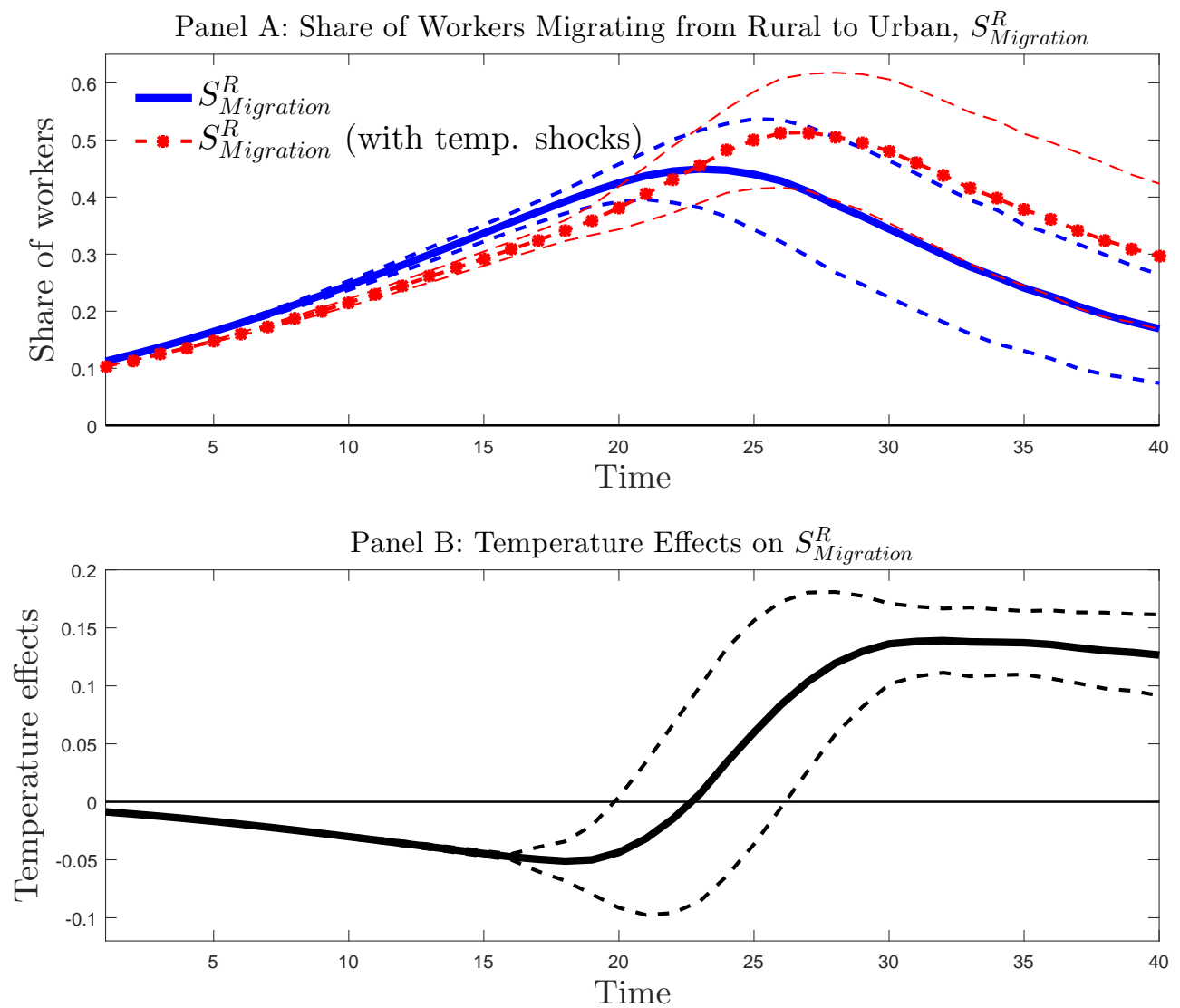

Notes: The solid lines indicate the mean of the variables from 1,000 simulations. See Table A3 for parameter values. 
Figure 8: The Theoretical Impact of Temperature Shocks on Internal Migrations in Poor and Middle-Income Countries

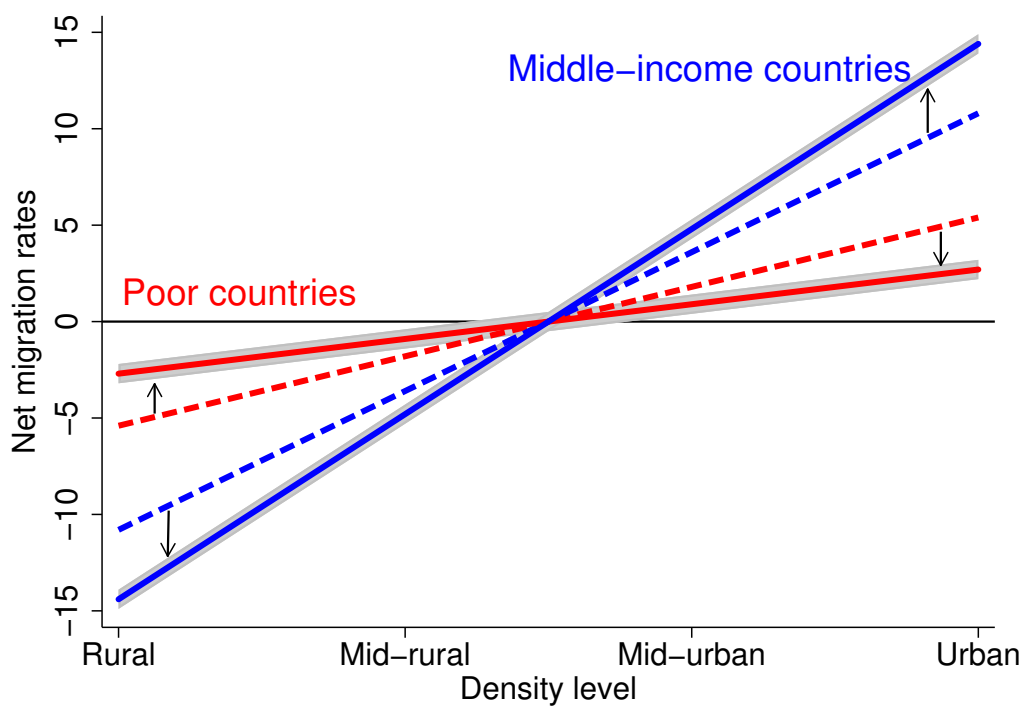

Notes: The figure shows theoretical impacts of rising temperatures on the internal migration rates in poor and middle-income countries.

Figure 9: Mean Grid Cell Level Net Migration Rates
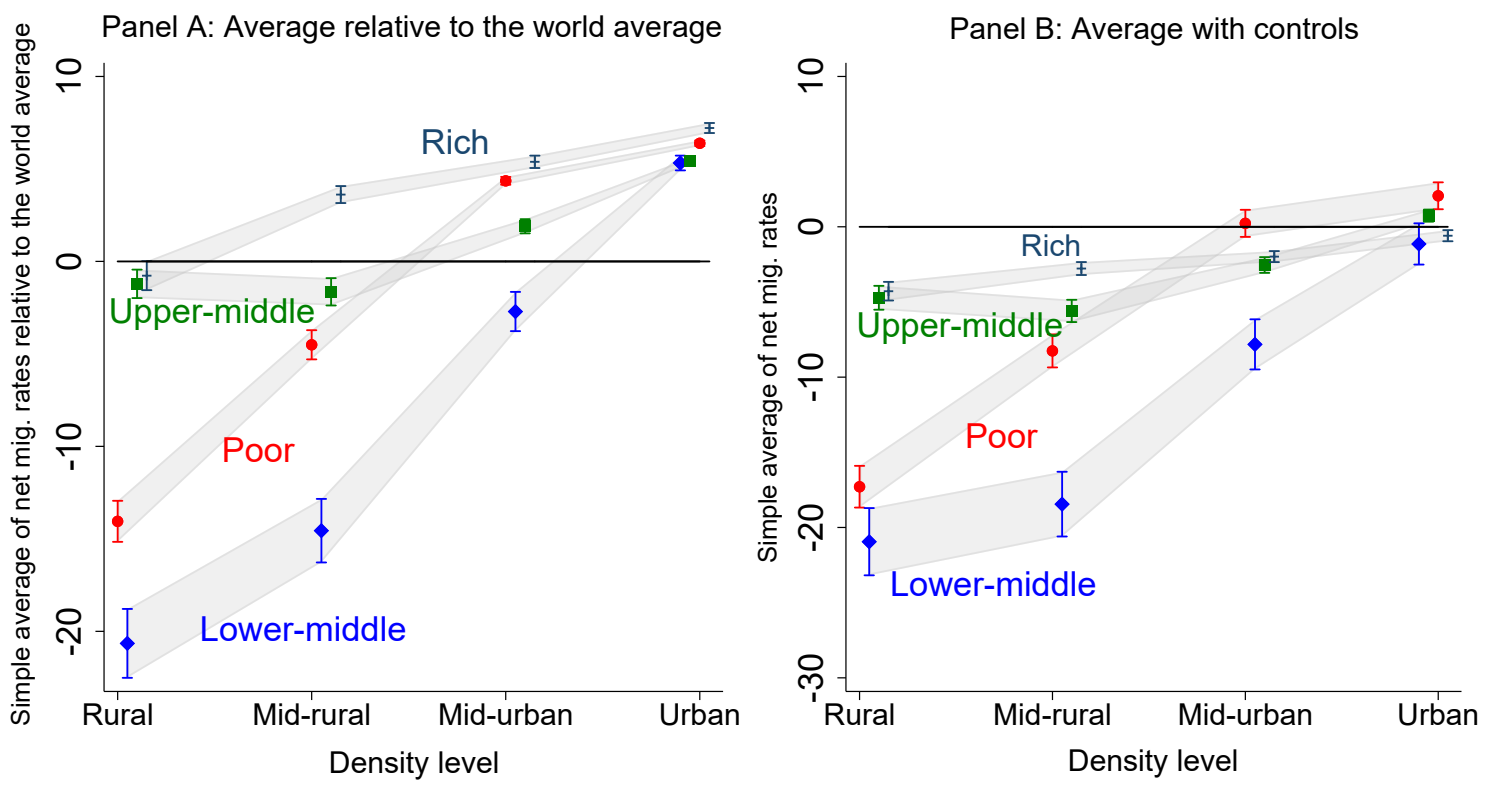

Notes: The vertical axis of the figure measures average net migration rates, for three decades during 1970-2000, in percent, with $95 \%$ confidence intervals. Top $1 \%$ and bottom $1 \%$ of net migration observations are dropped as outliers. In Panel A, the net migration rates are normalized so as to make the mean value to be zero for observations in each decade. Panel $\mathrm{B}$ shows the net migration rates (raw data, not relative to the world average) with control variables. See Table A4 for a regression table associated with this figure. 
Table 2: Grid Cell Level Regressions, Rural-Urban Dummies based on Population

Dependent variable $=$ Net migration rates Definition of rural-urban areas is based on Population at the grid cell level

\begin{tabular}{|c|c|c|c|c|c|c|}
\hline & \multicolumn{2}{|c|}{ Poor } & \multicolumn{2}{|c|}{ Lower-middle } & \multicolumn{2}{|c|}{ Upper-middle } \\
\hline & $(1)$ & $(2)$ & $(3)$ & $(4)$ & $(5)$ & $(6)$ \\
\hline \multirow{4}{*}{$D^{\text {Middle-urban }} \times \Delta T e m p$} & $1.484^{* * *}$ & -0.312 & $-0.674^{* *}$ & $-2.344^{* * *}$ & $-0.874^{* * *}$ & $-0.441^{* * *}$ \\
\hline & $(0.219)$ & $(0.192)$ & $(0.292)$ & $(0.386)$ & $(0.111)$ & $(0.0800)$ \\
\hline & & -0.330 & & 0.509 & & $-0.517^{* * *}$ \\
\hline & & $(0.249)$ & & $(0.664)$ & & $(0.139)$ \\
\hline \multirow[t]{2}{*}{$D^{\text {Middle-rural }} \times \Delta T e m p$} & & $0.908^{* *}$ & & $3.200^{* * *}$ & & -0.405 \\
\hline & & $(0.450)$ & & $(0.764)$ & & $(0.268)$ \\
\hline \multirow[t]{2}{*}{$D^{\text {Rural }} \times \Delta T e m p$} & & $5.054^{* * *}$ & & $2.853^{* * *}$ & & $-0.905^{* * *}$ \\
\hline & & $(0.619)$ & & $(0.768)$ & & $(0.291)$ \\
\hline Observations & 23,191 & 23,191 & 10,898 & 10,898 & 31,787 & 31,787 \\
\hline Grid cells & 7,851 & 7,851 & 3,734 & 3,734 & 10,770 & 10,770 \\
\hline$R$-squared & 0.263 & 0.272 & 0.248 & 0.256 & 0.135 & 0.146 \\
\hline \multicolumn{7}{|c|}{ Temperature effects (Linear combination of coefficients) } \\
\hline \multirow[t]{2}{*}{ Middle-urban areas } & & $-0.642^{* * *}$ & & $-1.834^{* * *}$ & & $-0.958^{* * *}$ \\
\hline & & $(0.199)$ & & $(0.563)$ & & $(0.140)$ \\
\hline \multirow[t]{2}{*}{ Middle-rural areas } & & 0.597 & & 0.857 & & $-0.845^{* * *}$ \\
\hline & & $(0.414)$ & & $(0.683)$ & & $(0.268)$ \\
\hline \multirow[t]{2}{*}{ Rural areas } & & $4.742^{* * *}$ & & 0.510 & & $-1.346^{* * *}$ \\
\hline & & $(0.592)$ & & $(0.660)$ & & $(0.286)$ \\
\hline$D^{\text {Rural-urban }} \times$ Year fixed effects & & Yes & & Yes & & Yes \\
\hline$D^{\text {Rural-urban }} \times \Delta$ Precipitation & & Yes & & Yes & & Yes \\
\hline
\end{tabular}

Notes: Robust standard errors clustered at the grid cell level are in parentheses. All regressions include $D^{\text {Region }} \times$ Year fixed effects, $D^{\text {Rural-urban }} \times$ Population growth rates, and country fixed effects, where $D^{\text {Rural-urban }}$ indicate dummy variables for rural areas, middle-rural areas, middle-urban areas, and urban areas and $D^{\text {Region }}$ denote dummy variables for regions in the world including Asia, Europe, North America, Oceania, South America, Middle East and North Africa, and Sub-Saharan Africa. $* * *, * *$, and $*$ indicate statistical significance at the $1 \%, 5 \%$, and $10 \%$ level, respectively. 


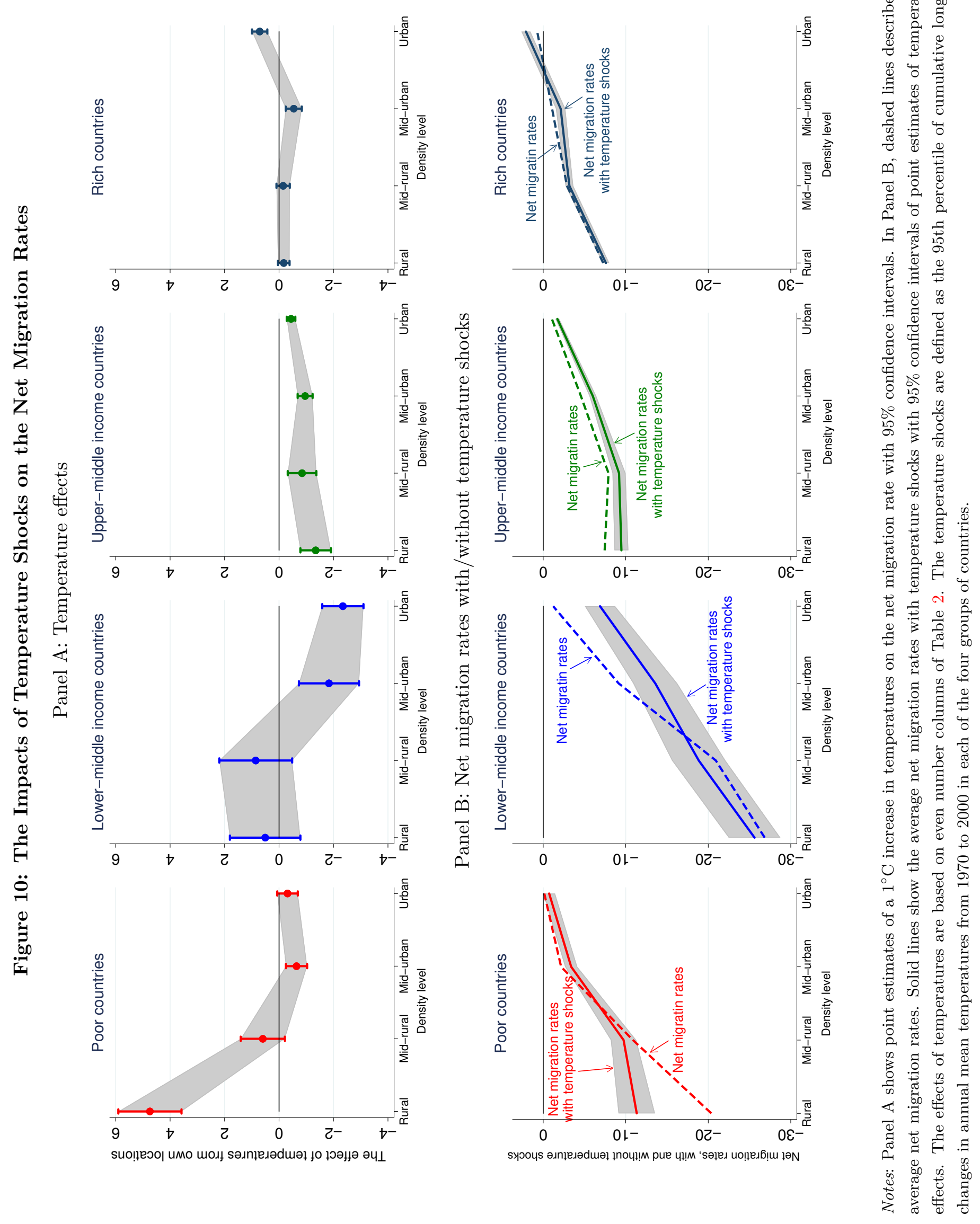


Figure 11: Grid Cell Level Regressions, Robustness Checks, Addressing Non-Linearity of Temperature Effects
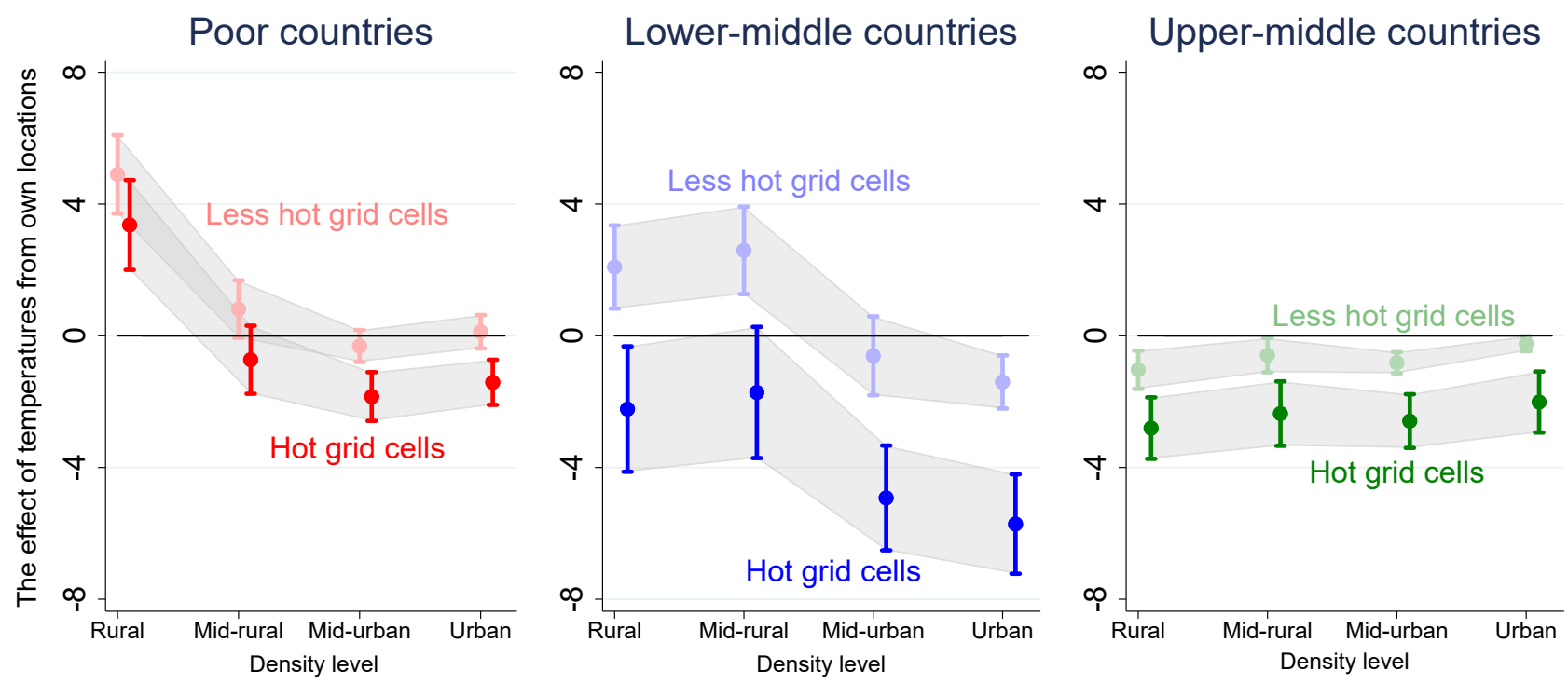

Notes: The figure shows point estimates of the impact of temperatures on the internal migration rates with hot location dummies to address non-linear effects of temperatures. Dots in the middle of bars denote point estimates and the bands indicate the $95 \%$ confidence intervals. See Table A5 in Appendix E for a regression table associated with this figure. Results from odd number columns in the table are plotted. 


\section{Figure 12: Grid Cell Level Regressions, Robustness Checks}

Panel A: Poor countries
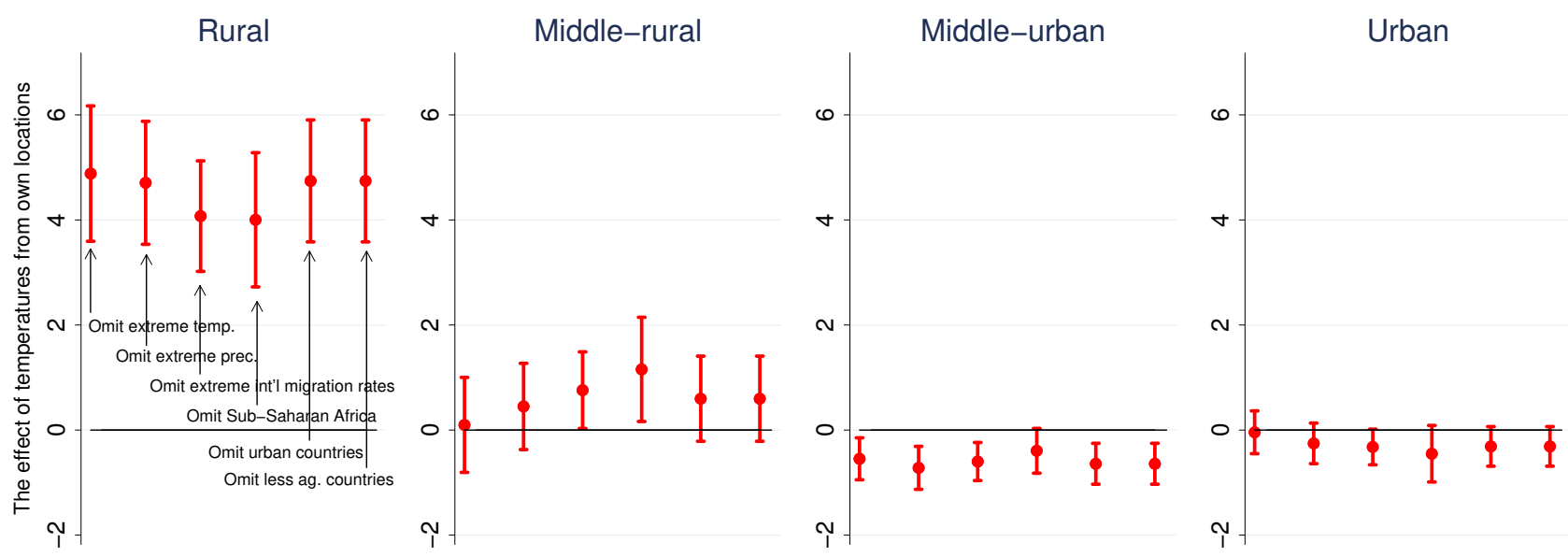

Panel B: Lower-middle income countries
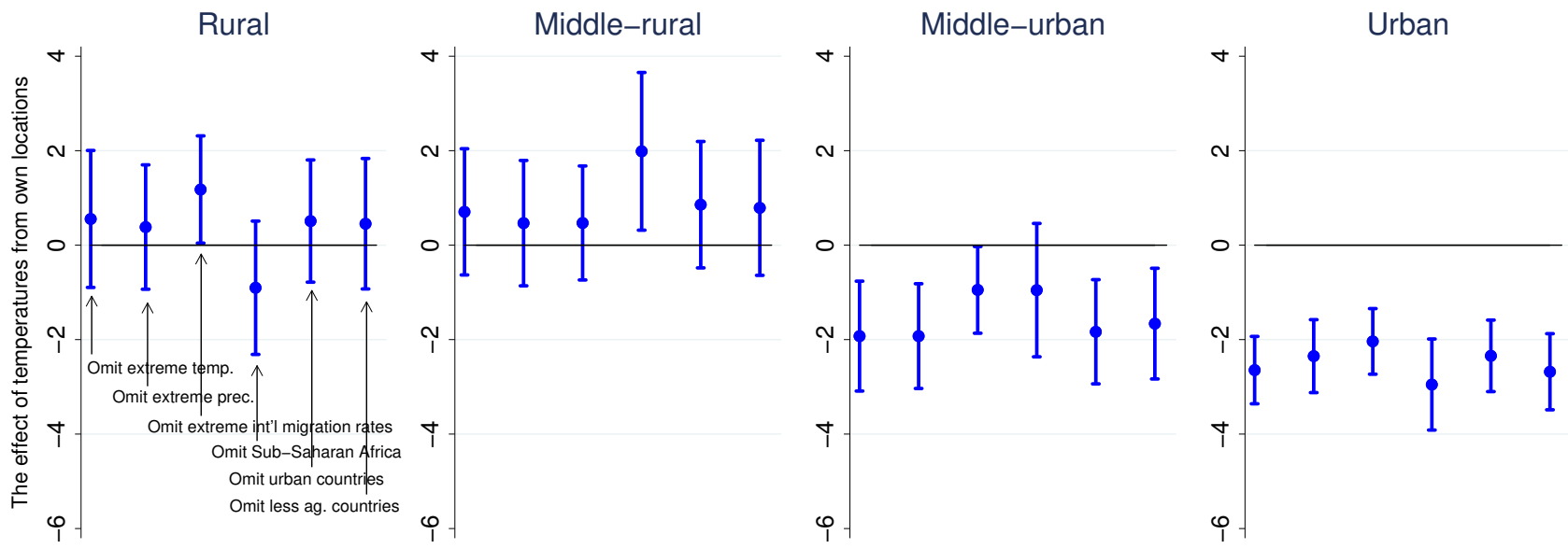

Panel C: Upper-middle income countries

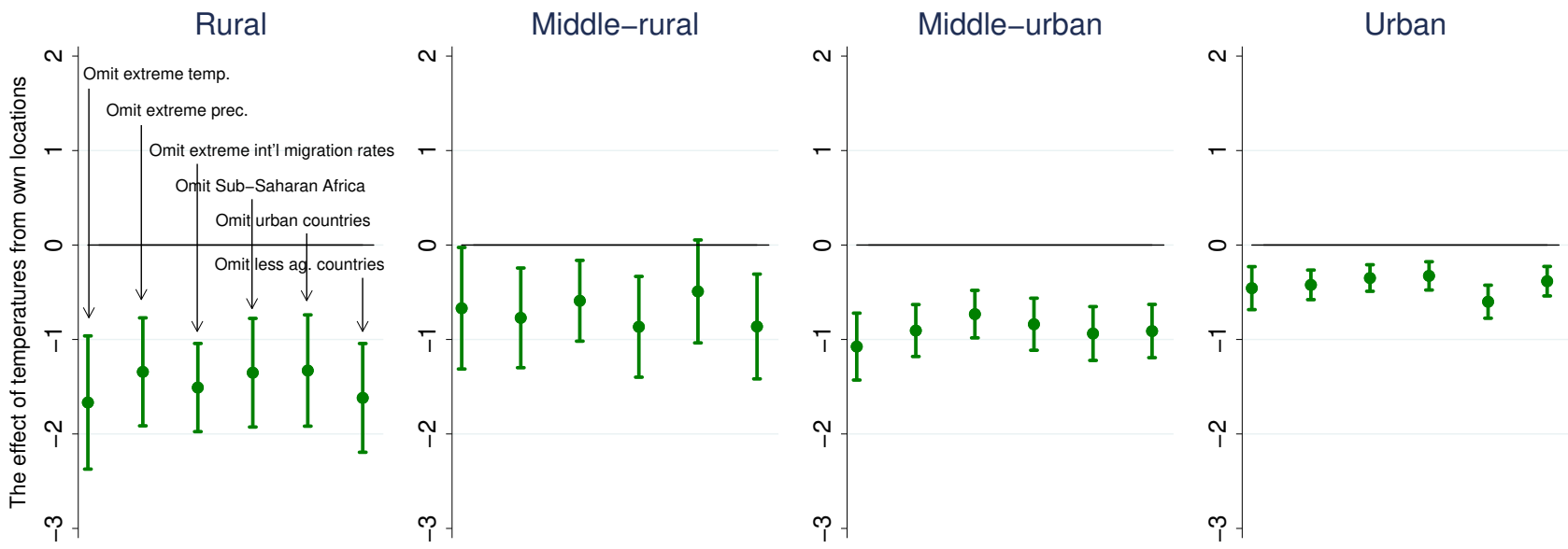

Notes: The figure shows point estimates of the impact of temperatures on the internal migration rates. Dots in the middle of bars denote point estimates and the bands indicate the $95 \%$ confidence intervals. See Table A6 in Appendix E for a regression table associated with this figure. 
Table 3: Country-level Regressions, Baseline Results

\begin{tabular}{|c|c|c|c|c|c|}
\hline & \multicolumn{5}{|c|}{ Panel A: Total internal migration rates } \\
\hline & (1) & $(2)$ & $(3)$ & $(4)$ & $(5)$ \\
\hline \multirow{2}{*}{$\Delta T e m p$} & 0.605 & $2.192^{* *}$ & $2.107^{*}$ & $2.643^{* *}$ & $3.076^{* *}$ \\
\hline & $(0.957)$ & $(1.054)$ & $(1.058)$ & $(1.090)$ & $(1.334)$ \\
\hline \multirow{2}{*}{$D^{\text {Lower-middle }} \times \Delta$ Temp } & & -1.527 & -1.417 & -1.822 & -2.054 \\
\hline & & $(1.923)$ & $(1.930)$ & $(2.745)$ & $(3.124)$ \\
\hline \multirow[t]{2}{*}{$D^{\text {Poor }} \times \Delta T e m p$} & & $-5.006 * * *$ & $-4.939 * * *$ & $-4.309^{*}$ & $-5.240^{*}$ \\
\hline & & $(1.711)$ & $(1.736)$ & $(2.491)$ & $(3.070)$ \\
\hline Observations & 202 & 202 & 202 & 144 & 140 \\
\hline Countries & 77 & 77 & 77 & 66 & 63 \\
\hline$R$-squared & 0.065 & 0.074 & 0.084 & 0.238 & 0.246 \\
\hline \multicolumn{6}{|c|}{ Temperature effects (Linear combination of coefficients) } \\
\hline \multirow[t]{2}{*}{ Lower-middle countries } & & 0.665 & $\overline{0.6} 90$ & 0.821 & 1.022 \\
\hline & & $(1.664)$ & $(1.671)$ & $(2.489)$ & $(2.653)$ \\
\hline \multirow[t]{4}{*}{ Poor countries } & & $-2.813^{*}$ & $-2.832^{*}$ & -1.666 & -2.164 \\
\hline & & $(1.434)$ & $(1.466)$ & $(2.374)$ & $(2.579)$ \\
\hline & Panel & Out-migre & ion rates, 1 & iural and $N$ & iddle-rural \\
\hline & $(1)$ & $(2)$ & $(3)$ & $(4)$ & $(5)$ \\
\hline \multirow[t]{2}{*}{$\Delta T e m p$} & 0.137 & $0.638^{* *}$ & $0.588^{*}$ & $0.904^{* *}$ & $1.117^{* * *}$ \\
\hline & $(0.307)$ & $(0.313)$ & $(0.314)$ & $(0.363)$ & $(0.348)$ \\
\hline \multirow[t]{2}{*}{$D^{\text {Lower-middle }} \times \Delta$ Temp } & & -0.177 & -0.116 & -0.204 & -0.345 \\
\hline & & $(0.560)$ & $(0.552)$ & $(0.778)$ & $(0.829)$ \\
\hline \multirow{2}{*}{$D^{\text {Poor }} \times \Delta T e m p$} & & $-2.638^{* * *}$ & $-2.516^{* * *}$ & $-3.025^{* * *}$ & $-3.276^{* * *}$ \\
\hline & & $(0.530)$ & $(0.522)$ & $(0.809)$ & $(0.865)$ \\
\hline Observations & 200 & 200 & 200 & 144 & 140 \\
\hline Countries & 77 & 77 & 77 & 66 & 63 \\
\hline$R$-squared & 0.067 & 0.092 & 0.111 & 0.250 & 0.285 \\
\hline \multicolumn{6}{|c|}{ Temperature effects (Linear combination of coefficients) } \\
\hline \multirow[t]{2}{*}{ Lower-middle countries } & & 0.461 & 0.471 & 0.699 & 0.773 \\
\hline & & $(0.500)$ & $(0.490)$ & $(0.686)$ & $(0.741)$ \\
\hline \multirow[t]{2}{*}{ Poor countries } & & $-2.000 * * *$ & $-1.928^{* * *}$ & $-2.121^{* * *}$ & $-2.158 * * *$ \\
\hline & & $(0.475)$ & $(0.474)$ & $(0.768)$ & $(0.775)$ \\
\hline \multicolumn{6}{|l|}{ Controls } \\
\hline$\Delta$ Precipitation & & & Yes & Yes & Yes \\
\hline $\ln ($ Pop $)$ & & & & Yes & Yes \\
\hline $\ln (G D P)$ & & & & Yes & Yes \\
\hline Ag. value-added share & & & & Yes & Yes \\
\hline Manu. value-added share & & & & Yes & Yes \\
\hline$\Delta \mathrm{Ag}$. value-added share & & & & & Yes \\
\hline$\Delta$ Manu. value-added share & & & & & Yes \\
\hline
\end{tabular}

Notes: All regressions include the population growth rates and the GDP growth rates during each decade as controls. Robust standard errors clustered at the country-level are in parentheses. $* * *, * *$, and * indicate statistical significance at the $1 \%$, $5 \%$, and $10 \%$ level, respectively. 
Figure 13: Results from Country-level Regressions

Panel A: Temperature effects on total internal migration rates

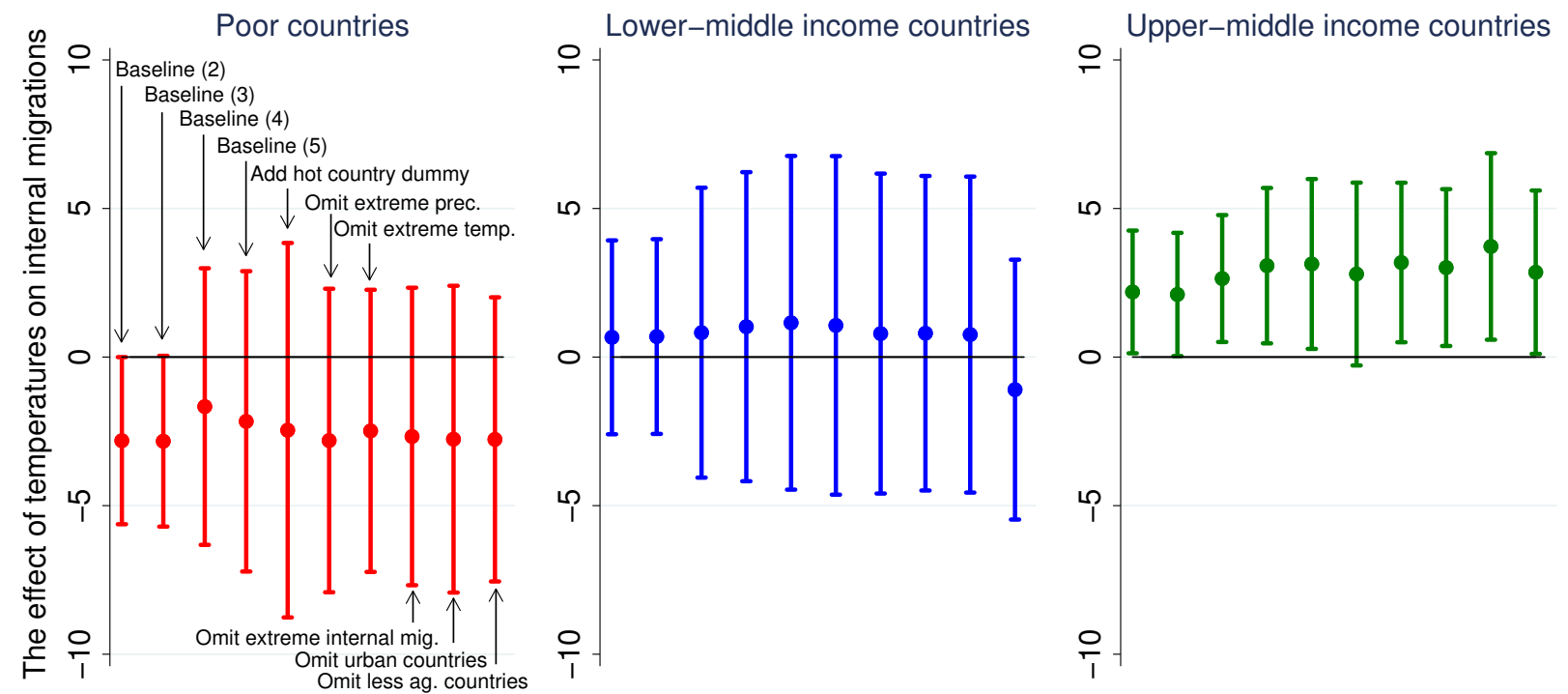

Panel B: Temperature effects out-migration rates, rural \& middle-rural

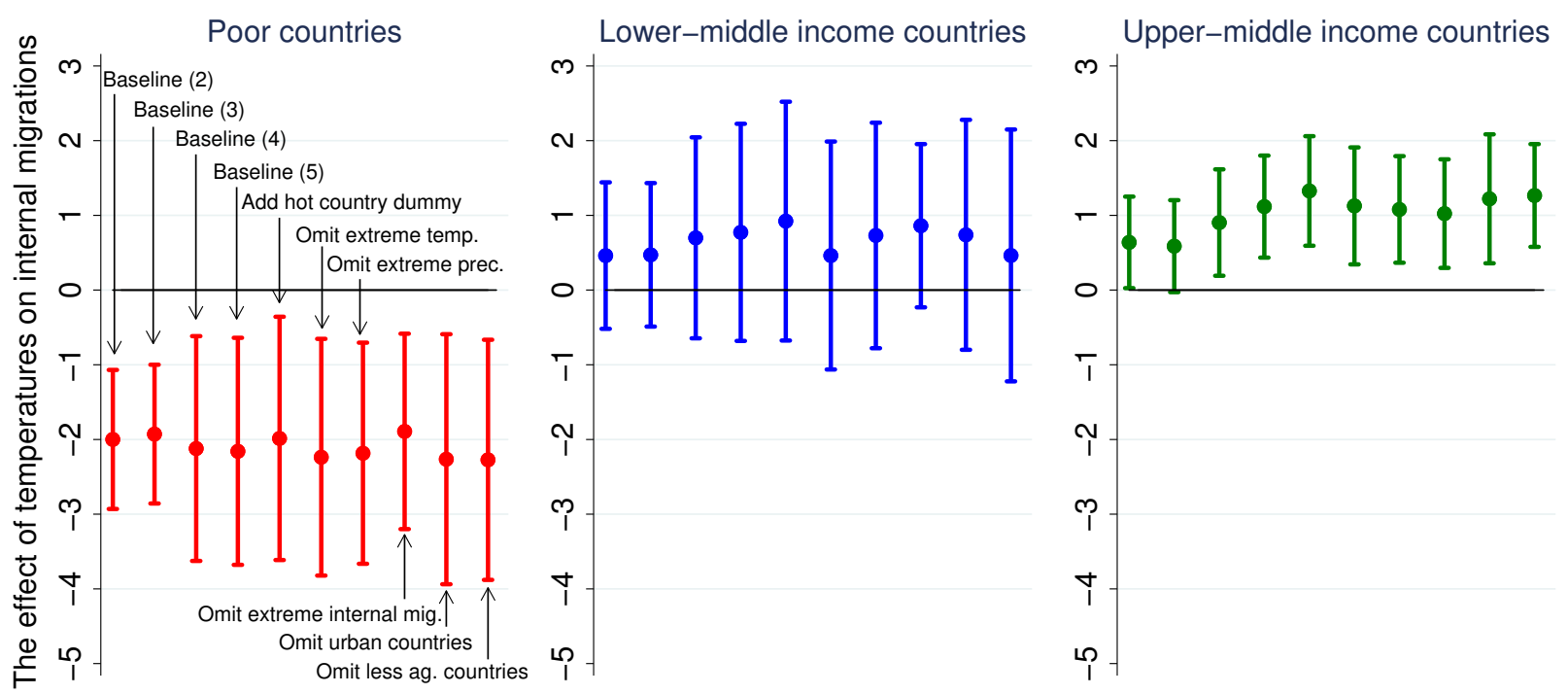

Notes: The figure shows plots point estimates and their $95 \%$ confidence intervals of the impact of temperatures on the internal migration rates. Plotted point estimates labeled as Baselines (2)-(5) are based on regression results reported in Table 3, columns (2)-(5). See Table A7 in Appendix E for other plotted point estimates. 


\section{Figure 14: Projected Temperature Change}
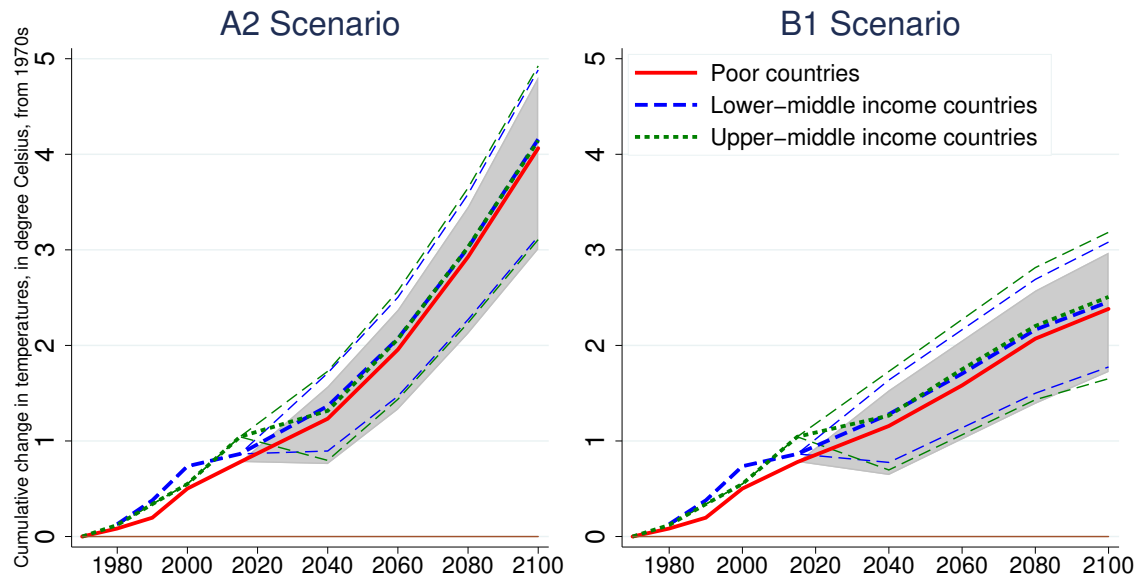

Notes: The data come from the Climate Change Knowledge Portal (World Bank, 2018).

\section{Figure 15: Projected Temperature Change and Precipitation Change}

Panel A: Predicted internal migration rates
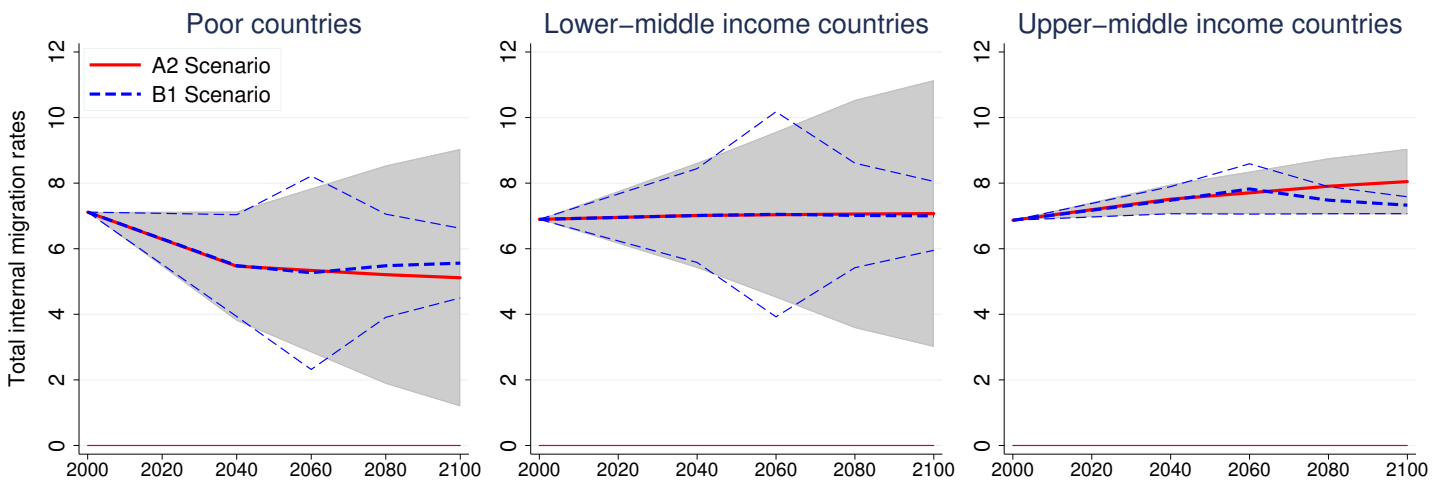

Panel B: Predicted out-migration rates, Rural and middle-rural
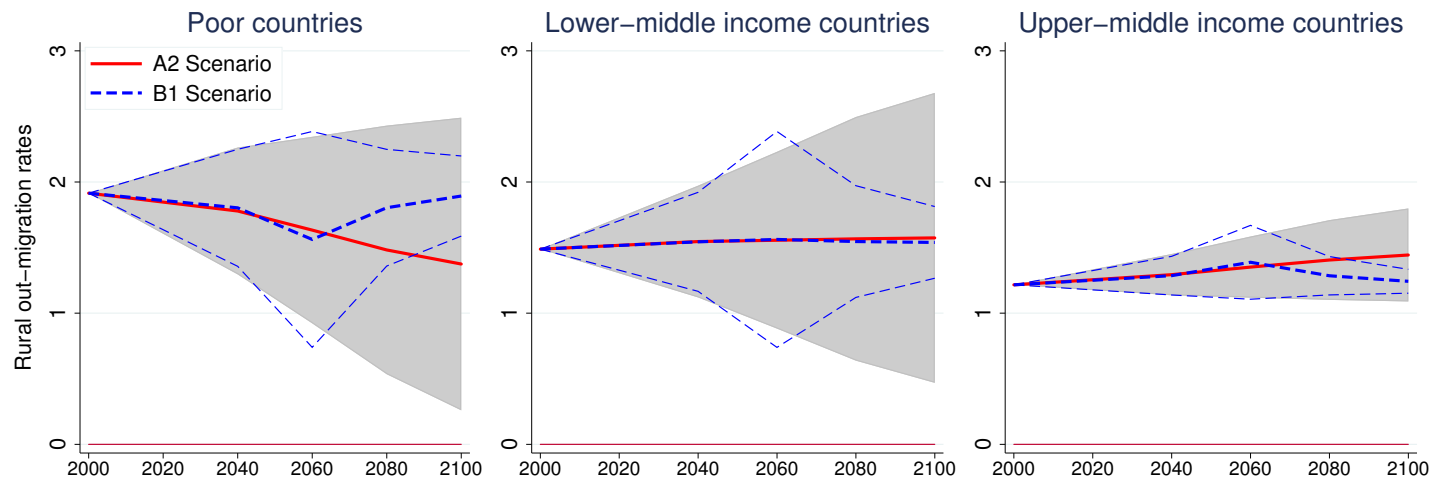

Notes: The figure shows anticipated net migration rates based on temperature projections from the Climate Change Knowledge Portal (World Bank, 2018). The bands are 90\% confidence intervals. See Tables A11 and A12 in Appendix G for data associated with this figure. 


\section{Appendix (Not for Publication)}

\section{A Dataset}

\section{A.1 Data Sources}

\section{A.1.1 Net Migration Data}

The net migration measure comes from the Global Estimated Net Migration Grids By Decade, v1 (1970-2000) (de Sherbinin et al., 2015). ${ }^{25}$ This dataset provides estimates of net migration (in-migration minus out-migration) per one-kilometer grid cell for three decades, 1970s, 1980s and 1990s. We present their method of imputing the net migration measure. The explanation below is based on de Sherbinin et al. (2015).

Step 1 They use the History Database of the Global Environment, Version 3.1 (HYDE) ${ }^{26}$ population grids for the years 1970, 1980, 1990 and 2000 to find one degree grids representing the rates of change in population in each decade.

Step 2 They applied those rates to the Global Rural-Urban Mapping Project, Version 1 (GRUMP) ${ }^{27}$ population grids for 2000, producing grids to 1970, 1975, 1980, 1985, 1990, and 1995, and forecast grids for 2005 and 2010. This ensured that the global population data set with the greatest number of census inputs was utilized to spatially allocate population in one time slice, and also enabled the analysis to be conducted at the higher resolution of the GRUMP product.

Step 3 They adjust the global grids to match country totals from the UN population estimates for the given year.

Step 4 In order to estimate that portion of population growth that is due to natural increase (birth minus deaths) for each grid cell in each decennial period, they applied subnational observed and imputed rates of natural increase (crude birth rates minus crude death rates) to the population grid at the beginning of each time to find decennial estimated natural increase. Similar to Step 3, they adjust the natural increase grids to match the UN estimates of natural increase at the country level.

Step 5 For each decade, they subtract the population in time 1 (e.g., 1970) from the population in time 2 (e.g., 1980) in order to find the change in population in the grid cell, and then subtract the natural increase in the grid cell (from Step 4) in order to find an estimate of net migration for the grid cell in the decade. This is based on population balancing equation:

$$
\text { Population growth }=(\text { Births }- \text { Deaths })+\text { Net migration, }
$$

which can be solved as

$$
\text { Net migration }=\text { Population growth }-(\text { Births }- \text { Deaths }) \text {. }
$$

The unit of the net migration measure in the original dataset is the net change of the number of people (due to migration) per $1 \mathrm{~km}^{2}$. We collapse the highly disaggregated observations to a $0.5 \times 0.5$ degree resolution. The original observations are aggregated by taking means. As a result, the unit of

\footnotetext{
${ }^{25}$ The same dataset on net migration is employed by de Sherbinin et al. (2012) in the context of environmental research. They investigate the association between the net migration and environmental factors such as risk of climate hazard. They find that, from 1970 to 2000, people tend to migrate from dryland and mountain areas toward coastal areas. Also, they find an opposite pattern for North America, i.e., there is a large influx of people in dry and high-latitude areas.

${ }^{26}$ Available at http://themasites.pbl.nl/tridion/en/themasites/hyde/

${ }^{27}$ Available at http://sedac.ciesin.columbia.edu/data/collection/grump-v1
} 
our net migration measure after aggregation is the number of people (due to migration) per $1 \mathrm{~km}^{2}$ in a $56 \mathrm{~km} \times 56 \mathrm{~km}$ grid cell (at the equator). de Sherbinin et al. (2015) acknowledge that there could be measurement errors at a local-level such as counties and municipals. We assume that these measurement errors are somehow mitigated by aggregating the observations into the $0.5 \times 0.5$ degree resolution. One grid cell after aggregation contains $56 \times 56=3,136$ of original grid cells.

\section{A.1.2 Climate Data}

We take the data on temperatures and precipitation from the Terrestrial Air Temperature and Precipitation: 1900-2006 Gridded Monthly Time Series, Version 1.01 (Matsuura and Willmott, 2007). The dataset includes temperatures and precipitation at the $0.5 \times 0.5$ degree grid cell level (approximately $56 \mathrm{~km} \times 56 \mathrm{~km}$ at the equator) and it covers the global land surface. It provides monthly average temperatures and precipitation for each grid cell.

\section{A.1.3 Other Grid Cell Level and Country-level Data}

The data on GDP and population come from the Global Dataset of Gridded Population and GDP Scenarios (Yamagata and Murakami, 2015). This dataset gives global GDP and population in $0.5 \times 0.5$ degree grids between 1980 and 2010 by 10 years. The data in 1980-2010 are estimated by downscaling actual populations and GDP by country and we use the data from 1980, 1990, and 2000. They map the country-level population and GDP data into $0.5 \times 0.5$ degree grid cells by using spatial and economic interactions between cities, and by utilizing road network and land cover. See Murakami and Yamagata (2017) for further details.

The country identifiers come from the Global Rural-Urban Mapping Project, Version 1 (GRUMPv1): National Identifier Grid (van Donkelaar et al., 2015). We aggregate the grid cell level dataset to a countrylevel and run country-level regressions. The data on country-level GDP, GDP growth rates, population, population growth rates, urban population, agricultural value-added, and manufacturing value-added are retrieved from the World Development Indicators (World Bank, 2018).

\section{A.2 Summary Statistics}

This section presents summary statistics of variables used in the country-level regressions in section 5. Table A1 shows the summary statics where observations come from poor, lower-middle income, and upper-middle income countries for three periods, '70s, '80s, and '90s. It shows summary statistics for the three internal migration measures, (1) total internal migration rates, (2) out-migration rates (from rural and middle-rural areas), and (3) out-migration rates (from rural areas). The population growth rate and the GDP growth rate are the annualized average growth rate during each decade. $\ln (G D P)$ and $\ln$ (Population) are natural $\log$ of GDP and population at the initial year of each decade. Agricultural and manufacturing value-added shares also come from the initial year of each decade. Changes in agricultural (and manufacturing) value-added shares are percentage point differences in the agricultural (and manufacturing) value-added shares between the initial year of the decade and the last year of the same decade. Table A2 shows more detailed summary statistics for the three internal migration variables. 
Table A1: Summary Statistics of the Data for Country-level Regressions

\begin{tabular}{|c|c|c|c|c|c|}
\hline & Obs. & Mean & St. dev. & Min & $\operatorname{Max}$ \\
\hline Total internal migration rates & 349 & 7.09 & 5.41 & 0.09 & 63.27 \\
\hline Out-migration rates (from rural and middle-rural areas) & 349 & 1.82 & 2.03 & 0.00 & 21.26 \\
\hline Out-migration rates (from rural areas) & 349 & 0.80 & 1.55 & 0.00 & 21.20 \\
\hline Population growth rate $(\%)$ & 349 & 2.04 & 1.13 & -1.83 & 4.67 \\
\hline GDP growth rate $(\%)$ & 242 & 3.28 & 2.45 & -9.81 & 1.45 \\
\hline $\ln (G D P)$ & 264 & 23.10 & 1.95 & 18.62 & 27.98 \\
\hline $\ln ($ Population $)$ & 349 & 15.64 & 1.68 & 10.99 & 20.85 \\
\hline Agricultural value-added share ( $\%$ of GDP) & 239 & 24.33 & 13.57 & 2.54 & 71.76 \\
\hline Manufacturing value-added share (\% of GDP) & 203 & 13.28 & 6.95 & 0.19 & 31.54 \\
\hline$\Delta$ Agricultural value-added share (\% points) & 238 & -2.76 & 6.89 & -21.82 & 21.70 \\
\hline$\Delta$ Manufacturing value-added share (\% points) & 195 & 0.12 & 4.76 & -22.57 & 14.91 \\
\hline
\end{tabular}

Notes: The table shows summary statistics of variables used for regressions using country-level observations.

Table A2: Summary Statistics of the Net Migration Rates by Income-level of Countries

\begin{tabular}{|c|c|c|c|c|c|}
\hline & Obs. & Mean & St. dev. & Min & $\operatorname{Max}$ \\
\hline \multicolumn{6}{|l|}{ Total internal migration rates } \\
\hline Full sample & 448 & 6.98 & 5.30 & 0.09 & 63.27 \\
\hline Poor countries & 115 & 6.83 & 3.92 & 0.09 & 25.70 \\
\hline Lower-middle income countries & 105 & 8.50 & 7.87 & 0.98 & 63.27 \\
\hline Upper-middle income countries & 129 & 6.17 & 3.61 & 0.75 & 15.92 \\
\hline Rich countries & 99 & 6.58 & 4.89 & 0.22 & 32.27 \\
\hline \multicolumn{6}{|c|}{ Out-migration rates from rural and middle-rural areas } \\
\hline Full sample & 448 & 1.69 & 1.94 & 0.00 & 21.26 \\
\hline Poor countries & 115 & 2.11 & 1.62 & 0.10 & 8.56 \\
\hline Lower-middle income countries & 105 & 2.26 & 2.94 & 0.04 & 21.26 \\
\hline Upper-middle income countries & 129 & 1.21 & 1.09 & 0.00 & 5.13 \\
\hline Rich countries & 99 & 1.24 & 1.53 & 0.01 & 10.70 \\
\hline \multicolumn{6}{|c|}{ Out-migration rates from rural areas } \\
\hline Full sample & 448 & 0.70 & 1.40 & 0.00 & 21.20 \\
\hline Poor countries & 115 & 0.86 & 0.73 & 0.00 & 3.97 \\
\hline Lower-middle income countries & 105 & 1.23 & 2.62 & 0.00 & 21.20 \\
\hline Upper-middle income countries & 129 & 0.39 & 0.43 & 0.00 & 1.86 \\
\hline Rich countries & 99 & 0.37 & 0.56 & 0.00 & 4.70 \\
\hline
\end{tabular}

Notes: The table shows summary statistics of the total internal migration rates for each decade. The country groups are based on the 25th, 50th, 75th percentiles of the distribution of GDP per capita. See Section 2.1 for the definition of the variables. 


\section{B List of Countries}

Countries are classified into four groups based on the income level of countries. ${ }^{28}$ Astarik $*$ indicates that the country is also included regression using the country-level aggregated observations. Poor countries (GDP per capita is less than 25th percentile) are:

Bangladesh* (BGD), Benin* (BEN), Bhutan* (BTN), Burkina Faso* (BFA), Burundi (BDI), Cabo Verde* (CPV), Cambodia (KHM), Central African Republic* (CAF), Chad* (TCD), China* (CHN), Comoros* (COM), Democratic Republic of the Congo (COD), Equatorial Guinea* (GNQ), Eritrea (ERI), Ethiopia* (ETH), Gambia* (GMB), Ghana* (GHA), Guinea (GIN), Guinea-Bissau* (GNB), Haiti (HTI), India* (IND), Kenya* (KEN), Lesotho* (LSO), Madagascar* (MDG), Malawi* (MWI), Mali* (MLI), Mauritania (MRT), Mozambique (MOZ), Myanmar* (MMR), Nepal* (NPL), Niger* (NER), Pakistan* (PAK), Rwanda (RWA), Senegal* (SEN), Sierra Leone* (SLE), Sri Lanka (LKA), Sudan (SDN), Tanzania* (TZA), Togo* (TGO), Uganda (UGA), Uzbekistan (UZB), Vietnam (VNM), and Yemen (YEM).

Lower-middle-income countries (GDP per capita is between 25th and 50th percentile) are:

Albania* (ALB), Angola* (AGO), Armenia (ARM), Belize* (BLZ), Bolivia* (BOL), Bosnia and Herzegovina (BIH), Botswana* (BWA), Cote d'Ivoire (CIV), Cameroon* (CMR), Rep. of Congo* (COG), Dominican Republic (DOM), Egypt* (EGY), El Salvador* (SLV), Guatemala* (GTM), Guyana* (GUY), Honduras* (HND), Indonesia* (IDN), Kiribati (KIR), Kyrgyzstan (KGZ), Liberia (LBR), Mauritius* (MUS), Mongolia* (MNG), Morocco (MAR), Nicaragua* (NIC), Nigeria* (NGA), Papua New Guinea (PNG), Paraguay (PRY), Philippines* (PHL), Saint Vincent and the Grenadines (VCT), Serbia and Montenegro (SRB), Solomon Islands* (SLB), Swaziland* (SWZ), Tajikistan (TJK), Thailand (THA), Timor-Leste (TLS), Tunisia* (TUN), Tuvalu (TUV), Vanuatu* (VUT), Zambia* (ZMB), and Zimbabwe* (ZWE).

Upper-middle-income countries (GDP per capita is between 50th and 75th percentile) are:

Algeria* (DZA), Argentina* (ARG), Azerbaijan (AZE), Belarus (BLR), Brazil* (BRA), Bulgaria* (BGR), Chile* (CHL), China (Hong Kong SAR) (HKG), Colombia* (COL), Costa Rica* (CRI), Cuba* (CUB), Ecuador* (ECU), Estonia (EST), Fiji* (FJI), Gabon* (GAB), Georgia (GEO), Hungary (HUN), Iran* (IRN), Iraq* (IRQ), Jamaica* (JAM), Jordan* (JOR), Kazakhstan (KAZ), Rep. of Korea* (KOR), Latvia (LVA), Lebanon (LBN), Libya* (LBY), Lithuania (LTU), Macedonia (MKD), Malaysia* (MYS), Maldives (MDV), Mexico* (MEX), Namibia (NAM), Oman* (OMN), Panama* (PAN), Peru* (PER), Poland (POL), Portugal (PRT), Romania (ROU), Russian Federation (RUS), Slovakia (SVK), South Africa (ZAF), Suriname* (SUR), Trinidad and Tobago (TTO), Turkey* (TUR), Turkmenistan (TKM), Ukraine (UKR), and Uruguay* (URY).

Rich countries (GDP per capita is more than 75th percentile) are:

Andorra (AND), Australia (AUS), Austria (AUT), Bahamas (BHS), Belgium (BEL), Canada (CAN), Denmark (DNK), Finland (FIN), France (FRA), Germany (DEU), Greece (GRC), Ireland (IRL), Israel (ISR), Italy (ITA), Japan (JPN), Luxembourg (LUX), Netherlands (NLD), New Zealand (NZL), Norway NOR), Puerto Rico (PRI), Saudi Arabia (SAU), Spain (ESP), Sweden (SWE), United Kingdom (GBR), United States of America (USA), and Venezuela (VEN).

\footnotetext{
${ }^{28}$ We use the data on GDP per capita from 1980 to define the four groups of countries. Poor countries are those with GDP per capita less than the 25th percentile of the distribution. Those between the 25th and the 50th are lower-middle income countries. Those between the 50th and the 75th percentile are upper-middle income countries. Lastly, those above the 75 th percentile are rich countries. The 1980 data on GDP per capita are not available for some countries. Therefore, in order to include as many countries as possible, we also compute the 25th, 50th, 75th percentiles of GDP per capita for all available countries in 1990 and 2000. If GDP per capita is not available from 1980 but available from 1990, then the income level group in 1990 is used to define the country's income level. Similarly, if GDP per capita is not available from 1980 and 1990 but available from 2000, then the income level group in 2000 is used to define the country's income level. The data on GDP per capita come from the WDI (World Bank, 2018)
} 


\section{Parameter Values for the Numerical Exercise}

This section discusses empirical backgrounds of our choice of parameter values for the numerical exercise in section 3.2, which are summarized in Table A3. We choose key parameter values to match a representative poor country, Vietnam.

Productivity in the urban and rural regions: We use industrial and agricultural value-added per worker as a measure of rural and urban productivity, respectively. The data on industrial and agricultural value-added per worker (USD, 2010 constant prices) are taken from the WDI (World Bank, 2018). Vietnam's industry-to-agriculture productivity ratio equal 6 in the earliest available year in the dataset, 1991. Therefore, we set our initial urban-to-rural productivity gap to 6 .

Table A3: Parameter values

\begin{tabular}{|c|c|c|}
\hline \multicolumn{2}{|l|}{ Parameters } & References \\
\hline \multicolumn{3}{|l|}{ Productivity in the urban region } \\
\hline & Assumed \\
\hline \multicolumn{2}{|c|}{ with $\ln \left(A_{1}^{U}\right)=1.5$ (i.e., $\left.A_{1}^{U}=4.48\right)$} & Assumed \\
\hline \multicolumn{3}{|c|}{$\epsilon_{t}$ follows a normal distribution with } \\
\hline \multicolumn{2}{|c|}{ mean zero and standard deviation 0.028} & Assumed \\
\hline \multicolumn{3}{|l|}{ Productivity in the rural region } \\
\hline \multicolumn{3}{|c|}{$A_{t}^{R}=\rho A_{t-1}^{U}+(1-\rho) A_{t-1}^{R}$ with $A_{0}^{R}=A_{0}^{U} /$ Gap } \\
\hline \multirow{2}{*}{\multicolumn{2}{|c|}{$\begin{array}{l}\text { where the initial productivity gap is } \operatorname{Gap}=6 \\
\text { and the speed of technology diffusion is } \rho=0.025\end{array}$}} & Based on the data from the WDI \\
\hline & & Assumed \\
\hline \multicolumn{3}{|l|}{ Temperature shocks } \\
\hline \multicolumn{2}{|c|}{ Constant $10 \%$ productivity decline throughout the periods } & Assumed \\
\hline \multicolumn{3}{|l|}{ Other parameters } \\
\hline Costs of migration & $C=0.6 \times A_{1}^{U}=2.69$ & Grogger and Hanson (2011) \\
\hline Return from skills in rural & $\beta^{R}=1.6$ & Assumed \\
\hline Return from skills in urban & $\beta^{U}=1.5 \times \beta^{R}=2.4$ & Herrendorf and Schoellman (2018) \\
\hline
\end{tabular}

The average annual growth rate of agricultural and industrial productivity were $1.85 \%$ and $3.89 \%$, respectively for Vietnam, during the period 1991-2016. Parameters governing the urban (industry) productivity evolution are chosen to match these average annual growth rates. As a result, we have: $\ln \left(A_{t}^{U}\right)=0.17+0.90 \ln \left(A_{t-1}^{U}\right)+\epsilon_{t}$ where $\epsilon_{t}$ follows a normal distribution with zero mean and standard deviation of 0.028 . We set the initial $\log$ productivity to be $\ln \left(A_{1}^{U}\right)=1.5$ therefore $A_{1}^{U} \approx 4.48$. Using the assumed initial productivity and parameters and the distribution of the error term, urban productivity paths are simulated for 1,000 times. The parameter determining the speed of technology diffusion $\rho$ is chosen in order to match the annual average rural (agricultural) productivity growth rate, 3.89\%. As a result, $\rho=0.025$. We first simulate a path without any disruptive effect from excessively high temperature, so that $\delta^{R}=1$ in each period. Then our exercise introduces deterministic temperature shocks along the growth path. We consider that a temperature increase above the threshold $T$ generates a $10 \%$ decline in rural productivity (i.e. assuming $\delta^{R}=\gamma=0.9$ ), and we analyze the new growth path with lower rural productivity.

Costs of migration: The existing literature does not provide much guidance about the costs of rural-urban migration within a country. We therefore adapt estimates of international migration costs to provide a rough approximation for these costs. Grogger and Hanson (2011) estimate international 
migration costs using bilateral migration flows across countries in 2000. They find that, for individuals in Vietnam, migration costs to relocate to the U.S. is the lowest among six destination countries presented in the paper and the costs are 26 thousand USD at the 2010 price. The international migration costs from Vietnam to the U.S. are about 6.2 times greater than Vietnam's industrial value-added per worker (our measure of urban productivity) in the same year, 4.2 thousand USD. The international migration costs to the U.S. from Guatemala and Dominican Republic are about 1.1 times and 0.64 times its industrial value-added per worker, respectively. Internal migration costs should be lower than these values, as they do not entail the same loss of human capital and search costs. Therefore, we assume, as reference, that the total costs of rural-to-urban migration costs in a poor country are equal to 0.6 times the value of one year of urban income.

Returns from skills: In the model, the relative value of returns from skills between rural and urban matters in determining individuals' incentive to migrate. However, note that the absolute value of returns from skills is not exactly the same as returns to schooling in the labor literature. In the model, skills are a random variable distributed following the standard normal distribution while the concept of returns to education applies to years of education. Re-scaling the units of this measure of skills one can also obtain different returns on one additional unit of skills. Therefore, an arbitrary value of returns from skills, $\beta^{R}$, suffices for an illustration of the model and we assume that the one for the rural region is $\beta^{R}=1.6$.

We choose a value of $\beta^{U}$ based on the relative returns from schooling in agriculture (which we assume rural) and industry (which we assume urban) as estimated in a poor country. Herrendorf and Schoellman (2018) estimate returns to schooling in agriculture and industry using the data from poor countries such as India and Indonesia. Panel A of Figure 2 in that paper suggests that returns to schooling is about 1.5 times greater in industry than agriculture. Therefore, returns from skills in the urban region is $\beta^{U}=1.6 \times 1.5=2.4$. 


\section{Urban-Rural Productivity Gap}

Figure A1 shows the relationship between the industry-to-agriculture productivity gap and GDP per capita where the data come from the year 2000. The figure excludes countries where their industry-toagriculture productivity gaps are greater than 12 as outliers. It shows that the industry-to-agriculture productivity gap declines as GDP per capita increases. Restuccia et al. (2008) also find such cross-cross sectional relationship between the level of development and productivity gap across sectors. In particular, they show, using the data from 1985, that the overall labor productivity in the richest five percent of the countries is 34 times greater than the poorest five percent countries, on the other hand, agricultural labor productivity of the richest is 78 times that of the poorest.

\section{Figure A1: Industry-to-Agriculture Productivity Gap and GDP per capita}

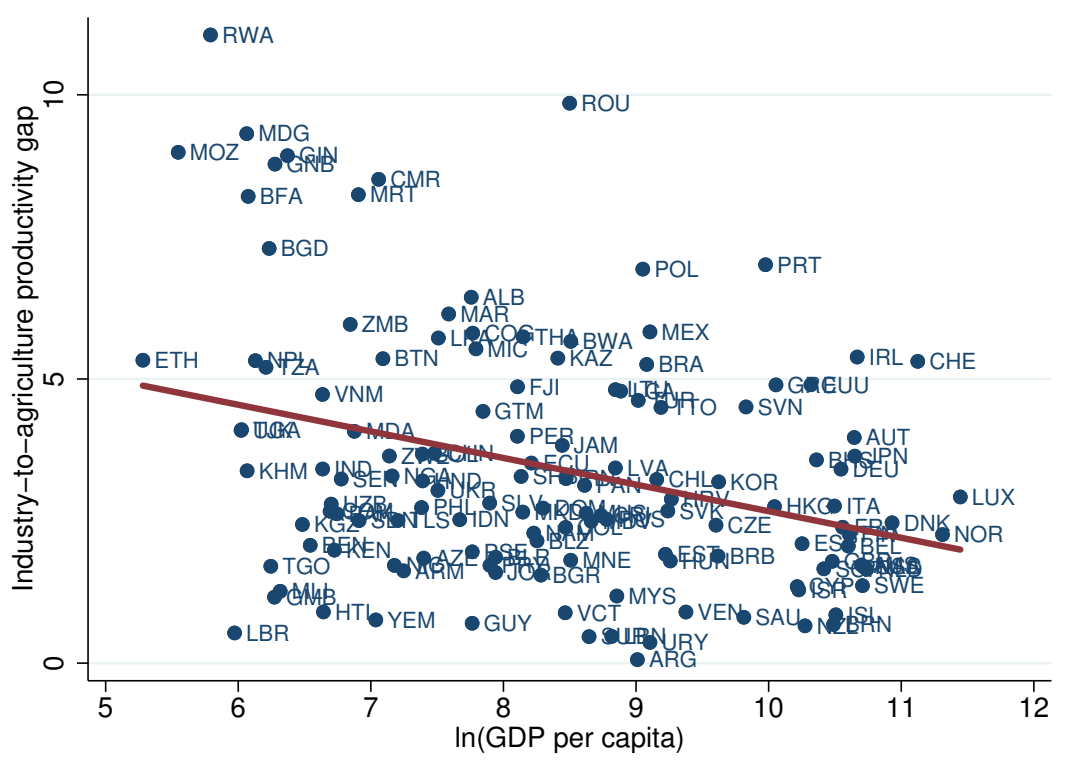

Notes: The data come from the WDI (World Bank, 2018).

These empirical observations are rational for agricultural productivity gap between urban (mostly industry-based economies) and rural regions (mostly agriculture-based economies). Our theoretical model presented in section 3 predicts that there are asymmetric migration responses to rising temperatures across poor and middle-income countries. The primary driver of this different migration reactions are rural-urban productivity gaps. In earlier periods of time in the simulation exercise in the main text, there are greater rural-urban productivity gaps. Due to this large productivity gap, there are some workers who are willing to migrate but unable to migrate because their feasibility constraint is binding. Therefore, a further decline of rural productivity level due to a temperature shock reduces the share of workers who migrate from rural to urban. On the other hand, when the rural-urban productivity gap is smaller, a greater share of people have non-binding feasibility constraints. Therefore, a decline of rural productivity due to a temperature shock widens a rural-urban productivity gap, which works to increase incentives to migrate from rural to urban areas.

Therefore, the cross-sectional relationship between the industry-to-agricultural productivity gap - a proxy of urban-to-rural productivity gap - and GDP per capita implies that the simulated time-series evolution of rural-urban productivity gaps (in section 3.2) can be mapped to a cross-section of countries. 


\section{E Regression Tables associated with Figures in the Main Text}

Our theoretical model predicts different patterns of rural-urban migrations depending upon the income level of countries and rural-urban status within each country. Therefore, we have a number of point estimates of the impact of temperatures on the net migration rates. In order to facilitate readers' understanding on our results, we relied on graphical presentation of our results by plotting point estimates and associated confidence intervals on figures. Because some readers might be interested in more details on our results - such as the number of observations, exact values of point estimates, and other statistics, this section presents regression tables that are plotted in figures in the main text. Specifically, regression results in Tables A4, A5, A6, and A7 are associated with Figures 9, 11, 12, and 13 in the main text, respectively.

Table A4: Grid Cell Level Regressions, Average Net Migration Rates by Area, 1970-2000

Dependent variable $=$ Net migration rates

Definition of rural-urban areas is based on Population at the grid cell level

Panel A: Average relative to the world average

\begin{tabular}{rcccc}
\hline \hline & Poor & Lower-middle & Upper-middle & Rich \\
& $(1)$ & $(2)$ & $(3)$ & $(4)$ \\
\hline Urban & $6.388^{* * *}$ & $5.321^{* * *}$ & $5.434^{* * *}$ & $7.213^{* * *}$ \\
& $(0.078)$ & $(0.204)$ & $(0.082)$ & $(0.138)$ \\
Middle-urban & $4.357^{* * *}$ & $-2.709^{* * *}$ & $1.900^{* * *}$ & $5.385^{* * *}$ \\
& $(0.108)$ & $(0.542)$ & $(0.195)$ & $(0.170)$ \\
Middle-rural & $-4.508^{* * *}$ & $-14.56^{* * *}$ & $-1.644^{* * *}$ & $3.614^{* * *}$ \\
& $(0.403)$ & $(0.876)$ & $(0.377)$ & $(0.234)$ \\
Rural & $-14.05^{* * *}$ & $-20.65^{* * *}$ & $-1.213^{* * *}$ & $-0.770^{*}$ \\
& $(0.566)$ & $(0.950)$ & $(0.393)$ & $(0.400)$ \\
\hline Observations & 24,236 & 12,703 & 33,695 & 26,158 \\
Grid cells & 8,219 & 4,345 & 11,439 & 8,772 \\
\hline \hline & Panel B: Average with controls & \\
\hline \hline Urban & $2.062^{* * *}$ & -1.142 & $0.743^{* * *}$ & $-0.593^{* * *}$ \\
& $(0.456)$ & $(0.700)$ & $(0.205)$ & $(0.188)$ \\
Moor & Lower-middle & Upper-middle & Rich \\
Middle-urban & 0.229 & $-7.820^{* * *}$ & $-2.541^{* * *}$ & $-1.981^{* * *}$ \\
& $(0.459)$ & $(0.850)$ & $(0.267)$ & $(0.187)$ \\
Middle-rural & $-8.255^{* * *}$ & $-18.45^{* * *}$ & $-5.597^{* * *}$ & $-2.776^{* * *}$ \\
& $(0.560)$ & $(1.099)$ & $(0.378)$ & $(0.219)$ \\
Rural & $-17.29^{* * *}$ & $-20.95^{* * *}$ & $-4.722^{* * *}$ & $-4.284^{* * *}$ \\
& $(0.708)$ & $(1.141)$ & $(0.406)$ & $(0.316)$ \\
\hline \hline Observations & 23,191 & 10,898 & 31,787 & 22,893 \\
Grid cells & 7,851 & 3,734 & 10,770 & 7,654 \\
\hline \hline
\end{tabular}

Notes: Regressions do not include a constant term. Panel B include $\Delta T e m p, \Delta$ Prec, and the population growth rate as controls. $* * *, * *$, and * indicate statistical significance at the $1 \%, 5 \%$, and $10 \%$ level, respectively. Robust standard errors clustered at the grid cell level are in parentheses. Point estimates shown in Panels A and B are plotted in Panels A and B in Figure 9, respectively. 
Table A5: Grid Cell Level Regressions, Rural-Urban Dummies based on Population, Addressing Non-Linearity of Temperature Effects

Dependent variable $=$ Net migration rates

Definition of rural-urban areas is based on Population at the grid cell level

\begin{tabular}{|c|c|c|c|c|c|c|}
\hline & \multicolumn{2}{|c|}{ Poor } & \multicolumn{2}{|c|}{ Lower-middle } & \multicolumn{2}{|c|}{ Upper-middle } \\
\hline & $\begin{array}{c}\text { Uniform } \\
\text { cutoff } \\
\text { (1) }\end{array}$ & $\begin{array}{c}\text { Group- } \\
\text { based } \\
\text { cutoffs } \\
(2)\end{array}$ & $\begin{array}{c}\text { Uniform } \\
\text { cutoff } \\
\text { (3) }\end{array}$ & $\begin{array}{c}\text { Group- } \\
\text { based } \\
\text { cutoffs } \\
(4)\end{array}$ & $\begin{array}{c}\text { Uniform } \\
\text { cutoff } \\
(5)\end{array}$ & $\begin{array}{c}\text { Group- } \\
\text { based } \\
\text { cutoffs } \\
(6)\end{array}$ \\
\hline$\Delta T e m p$ & $\begin{array}{c}0.122 \\
(0.259)\end{array}$ & $\begin{array}{l}-0.0945 \\
(0.223)\end{array}$ & $\begin{array}{c}-1.403^{* * *} \\
(0.412)\end{array}$ & $\begin{array}{c}-2.019^{* * *} \\
(0.394)\end{array}$ & $\begin{array}{c}-0.241^{* *} \\
(0.116)\end{array}$ & $\begin{array}{l}-0.121 \\
(0.129)\end{array}$ \\
\hline$D^{\text {Hot }} \times \Delta T e m p$ & $\begin{array}{c}-1.536^{* * *} \\
(0.467)\end{array}$ & $\begin{array}{c}-1.525^{* * *} \\
(0.528)\end{array}$ & $\begin{array}{c}-4.314^{* * *} \\
(0.816)\end{array}$ & $\begin{array}{l}-1.344 \\
(1.069)\end{array}$ & $\begin{array}{c}-1.772^{* * *} \\
(0.445)\end{array}$ & $\begin{array}{c}-2.215^{* * *} \\
(0.408)\end{array}$ \\
\hline$D^{\text {Middle-urban }} \times \Delta T e m p$ & $\begin{array}{c}-0.431^{*} \\
(0.248)\end{array}$ & $\begin{array}{c}-0.398^{*} \\
(0.242)\end{array}$ & $\begin{array}{c}0.793 \\
(0.652)\end{array}$ & $\begin{array}{c}0.503 \\
(0.659)\end{array}$ & $\begin{array}{c}-0.578^{* * *} \\
(0.183)\end{array}$ & $\begin{array}{c}-0.538^{* * *} \\
(0.200)\end{array}$ \\
\hline$D^{\text {Middle-rural }} \times \Delta T e m p$ & $\begin{array}{c}0.686 \\
(0.454)\end{array}$ & $\begin{array}{l}0.793^{*} \\
(0.449)\end{array}$ & $\begin{array}{c}3.995^{* * *} \\
(0.761)\end{array}$ & $\begin{array}{c}3.313^{* * *} \\
(0.769)\end{array}$ & $\begin{array}{l}-0.350 \\
(0.285)\end{array}$ & $\begin{array}{l}-0.315 \\
(0.297)\end{array}$ \\
\hline$D^{\text {Rural }} \times \Delta T e m p$ & $\begin{array}{c}4.779^{* * *} \\
(0.626)\end{array}$ & $\begin{array}{c}4.884^{* * *} \\
(0.620)\end{array}$ & $\begin{array}{c}3.491^{* * *} \\
(0.741)\end{array}$ & $\begin{array}{c}2.828^{* * *} \\
(0.768)\end{array}$ & $\begin{array}{c}-0.792^{* *} \\
(0.312)\end{array}$ & $\begin{array}{c}-0.756^{* *} \\
(0.321)\end{array}$ \\
\hline Observations & 23,191 & 23,191 & 10,898 & 10,898 & 31,787 & 31,787 \\
\hline Grid cells & 7,851 & 7,851 & 3,734 & 3,734 & 10,770 & 10,770 \\
\hline$R$-squared & 0.261 & 0.261 & 0.267 & 0.257 & 0.144 & 0.142 \\
\hline perature effects (Li & ar combi & ion of $\mathrm{cc}$ & icients) & & & \\
\hline Middle-urban areas & $\begin{array}{l}-0.309 \\
(0.247)\end{array}$ & $\begin{array}{c}-0.493^{* *} \\
(0.217)\end{array}$ & $\begin{array}{l}-0.610 \\
(0.611)\end{array}$ & $\begin{array}{c}-1.516^{* *} \\
(0.593)\end{array}$ & $\begin{array}{c}-0.818^{* * *} \\
(0.164)\end{array}$ & $\begin{array}{c}-0.659^{* * *} \\
(0.167)\end{array}$ \\
\hline Middle-rural areas & $\begin{array}{l}0.808^{*} \\
(0.446)\end{array}$ & $\begin{array}{c}0.698 \\
(0.433)\end{array}$ & $\begin{array}{c}2.592^{* * *} \\
(0.677)\end{array}$ & $\begin{array}{l}1.294^{*} \\
(0.677)\end{array}$ & $\begin{array}{c}-0.591^{* *} \\
(0.265)\end{array}$ & $\begin{array}{l}-0.436 \\
(0.272)\end{array}$ \\
\hline Rural areas & $\begin{array}{c}4.901^{* * *} \\
(0.607)\end{array}$ & $\begin{array}{c}4.790^{* * *} \\
(0.602)\end{array}$ & $\begin{array}{c}2.088^{* * *} \\
(0.644)\end{array}$ & $\begin{array}{c}0.809 \\
(0.669)\end{array}$ & $\begin{array}{c}-1.032^{\text {*** }} \\
(0.296)\end{array}$ & $\begin{array}{c}-0.877^{* * * *} \\
(0.294)\end{array}$ \\
\hline
\end{tabular}

Notes: All regressions include $D^{\text {Hot }} \times$ Year fixed effects, $D^{\text {Rural-urban }} \times$ Year fixed effects, $D^{\text {Rural-urban }} \times \Delta$ Precipitation, $D^{\text {Region }} \times$ Year fixed effects, $D^{\text {Rural-urban }} \times$ Population growth rates, and country fixed effects as controls. The hot country dummy $D^{\text {Hot }}$ in columns (1), (3), and (5) takes unity if the mean temperatures during 1970-2000 are above the 75th percentile of the distribution in all locations. The hot country dummy $D^{\text {Hot }}$ in columns (2), (4), and (6) takes unity if the mean temperatures during 1970-2000 are above the 75th percentile of the distribution in locations in each group of countries. Robust standard errors clustered at the grid cell level are in parentheses. ${ }^{* * *}, * *$, and * indicate statistical significance at the $1 \%, 5 \%$, and $10 \%$ level, respectively. Figure 11 plots point estimates shown in odd number columns. 


\section{Table A6: Grid Cell Level Regressions, Rural-Urban Dummies based on Population, Ro- bustness Checks}

Temperature effects (Linear combination of coefficients)

Dependent variable $=$ Net migration rates

Definition of rural-urban areas is based on Population at the grid cell level

\begin{tabular}{|c|c|c|c|c|c|c|}
\hline & $\begin{array}{c}\text { Omit } \\
\text { extreme } \\
\text { temp. }\end{array}$ & $\begin{array}{c}\text { Omit } \\
\text { extreme } \\
\text { prec. }\end{array}$ & $\begin{array}{c}\text { Omit } \\
\text { extreme } \\
\text { internal } \\
\text { migration } \\
\text { Panel } A: P \\
\text { (3) }\end{array}$ & $\begin{array}{c}\text { Omit } \\
\text { Sub- } \\
\text { Saharan } \\
\text { Africa } \\
\text { or countries } \\
\quad(4)\end{array}$ & $\begin{array}{c}\text { Omit } \\
\text { urban } \\
\text { count- } \\
\text { ries }\end{array}$ & $\begin{array}{c}\text { Omit } \\
\text { less ag. } \\
\text { count- } \\
\text { ries }\end{array}$ \\
\hline \multirow{4}{*}{ Middle-urban areas } & -0.043 & -0.254 & $-0.322^{*}$ & -0.451 & -0.312 & -0.312 \\
\hline & $(0.208)$ & $(0.197)$ & $(0.173)$ & $(0.274)$ & $(0.192)$ & $(0.192)$ \\
\hline & $-0.547^{* * *}$ & $-0.720 * * *$ & $-0.599 * * *$ & $-0.395^{*}$ & $-0.642^{* * *}$ & $-0.642^{* * *}$ \\
\hline & $(0.204)$ & $(0.209)$ & $(0.185)$ & $(0.217)$ & $(0.199)$ & $(0.199)$ \\
\hline \multirow[t]{2}{*}{ Middle-rural areas } & 0.098 & 0.449 & $0.759^{* *}$ & $1.155^{* *}$ & 0.597 & 0.597 \\
\hline & $(0.461)$ & $(0.419)$ & $(0.372)$ & $(0.506)$ & $(0.414)$ & $(0.414)$ \\
\hline \multirow[t]{2}{*}{ Rural areas } & $4.882^{* * *}$ & $4.707 * * *$ & $4.072 * * *$ & $4.003^{* * *}$ & $4.742^{* * *}$ & $4.742^{* * *}$ \\
\hline & $(0.657)$ & $(0.597)$ & $(0.537)$ & $(0.652)$ & $(0.592)$ & $(0.592)$ \\
\hline Observations & 23,055 & 22,724 & 22,875 & 23,191 & 14,078 & 23,191 \\
\hline \multirow[t]{3}{*}{ Grid cells } & 7,851 & 7,838 & 7,821 & 7,851 & 4,759 & 7,851 \\
\hline & \multicolumn{6}{|c|}{ Panel B: Lower-middle income countries } \\
\hline & (1) & $(2)$ & $(3)$ & $(4)$ & $(5)$ & $(6)$ \\
\hline \multirow{4}{*}{ Middle-urban areas } & $-2.646^{* * *}$ & $-2.350 * * *$ & $-2.038^{* * *}$ & $-2.951^{* * *}$ & $-2.344^{* * *}$ & $-2.681^{* * *}$ \\
\hline & $(0.364)$ & $(0.394)$ & $(0.354)$ & $(0.492)$ & $(0.386)$ & $(0.411)$ \\
\hline & $-1.926 * * *$ & $-1.926^{* * *}$ & $-0.947^{* *}$ & -0.952 & $-1.834^{* * *}$ & $-1.662 * * *$ \\
\hline & $(0.594)$ & $(0.566)$ & $(0.469)$ & $(0.720)$ & $(0.563)$ & $(0.598)$ \\
\hline \multirow[t]{2}{*}{ Middle-rural areas } & 0.705 & 0.466 & 0.469 & 1.986 & 0.857 & 0.790 \\
\hline & $(0.682)$ & $(0.677)$ & $(0.615)$ & $(0.852)$ & $(0.683)$ & $(0.729)$ \\
\hline \multirow[t]{2}{*}{ Rural areas } & 0.554 & 0.382 & $1.178^{* *}$ & -0.902 & 0.510 & 0.453 \\
\hline & $(0.740)$ & $(0.672)$ & $(0.579)$ & $(0.720)$ & $(0.660)$ & $(0.705)$ \\
\hline Observations & 10,821 & 10,508 & 10,577 & 10,898 & 7,011 & 10,532 \\
\hline \multirow[t]{3}{*}{ Grid cells } & 3,734 & 3,722 & 3,700 & 3,734 & 2,408 & 3,609 \\
\hline & & & $U p p$ & incor & ntries & \\
\hline & $(1)$ & $(2)$ & $(3)$ & $(4)$ & $(5)$ & $(6)$ \\
\hline \multirow[t]{3}{*}{ Urban areas } & $\begin{array}{c}-0.500^{* * *} \\
(0.119)\end{array}$ & $\begin{array}{c}-0.436^{* * *} \\
(0.082)\end{array}$ & $\begin{array}{c}-0.376^{* * *} \\
(0.073)\end{array}$ & $\begin{array}{c}-0.348^{* * *} \\
(0.078)\end{array}$ & $\begin{array}{c}-0.629^{* * *} \\
(0.092)\end{array}$ & $\begin{array}{c}-0.406^{* * *} \\
(0.081)\end{array}$ \\
\hline & $-1.000 * * *$ & $-0.876^{* * *}$ & $-0.682^{* * *}$ & $-0.777^{* * *}$ & $-0.877 * * *$ & $-0.863^{* * *}$ \\
\hline & $(0.183)$ & $(0.140)$ & $(0.128)$ & $(0.140)$ & $(0.146)$ & $(0.145)$ \\
\hline \multirow[t]{2}{*}{ Middle-rural areas } & $-0.629 * * *$ & $-0.752^{* * *}$ & $-0.556^{* * *}$ & $-0.907^{* * *}$ & $-0.544^{* * *}$ & $-0.859 * * *$ \\
\hline & $(0.326)$ & $(0.274)$ & $(0.221)$ & $(0.277)$ & $(0.283)$ & $(0.287)$ \\
\hline \multirow[t]{2}{*}{ Rural areas } & $-1.796^{* * *}$ & $-1.414^{* * *}$ & $-1.622 * * *$ & $-1.433^{* * *}$ & $-1.358 * * *$ & $-1.705^{* * *}$ \\
\hline & $(0.361)$ & $(0.293)$ & $(0.240)$ & $(0.295)$ & $(0.302)$ & $(0.296)$ \\
\hline Observations & 30,769 & 31,078 & 31,305 & 28,007 & 30,074 & 29,462 \\
\hline Grid cells & 10,763 & 10,755 & 10,717 & 9,505 & 10,185 & 9,981 \\
\hline
\end{tabular}

Notes: All regressions include $D^{\text {Rural-urban }} \times$ Year fixed effects, $D^{\text {Rural-urban }} \times \Delta$ Precipitation, $D^{\text {Region }} \times$ Year fixed effects, $D^{\text {Rural-urban }} \times$ Population growth rates, and country fixed effects as controls. Robust standard errors clustered at the grid cell level are in parentheses. ${ }^{* *}, * *$, and $*$ indicate statistical significance at the $1 \%, 5 \%$, and $10 \%$ level, respectively. Figure 12 plots point estimates presented in the table. 
Table A7: Country-level Regressions, Robustness Checks

\begin{tabular}{|c|c|c|c|c|c|c|}
\hline & $\begin{array}{c}\text { Add } \\
\text { hot } \\
\text { country } \\
\text { dummy }\end{array}$ & $\begin{array}{c}\text { Omit } \\
\text { extreme } \\
\text { temp. }\end{array}$ & $\begin{array}{c}\text { Omit } \\
\text { extreme } \\
\text { prec. }\end{array}$ & $\begin{array}{c}\text { Omit } \\
\text { extreme } \\
\text { internal } \\
\text { migration }\end{array}$ & $\begin{array}{l}\text { Omit } \\
\text { urban } \\
\text { count- } \\
\text { ries }\end{array}$ & $\begin{array}{l}\text { Omit } \\
\text { less ag. } \\
\text { count- } \\
\text { ries }\end{array}$ \\
\hline & \multicolumn{6}{|c|}{$\begin{array}{l}\text { Panel A: Total internal migration rates } \\
(2)\end{array}$} \\
\hline \multirow[b]{2}{*}{$D^{\text {Lower-middle }} \times \Delta T e m p$} & $\begin{array}{l}3.133^{* *} \\
(1.458)\end{array}$ & $\begin{array}{l}2.794^{*} \\
(1.569)\end{array}$ & $\begin{array}{l}3.183^{* *} \\
(1.369)\end{array}$ & $\begin{array}{l}3.012^{* *} \\
(1.347)\end{array}$ & $\begin{array}{l}3.722^{* *} \\
(1.601)\end{array}$ & $\begin{array}{l}2.856^{* *} \\
(1.402)\end{array}$ \\
\hline & $\begin{array}{l}-1.980 \\
(3.123)\end{array}$ & $\begin{array}{l}-1.728 \\
(3.492)\end{array}$ & $\begin{array}{l}-2.392 \\
(3.205)\end{array}$ & $\begin{array}{l}-2.209 \\
(3.149)\end{array}$ & $\begin{array}{l}-2.966 \\
(3.342)\end{array}$ & $\begin{array}{l}-3.952 \\
(2.686)\end{array}$ \\
\hline$D^{\text {Poor }} \times \Delta T e m p$ & $\begin{array}{l}-5.594 \\
(3.758)\end{array}$ & $\begin{array}{c}-5.603^{*} \\
(3.143)\end{array}$ & $\begin{array}{l}-5.666^{*} \\
(2.977)\end{array}$ & $\begin{array}{c}-5.684^{*} \\
(3.052)\end{array}$ & $\begin{array}{c}-6.486^{*} \\
(3.449)\end{array}$ & $\begin{array}{c}-5.627^{*} \\
(2.952)\end{array}$ \\
\hline Observations & 140 & 137 & 136 & 140 & 130 & 134 \\
\hline Countries & 63 & 63 & 61 & 63 & 59 & 61 \\
\hline$R$-squared & 0.287 & 0.268 & 0.268 & 0.269 & 0.268 & 0.245 \\
\hline \multicolumn{7}{|c|}{ Temperature effects (Linear combination of coefficients) } \\
\hline \multirow[t]{3}{*}{ Lower-middle countries } & $\begin{array}{l}1.153 \\
(2.865)\end{array}$ & $\begin{array}{l}1.066 \\
(2.907)\end{array}$ & $\begin{array}{c}0.791 \\
(2.746)\end{array}$ & $\begin{array}{c}0.802 \\
(2.700)\end{array}$ & $\begin{array}{c}0.756 \\
(2.712)\end{array}$ & $\begin{array}{l}-1.096 \\
(2.231)\end{array}$ \\
\hline & $\begin{array}{l}-2.461 \\
(3.215) \\
\end{array}$ & $\begin{array}{l}-2.808 \\
(2.606) \\
\end{array}$ & $\begin{array}{l}-2.483 \\
(2.422) \\
\end{array}$ & $\begin{array}{l}-2.672 \\
(2.554) \\
\end{array}$ & $\begin{array}{l}-2.764 \\
(2.634) \\
\end{array}$ & $\begin{array}{l}-2.770 \\
(2.439) \\
\end{array}$ \\
\hline & \multicolumn{6}{|c|}{ Panel B: Out-migration rates, Rural and Middle-rural } \\
\hline$\Delta T e m p$ & $\begin{array}{c}1.327^{* * *} \\
(0.374)\end{array}$ & $\begin{array}{c}1.127^{* * *} \\
(0.399)\end{array}$ & $\begin{array}{c}1.079^{* * *} \\
(0.364)\end{array}$ & $\begin{array}{c}1.023^{* * *} \\
(0.371)\end{array}$ & $\begin{array}{c}1.221^{* * *} \\
(0.440)\end{array}$ & $\begin{array}{c}1.266^{* * *} \\
(0.351)\end{array}$ \\
\hline$D^{\text {Lower-middle }} \times \Delta$ Temp & $\begin{array}{l}-0.404 \\
(0.845)\end{array}$ & $\begin{array}{l}-0.664 \\
(0.913)\end{array}$ & $\begin{array}{l}-0.349 \\
(0.870)\end{array}$ & $\begin{array}{l}-0.162 \\
(0.693)\end{array}$ & $\begin{array}{l}-0.482 \\
(0.933)\end{array}$ & $\begin{array}{l}-0.802 \\
(0.947)\end{array}$ \\
\hline$D^{\text {Poor }} \times \Delta T e m p$ & $\begin{array}{c}-3.312^{* * *} \\
(0.960)\end{array}$ & $\begin{array}{c}-3.364^{* * *} \\
(0.886) \\
\end{array}$ & $\begin{array}{c}-3.264^{* * *} \\
(0.863) \\
\end{array}$ & $\begin{array}{c}-2.915^{* * *} \\
(0.747)\end{array}$ & $\begin{array}{c}-3.486^{* * *} \\
(1.026)\end{array}$ & $\begin{array}{c}-3.538^{* * *} \\
(0.904)\end{array}$ \\
\hline Observations & 140 & 137 & 136 & 138 & 130 & 134 \\
\hline Countries & 63 & 63 & 61 & 62 & 59 & 61 \\
\hline$R$-squared & 0.308 & 0.304 & 0.296 & 0.319 & 0.284 & 0.306 \\
\hline \multicolumn{7}{|c|}{ Temperature effects (Linear combination of coefficients) } \\
\hline Lower-middle countries & $\begin{array}{c}0.923 \\
(0.815)\end{array}$ & $\begin{array}{c}0.462 \\
(0.778)\end{array}$ & $\begin{array}{c}0.731 \\
(0.770)\end{array}$ & $\begin{array}{c}0.861 \\
(0.557)\end{array}$ & $\begin{array}{c}0.740 \\
(0.785)\end{array}$ & $\begin{array}{c}0.464 \\
(0.860)\end{array}$ \\
\hline Poor countries & $\begin{array}{c}-1.986^{* *} \\
(0.831)\end{array}$ & $\begin{array}{c}-2.238^{* * *} \\
(0.808)\end{array}$ & $\begin{array}{c}-2.184^{* * *} \\
(0.755)\end{array}$ & $\begin{array}{c}-1.892^{* * *} \\
(0.667)\end{array}$ & $\begin{array}{c}-2.264^{* * *} \\
(0.854)\end{array}$ & $\begin{array}{c}-2.272^{\text {*** }} \\
(0.820)\end{array}$ \\
\hline
\end{tabular}

Notes: All regressions include population growth rates, GDP growth rates, and $\Delta$ Precipitation as controls. Robust standard errors clustered at the country-level are in parentheses. ***,**, and * indicate statistical significance at the $1 \%, 5 \%$, and $10 \%$ level, respectively. Figure 13 plots point estimates shown in the table. 


\section{F Further Robustness Checks}

\section{F.1 Different Definitions of Rural-Urban Grid Cells}

In the regressions using the grid cell level observations in the main text, we define rural/urban areas based on population density following a conventional definition (e.g., Ratcliffe et al., 2016). This section provides robustness checks concerning this baseline definition of rural/urban areas. Our dataset contains grid cell level GDP data and we can use within-country thresholds, the 25th, 50th, and 75th percentiles of GDP to define rural, middle-rural, middle-urban, and urban areas in each country. GDP may measure geographical distribution of economic activities more accurately than population density. For example, as described in Ratcliffe et al. (2016), containing an airport in a grid cell would reduce population density due to a lack of population who actually live there. However, that location should be classified as "urban" due to a large scale of economic activities by passengers and workers. If there is such special case, it might be better to employ GDP to define rural/urban areas within a country.

Therefore, we estimate regressions with grid cell level observations by defining rural, middle-rural, middle-urban, and urban based on grid cell level GDP, in order to show robustness of our results. Table A8 reports results from baseline specifications, which are summarized in the same manner as Table 2. It shows that employing rural-urban dummies based on GDP makes a little difference from our baseline results. The point estimates shown in columns (2), (4), and (6) are plotted in Panel A of Figure A2. Panel $\mathrm{B}$ in the same figure shows how the average net migration rates in each location change due to rising temperatures. The figure also includes estimates from rich countries that are not reported in the regression table as a reference. Comparing with our baseline results based on rural-urban dummies constructed based on population dummies shown in Figure 10, Figure A2 presents similar results.

\section{Table A8: Grid Cell Level Regressions, Rural-Urban Dummies based on GDP}

\begin{tabular}{|c|c|c|c|c|c|c|}
\hline \multicolumn{7}{|c|}{$\begin{array}{l}\text { Dependent variable }=\text { Net migration rates } \\
\text { Definition of rural-urban areas is based on GDP at the grid cell level }\end{array}$} \\
\hline & \multicolumn{2}{|c|}{ Poor } & \multicolumn{2}{|c|}{ Lower-middle } & \multicolumn{2}{|c|}{ Upper-middle } \\
\hline & $(1)$ & $(2)$ & $(3)$ & $(4)$ & $(5)$ & $(6)$ \\
\hline$\Delta T e m p$ & $\begin{array}{c}1.488^{* * *} \\
(0.220)\end{array}$ & $\begin{array}{c}-0.508^{* *} \\
(0.213)\end{array}$ & $\begin{array}{c}-0.642^{* *} \\
(0.291)\end{array}$ & $\begin{array}{l}-2.298^{* * *} \\
(0.392)\end{array}$ & $\begin{array}{c}-0.869^{* * *} \\
(0.111)\end{array}$ & $\begin{array}{c}-0.468^{* * *} \\
(0.0820)\end{array}$ \\
\hline$D^{\text {Middle-urban }} \times \Delta$ Temp & & $\begin{array}{r}-0.0294 \\
(0.268)\end{array}$ & & $\begin{array}{c}0.634 \\
(0.651)\end{array}$ & & $-0.434^{* * *}$ \\
\hline$D^{\text {Middle-rural }} \times \Delta T e m p$ & & $\begin{array}{c}1.347^{* * *} \\
(0.471)\end{array}$ & & $\begin{array}{c}3.046^{* * *} \\
(0.792)\end{array}$ & & $\begin{array}{l}-0.383 \\
(0.272)\end{array}$ \\
\hline$D^{\text {Rural }} \times \Delta$ Temp & & $\begin{array}{c}5.218^{* * *} \\
(0.625)\end{array}$ & & $\begin{array}{c}2.804^{* * *} \\
(0.771)\end{array}$ & & $\begin{array}{c}-0.960^{* * *} \\
(0.292)\end{array}$ \\
\hline Observations & 23,191 & 23,191 & 10,898 & 10,898 & 31,787 & 31,787 \\
\hline Grid cells & 7,851 & 7,851 & 3,734 & 3,734 & 10,770 & 10,770 \\
\hline$R$-squared & 0.259 & 0.268 & 0.247 & 0.255 & 0.135 & 0.145 \\
\hline \multicolumn{7}{|c|}{ Temperature effects (Linear combination of coefficients) } \\
\hline \multicolumn{2}{|c|}{ Middle-urban areas } & $\begin{array}{c}-0.537^{* * *} \\
(0.202)\end{array}$ & & $\begin{array}{c}-1.664^{* * *} \\
(0.541)\end{array}$ & & $\begin{array}{c}-0.902^{* * *} \\
(0.141)\end{array}$ \\
\hline \multicolumn{2}{|l|}{ Middle-rural areas } & $\begin{array}{c}0.839 \\
(0.425)\end{array}$ & & $\begin{array}{l}0.749 \\
(0.714)\end{array}$ & & $\begin{array}{c}-0.851^{* * *} \\
(0.272)\end{array}$ \\
\hline \multicolumn{2}{|l|}{ Rural areas } & $\begin{array}{c}4.710^{* * *} \\
(0.590)\end{array}$ & & $\begin{array}{l}0.507 \\
(0.660)\end{array}$ & & $\begin{array}{c}-1.428^{* * *} \\
(0.288)\end{array}$ \\
\hline \multirow{2}{*}{\multicolumn{2}{|c|}{$\begin{array}{l}\text { Controls } \\
D^{\text {Rural-urban }} \times \text { Year fixed effects } \\
D^{\text {Rural-urban }} \times \Delta \text { Precipitation }\end{array}$}} & Yes & & Yes & & Yes \\
\hline & & Yes & & Yes & & Yes \\
\hline
\end{tabular}

Notes: All regressions include $D^{\text {Region }} \times$ Year fixed effects, $D^{\text {Rural-urban }} \times$ population growth rates, and country fixed effects as controls. Robust standard errors clustered at the country-level are in parentheses. ***, **, and * indicate statistical significance at the $1 \%, 5 \%$, and $10 \%$ level, respectively. 


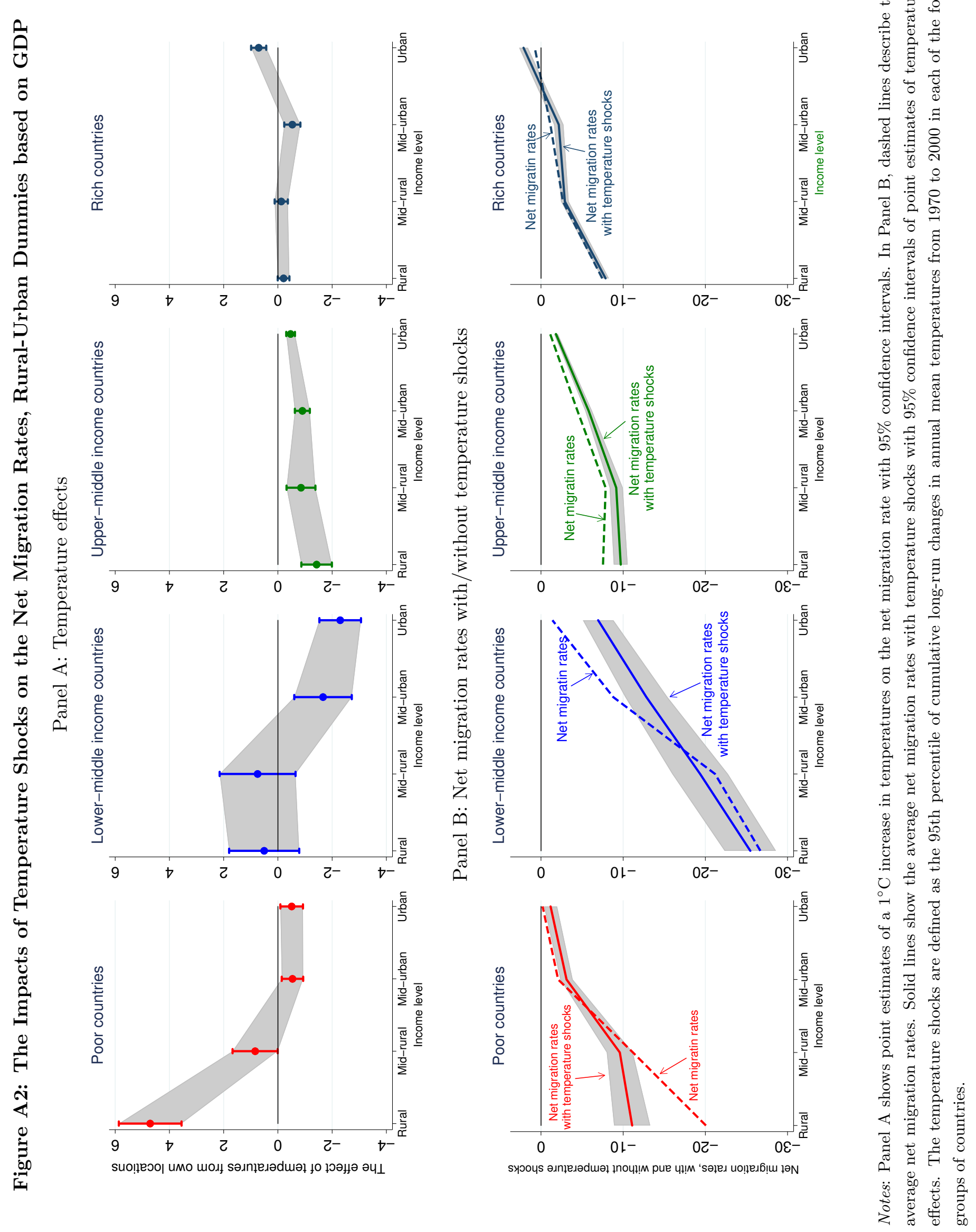




\section{F.2 Is China Special?}

This section considers the case of China because a number of studies document that China is special in terms of its patterns of internal migrations in some ways. For example, Au and Henderson (2006) considers an effect of immigration restrictions in China called the Hukou system. They show that restricted internal migrations led to insufficient agglomeration of economic activities, resulted in a GDP loss. On the other hand, Chen et al. (2010) describe that, despite the fact that there were migration restrictions, 34.1 million, 67 million, and 140 million rural population migrated to urban China in 1990, 1999, and 2008, respectively, by referencing to prior studies. ${ }^{29}$ These suggest that China might be special in terms of internal migration patterns in some ways. Therefore, we estimate grid cell level regressions without China.

\section{Table A9: Grid Cell Level Regressions, Poor Countries, Excluding China}

Dependent variable $=$ Net migration rates

Definition of rural-urban areas is based on Population at the grid cell level

\begin{tabular}{|c|c|c|c|c|c|c|}
\hline & \multicolumn{2}{|c|}{ Baseline } & \multicolumn{2}{|c|}{ Excluding China } & \multicolumn{2}{|c|}{ Only China } \\
\hline & $(1)$ & $(2)$ & $(3)$ & $(4)$ & $(5)$ & $(6)$ \\
\hline \multirow{4}{*}{$D^{\text {Middle-urban }} \times \Delta T e m p$} & $1.484^{* * *}$ & -0.312 & $0.641^{*}$ & 0.307 & $2.283^{* * *}$ & $0.233^{* *}$ \\
\hline & $(0.219)$ & $(0.192)$ & $(0.340)$ & $(0.238)$ & $(0.307)$ & $(0.099)$ \\
\hline & & -0.330 & & $-0.925^{* *}$ & & $0.271^{*}$ \\
\hline & & $(0.249)$ & & $(0.394)$ & & $(0.153)$ \\
\hline \multirow[t]{2}{*}{$D^{\text {Middle-rural }} \times \Delta T e m p$} & & $0.908^{* *}$ & & -1.072 & & $1.552^{* *}$ \\
\hline & & $(0.450)$ & & $(0.749)$ & & $(0.664)$ \\
\hline \multirow[t]{2}{*}{$D^{\text {Rural }} \times \Delta T e m p$} & & $5.054^{* * *}$ & & $4.095^{* * *}$ & & $2.664^{* * *}$ \\
\hline & & $(0.619)$ & & $(1.224)$ & & $(0.745)$ \\
\hline Observations & 23,191 & 23,191 & 14,900 & 14,900 & 8,291 & 8,291 \\
\hline Grid cells & 7,851 & 7,851 & 5,068 & 5,068 & 2,783 & 2,783 \\
\hline$R$-squared & 0.263 & 0.272 & 0.302 & 0.311 & 0.124 & 0.161 \\
\hline \multicolumn{7}{|c|}{ Temperature effects (Linear combination of coefficients) } \\
\hline \multirow[t]{2}{*}{ Middle-urban } & & $-0.642^{* * *}$ & & $-0.618^{*}$ & & $0.504^{* * *}$ \\
\hline & & $(0.199)$ & & $(0.332)$ & & $(0.116)$ \\
\hline \multirow{2}{*}{\multicolumn{2}{|c|}{ Middle-rural }} & 0.597 & & -0.765 & & $1.785^{* * *}$ \\
\hline & & $(0.414)$ & & $(0.710)$ & & $(0.657)$ \\
\hline \multirow[t]{2}{*}{ Rural } & & $4.742^{* * *}$ & & $4.402^{* * *}$ & & $2.897^{* * *}$ \\
\hline & & $(0.592)$ & & $(1.206)$ & & $(0.739)$ \\
\hline \multicolumn{7}{|l|}{ Controls } \\
\hline$D^{\text {Rural-urban }} \times$ Year fixed effects & & Yes & & Yes & & Yes \\
\hline$D^{\text {Rural-urban }} \times \Delta$ Precipitation & & Yes & & Yes & & Yes \\
\hline
\end{tabular}

Notes: All regressions include $D^{\text {Region }} \times$ Year fixed effects, $D^{\text {Rural-urban }} \times$ Population growth rates, and country fixed effects, where $D^{\text {Rural-urban }}$ indicate dummy variables for rural areas, middle-rural areas, middle-urban areas, and urban areas and $D^{\text {Region }}$ denote dummy variables for regions in the world including Asia, Europe, North America, Oceania, South America, Middle East and North Africa, and Sub-Saharan Africa. Rural-urban locations are defined by population at the grid cell level. Robust standard errors clustered at the grid cell level are in parentheses. $* * *, * *$, and $*$ indicate statistical significance at the $1 \%, 5 \%$, and $10 \%$ level, respectively.

In our sample China is included as a poor country due to its low income level in 1980. Therefore, we re-estimate regressions with grid cell level data from poor countries without China. The first two columns of Table A9 show baseline results with grid cells from China as a reference. These come from

\footnotetext{
${ }^{29}$ The articles they reference are Cai (1996), Huang and Pieke (2003), and China's National Bureau of Statistics reports.
} 
columns (1) and (2) in Table 2. Columns (3) and (4) show results from excluding grid cells from China. The results qualitatively stay the same - the temperature effects are positive in rural areas and basically there is essentially no effect in urban area. Columns (5) and (6) present results from grid cells from China only. Column (6) shows that temperature effects on the net migration rates are positive in all areas 0.23 (urban), 0.50 (middle-urban), 1.79 (middle-rural), and 2.90 (rural) — and these are all statistically significant. However, the magnitude of the temperature is greater for rural areas, which is consistent with our hypothesis that rural areas are more sensitively affected by rising temperatures. These results suggest that internal migration patterns in China still fit to our theoretical framework.

\section{F.3 Spatial Correlation of the Error Term}

We consider possible spatial correlation of the error term because the size of one grid cell is fairly small $-50 \mathrm{~km} \times 50 \mathrm{~km}$ around the equator - and there may be correlation of climatic conditions across space. In order to address this, we cluster standard errors at more aggregated grid cells.

Table A10: Different Standard Errors

\begin{tabular}{|c|c|c|c|c|c|}
\hline & \multirow[b]{2}{*}{ Coefficients } & \multicolumn{4}{|c|}{ Clustering robust standard errors } \\
\hline & & $\overline{\mathrm{I} \text { (Baseline) }}$ & II & III & IV \\
\hline Urban & -0.312 & $(0.268)$ & $(0.255)$ & $(0.600)$ & $(0.772)$ \\
\hline Middle-urban & -0.642 & $(0.279)^{* *}$ & $(0.242)^{* * *}$ & $(0.610)$ & $(0.686)$ \\
\hline Middle-rural & 0.597 & $(0.476)$ & $(0.453)$ & $(0.872)$ & $(0.957)$ \\
\hline Rural & 4.742 & $(0.810)^{* * *}$ & $(0.785)^{* * *}$ & $(1.408)^{* * *}$ & $(2.000)^{* *}$ \\
\hline \# of grid cells & in one cluster & 1 & 3 & 85 & 253 \\
\hline & \# of clusters & 7,851 & 2,553 & 92 & 31 \\
\hline \multicolumn{6}{|c|}{ Panel B: Lower-middle income countries } \\
\hline & & \multicolumn{4}{|c|}{ Clustering robust standard errors } \\
\hline & Coefficients & I (Baseline) & II & III & IV \\
\hline Urban & -2.344 & $(0.576)^{* * *}$ & $(0.464)^{* * *}$ & $(1.172)^{* *}$ & $(1.780)$ \\
\hline Middle-urban & -1.834 & $(0.778)^{* *}$ & $(0.675)^{* * *}$ & $(1.185)$ & $(1.327)$ \\
\hline Middle-rural & 0.857 & $(0.916)$ & $(0.772)$ & $(1.796)$ & $(2.333)$ \\
\hline Rural & 0.510 & $(0.982)$ & $(0.790)$ & $(1.865)$ & $(2.787)$ \\
\hline \# of grid cells & in one cluster & 1 & 3 & 37 & 98 \\
\hline & \# of clusters & 3,734 & 1,411 & 102 & 38 \\
\hline \multicolumn{6}{|c|}{ Panel C: Upper-middle income countries } \\
\hline & & \multicolumn{4}{|c|}{ Clustering robust standard errors } \\
\hline & Coefficients & $\overline{\mathrm{I}}$ (Baseline) & II & III & IV \\
\hline Urban & -0.441 & $(0.099)^{* * *}$ & $(0.101)^{* * *}$ & $(0.223)^{* * *}$ & $(0.309)$ \\
\hline Middle-urban & -0.958 & $(0.188)^{* * *}$ & $(0.172)^{* * *}$ & $(0.371)^{* *}$ & $(0.310)^{* * *}$ \\
\hline Middle-rural & -0.845 & $(0.367)^{* *}$ & $(0.341)^{* *}$ & $(0.711)$ & $(0.773)$ \\
\hline Rural & -1.346 & $(0.377)^{* * *}$ & $(0.350)^{* * *}$ & $(0.640)^{* *}$ & $(0.630)^{* *}$ \\
\hline \multirow{2}{*}{\multicolumn{2}{|c|}{$\begin{array}{r}\text { \# of grid cells in one cluster } \\
\text { \# of clusters }\end{array}$}} & 1 & 3 & 67 & 207 \\
\hline & & 10,770 & 3,683 & 160 & 52 \\
\hline
\end{tabular}

Notes: The table reports different clustering robust standard errors corresponding to point estimates shown in even number columns in Table 2. ***,**, and * indicate statistical significance at the $1 \%, 5 \%$, and $10 \%$ level, respectively.

Table A10 shows point estimates of temperature effects on the internal migration rates in even number 
columns in Table 2. Panels A, B, and C summarize results from poor countries, lower-middle income countries, and upper-middle income countries, respectively. For each point estimates for Urban, Middleurban, Middle-rural, and Rural areas, it shows robust standard errors clustered at four different cross sectional units.

We construct more aggregated grid cells by using longitude and latitude of original grid cells. As a result, aggregated grid cells include original grid cells that are geographically close. Because we do not take countries' borders into consideration, two grid cells from different countries may be included in one aggregated grid cells (e.g., a grid cell from Belgium and a grid cell in Luxembourg may be included in one aggregated grid cell). Also, two grid cells from one country can be in different aggregated grid cells (e.g., a grid cell from California and a grid cell from Florida are in different aggregated grid cells because these two locations are away from each other even though these are in the same country).

Column I shows our baseline standard errors clustered at $0.5 \times 0.5$ grid cells. Column II reports standard errors clustered at more aggregated grid cells — cross-sectional unit II includes three original grid cells on average and the number of clusters is $2,553,1,411$, and 3,683 for poor countries, lowermiddle income countries, and upper-middle income countries, respectively. It shows that standard errors in column B are similar to those in column I. Therefore, statistical significance is also similar as column I. Because clustering-robust standard errors in column II are slightly smaller than those in column I, the statistical significance increased in some rows.

Column III reports standard errors even more aggregated grid cells - the average number of grid cells contained in one cluster is 85, 37, and 67 for poor countries, lower-middle income countries, and upper-middle income countries, respectively. As a result, the number of clusters is 92, 102, and 160 for these groups of countries, respectively. Clustering at these even more aggregated grid cells blows up standard errors. As a result, coefficients from Middle-urban areas in poor countries, Middle-rural areas in lower-middle countries, and Middle-rural areas in upper-middle countries become insignificant (both are significant at the 5 percent level in column I).

Lastly, column IV resents clustering robust standard errors based on the largest aggregation — the average number of grid cells included in one cluster is 253, 98, and 207 for poor countries, lower-middle income countries, and upper-middle income countries, respectively. This increases standard errors substantially. As a result, the coefficient from Middle-urban areas in poor countries lost its significance. It also makes all coefficients from lower-middle income countries insignificant. The coefficient for Urban areas in upper-middle income countries turns to be insignificant as well. However, the most important sets of results remain hold true - a higher temperature increases the net migration rate in Rural areas in poor countries and reduces it in Rural areas in upper-middle income countries. Overall, our baseline results remain the same even clustering at more aggregated geographical units. 


\section{G Expected Internal Migration Rates}

This section describes procedures to find expected internal migration rates for 2010-2080 in detail and discusses results. As described in section 5.4, we find expected internal migration rates using estimated coefficients and projected temperature changes provided by the World Bank. Tables A11 and A12 summarize estimated expected internal migration rates shown in Figure 15 with some additional information. Panels A, B, and C show results for poor, lower-middle, and upper-middle countries, respectively. Panel D summarizes overall impact for the three groups of countries.

\section{G.1 Procedures and details}

In the first three panels, column (1) shows the actual average internal migration rates during 1990-2000 and implied number of migrants. These average internal migration rates are slightly different from the ones shown in Table 3 because we restrict our focus on countries actually used in country-level regressions only. We use the average internal migration rates and the total population in the three groups of countries in the year 2000 - 3,218 million, 758 million, 1,093 million for poor, lower-middle, and upper-middle, respectively - to find the total number of migrants shown in column (1). ${ }^{30}$ In the regression, we use $A M R_{c, t}^{s}=100 \times A g g M i g_{c, t}^{s} / P_{o p}, t-10$ as the dependent variable where $A g g M i g_{c, t}^{s}$ denotes country c's aggregate internal migrations during the decade from year $t=10$ to year $t$ and $P o p_{c, t-10}$ indicates population in year $t-10$ for $s=$ 'Total' and 'Rural Mid-Rural'. ${ }^{31}$ It shows that we use initial population in the denominator. However, in Tables A11 and A12, we use population data from the year 2000 to infer how many people would migrate during the decade 2000-2010 given the level of population in 2000 under the condition where the internal migration rates and economic conditions were the same as the previous decade 1990-2000. The calculation implies that 228 million, 53 million, and 76 million of people would internally migrate during 2000-2010 in poor, lower-middle, and upper-middle countries, respectively.

The expected internal migration rates presented in columns (3)-(6) are estimated using the method explained in section 5.4 in the main text. We have two different estimates based on A2 and B1 scenarios for each group of countries. Temperature changes used for column (3) are $\left(\right.$ Temp $p_{c, 2020-2040}-$

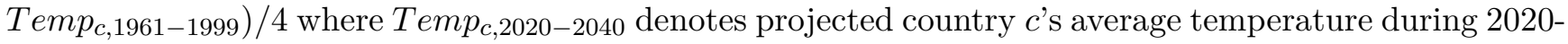
2040 and $T e m p_{c, 1961-1999}$ is the average temperature during 1961-1999 in the same country. It is divided by four to make it decennial change. Temperature changes used for column (4) are $\left(\right.$ Temp $p_{c, 2040-2060-}$ $\left.\mathrm{Temp}_{c, 2020-2040}\right) / 2$ where it is divided by two to make it decennial change. Temperature changes used in Columns (5) and (6) are found by using the same equation for column (4). Because we use the temperature change from the previous column for columns (4)-(6), the expected internal migration rates in those columns are based on decennial change in temperatures from the previous decade rather than cumulative changes from the level 1961-1999. We use these expected internal migration rates and the population data from the year 2000 to find the total number of people who are expected to migrate due to projected temperature changes when the population level were the 2000 level and economic conditions are the same as the decade 1990-2000.

Column (2) shows the expected migration rates during the period from 2000 to 2015 . We use actual temperature changes (from the level 1961-1999 to the level 2015) to find the expected migration rates. ${ }^{32}$ We take different calculation steps to find expected internal migration rates for the period because crosscountry variations in actual temperature changes for 2015 are different from the World Banks' projections

\footnotetext{
${ }^{30}$ We obtain data on population on individual countries in 2000 from the WDI (World Bank, 2018) then we calculate the total population for each country group. All available countries' populations are included (not just countries used in the country-level regression analysis).

${ }^{31}$ The notation AggMigRate is employed in the main text but we use a notation $A M R$ to simplify equations in this section.

${ }^{32}$ The average temperature level for 2015 is calculated as follows. First, we find the average temperatures during the period 2010-2015 for each country using the data from the Climate Change Knowledge Portal (World Bank, 2018). We use the average of the six years 2010-2015 to reduce the impact of weather anomalies in certain years. Second, we compute the group average of these country-level average temperatures during 2010-2015. Third, we find the change in the average temperatures from the 1961-1999 level, which is denoted as $\Delta T e m p_{h, 1961-1999}^{2015}$ for country group $h$.
} 
for 2020-2100 probably due to the fact that some countries experienced weather anomalies. The differences in cross-country variations across time lead to an estimate for 2000-2015 that is different from other periods in the sense that the estimate for 2000-2015 does not fall in the range between the one from 1990-2000 and 2020-40. For this reason, we use the average temperature change four each country group rather than individual countries' temperature changes.

Specifically, the internal migration rates for 2000-2015 are found by taking the following steps. First, we find the average temperature change between the 1961-1999 level and the 2015 level. For example, this figure is $0.356^{\circ} \mathrm{C}$ for poor countries. Second, we find the average projected temperature change between the 1961-1999 level and the 2020-40 level. Third, we use the expected internal migration rates in 2020-40 in country group $h, A M R_{h, 2020-40}^{s}$, the actual internal migration rates in 1990-2000AMR $R_{h, 1990-2000}^{s}$, and the temperature changes in the previous steps as follows:

$$
\begin{aligned}
A M R_{h, 2000-15}^{s} & =A M R_{g, 2020-40}^{s}-\left(A M R_{h, 2020-40}^{s}-A M R_{h, 1990-2000}^{s}\right) \times \frac{\Delta T e m p_{h, 1961-1999}^{2015}}{\Delta T e m p_{h, 1961-1999}^{2020-40}} \\
& =5.38 \%-(5.38 \%-7.10 \%) \times \frac{0.356^{\circ} C}{1^{\circ} C} \\
& =6.49 \%
\end{aligned}
$$

for $h=$ Poor under A2 scenario. This is $A M R_{h, 2000-15}^{s}=5.40 \%-(5.40 \%-7.10 \%) \times 0.356^{\circ} C / 1^{\circ} C=$ $6.50 \%$ under B1 scenario. The expected internal migration rates for 2000-2015 are different between two scenarios because we use the expected net migration rates in 2020-40, $A M R_{h, 2020-40}^{s}$, which depends on the scenarios.

\section{G.2 Results}

\section{G.2.1 Poor countries}

We discuss projection results, starting from poor countries. Panel A of Table A11 shows the expected total internal migration rates for this group. The regression results in the main text suggest insignificant temperature effects on poor countries when we employ the total internal migration rate as the dependent variable. Therefore, we should take these results with caution. Nonetheless, it gives a good understanding of what the estimated coefficients imply. Column (1) shows that the actual internal migration rate during 1990-2000, $A M R_{h, 1990-2000}^{\text {Total }}=100 \times A g g M i g_{h, 1990-2000}^{\text {Total }} / P_{\text {op }}, 1990=7.1 \%$. By multiplying the total population in the year 2000 in this group of countries, we find that 228.5 million people would have internally migrated during 2000-2010. This can be interpreted as hypothetical number of migrants during 2000-2010, given the level of population in 2000, when temperature changes and economic conditions were kept as the 1990-2000 level.

Column (2) uses actual temperature changes during 2000-2015 to find the internal migration rates and the number of migrants. The only difference between columns (1) and (2) are temperature changes. Therefore, temperature rises during 2000-2015 alone imply a 8.6\% decline of internal migrations under A2 scenario and a $8.5 \%$ decline under B1 scenario. Subsequent columns, (3)-(4), show expected internal migration rates for the period 2020-2100. These show that rising temperature reduce total internal migrations by $29 \%$ and $23 \%$ by $2080-2100$ under A2 and B1 scenarios, respectively. Equivalently, the number of people migrate declines by 66.6 millions and 52.2 millions from 2000 to 2080-2100.

Panel A of Table A12 present expected rural out-migration rates computed using the same procedure. Because the country-level regressions in the main text find statistically significant temperature effects on the rural out-migration rates, results from Table A12 are more reliable for poor countries. It shows that the number of rural out-migrations is expected decline from 61.6 millions to 44.2 millions by 20802100, a decline of 17.4 millions, under A2 scenario. On the other hand, the expected decline of rural out-migrations is 0.7 millions under B2 scenario. 


\section{G.2.2 Lower-middle income countries}

Panel B of Table A11 shows that, the total number of migrations was 53.2 millions in the beginning of the century and it is expected to increase to 54.6 millions, an 1.4 million increase, which is equivalent to a $2.7 \%$ increase, under A2 scenario. B1 scenario implies even mode moderate increase of $1.7 \%$. Panel B of Table A12 indicates that, under A2 scenario, the number of rural out-migrations is expected to increase from 11.28 millions to 11.93 millions by 2080-2100, a 0.6 million increase, which is equal to a $5.7 \%$ rise. This figure remains at 3.5\% under B1 scenario. We acknowledge that the country-level regressions find insignificant temperature effects on lower-middle income countries. Therefore, we should see these results with caution.

\section{G.2.3 Upper-middle income countries}

Panel C of Table A11 describes the expected total internal migrations for upper-middle income countries. The number of internal migrations was 76.4 millions in the beginning of this century. Under A2 scenario, This figure is expected to increase to 85.2 millions by $2080-2100$, which is an increase of 8.9 millions or a $11.7 \%$ rise from the earlier century. On the other hand, under B1 scenario, it remains at a $0.9 \%$ rise by $2080-2100$. This scenario predicts the largest response of $8.5 \%$ rise during $2040-60$ because changes in temperatures are expected to be greatest during this period. Panel $\mathrm{C}$ of Table A12 indicates the expected rural out-migrations. It shows that, under A1 scenario, the number of rural out-migrations is expected to change to 15.8 millions by 2080-2100, which was 13.3 millions in the beginning of the century. These numbers suggest a 2.5 million increase or a $18.7 \%$ increase from the earlier century. On the other hand, these figures are merely 0.3 million increase or a $2.2 \%$ increase under B1 scenario, respectively.

\section{G.2.4 Overall expected impacts of the projected temperature rise}

Lastly, Panel D of the two tables show the total number of people affected by temperature rises. We compute this figure by summing a change in the number of migrants - the number of migrants in each of the columns (2)-(6) minus the one shown in column (1). The total number of people migrated due to a rise in temperatures is 21.0-21.4 millions during 2000-2015. By 2080-2100, this figure is expected to increase to 76.9 millions and 53.8 millions under A2 and B1 scenarios, respectively. These numbers of migrants are $1.53 \%$ and $1.06 \%$ of the total population in the three groups of countries, respectively.

The total numbers of rural out-migrations induced to migrate by temperature rises are also shown in Panel D of Table A12. It is 1.8-2.1 millions during 2000-2015. This number is expected to change to 20.5 millions and 1.4 millions under A2 and B1 scenarios, respectively, which are equivalent to $0.4 \%$ and $0.03 \%$ of the total population, respectively, under the two scenarios. 


\section{Table A11: Expected Total Internal Migration Rates}

\begin{tabular}{|c|c|c|c|c|c|c|}
\hline \multicolumn{7}{|c|}{ Panel A: Poor countries } \\
\hline & $(1)$ & $(2)$ & $(3)$ & $(4)$ & $(5)$ & $(6)$ \\
\hline & $1990-2000^{*}$ & $2000-2015^{* *}$ & $2020-40$ & $2040-60$ & $2060-80$ & $2080-2100$ \\
\hline \multicolumn{7}{|l|}{ A2 Scenario } \\
\hline Total internal migration rates & $7.10 \%$ & $6.49 \%$ & $5.38 \%$ & $5.25 \%$ & $5.13 \%$ & $5.03 \%$ \\
\hline \# of migrants (million) & 228.5 & 208.8 & 173.1 & 169.1 & 164.9 & 161.9 \\
\hline $\begin{array}{l}\text { Rate of change from } 2000 \\
\text { B1 Scenario }\end{array}$ & & $-8.6 \%$ & $-24.2 \%$ & $-26.0 \%$ & $-27.8 \%$ & $-29.1 \%$ \\
\hline Total internal migration rates & $7.10 \%$ & $6.50 \%$ & $5.40 \%$ & $5.19 \%$ & $5.40 \%$ & $5.48 \%$ \\
\hline \# of migrants (million) & 228.5 & 209.0 & 173.8 & 167.0 & 173.8 & 176.3 \\
\hline Rate of change from 2000 & & $-8.5 \%$ & $-24.0 \%$ & $-26.9 \%$ & $-23.9 \%$ & $-22.8 \%$ \\
\hline \multicolumn{7}{|c|}{ Panel B: Lower-middle income countries } \\
\hline & $1990-2000^{*}$ & $2000-2015^{* *}$ & $2020-40$ & $2040-60$ & $2060-80$ & $2080-2100$ \\
\hline \multicolumn{7}{|l|}{ A2 Scenario } \\
\hline Total internal migration rates & $7.02 \%$ & $7.04 \%$ & $7.15 \%$ & $7.17 \%$ & $7.19 \%$ & $7.20 \%$ \\
\hline \# of migrants (million) & 53.2 & 53.4 & 54.2 & 54.3 & 54.5 & 54.6 \\
\hline $\begin{array}{l}\text { Rate of change from } 2000 \\
\text { B1 Scenario }\end{array}$ & & $0.3 \%$ & $1.9 \%$ & $2.1 \%$ & $2.4 \%$ & $2.7 \%$ \\
\hline Total internal migration rates & $7.02 \%$ & $7.04 \%$ & $7.14 \%$ & $7.18 \%$ & $7.15 \%$ & $7.13 \%$ \\
\hline \# of $\mathrm{m}$ & 53.2 & 53.4 & 54.1 & 54.5 & 54.2 & 54.1 \\
\hline Rate of change from 2000 & & $0.3 \%$ & $1.8 \%$ & $2.3 \%$ & $1.9 \%$ & $1.7 \%$ \\
\hline \multicolumn{7}{|c|}{ Panel C: Upper-middle income countries } \\
\hline & 1990-2000* & $2000-2015^{* *}$ & $2020-40$ & $2040-60$ & $2060-80$ & $2080-2100$ \\
\hline \multicolumn{7}{|l|}{ A2 Scenario } \\
\hline$\overline{\text { Total internal migration rates }}$ & $6.99 \%$ & $7.13 \%$ & $7.24 \%$ & $7.45 \%$ & $7.65 \%$ & $7.80 \%$ \\
\hline \# of migrants (million) & 76.4 & 77.9 & 79.1 & 81.5 & 83.7 & 85.2 \\
\hline $\begin{array}{l}\text { Rate of change from } 2000 \\
\text { B1 Scenario }\end{array}$ & & $2.0 \%$ & $3.6 \%$ & $6.7 \%$ & $9.6 \%$ & $11.7 \%$ \\
\hline al migration rates & $6.99 \%$ & $7.11 \%$ & $7.21 \%$ & $7.58 \%$ & $7.20 \%$ & $7.05 \%$ \\
\hline \# of $\mathrm{n}$ & 76.4 & 77.7 & 78.8 & 82.9 & 78.7 & 77.1 \\
\hline Rate of change from 2000 & & $1.8 \%$ & $3.2 \%$ & $8.5 \%$ & $3.1 \%$ & $0.9 \%$ \\
\hline \multicolumn{7}{|c|}{ Panel D: Number of people affected by rising temperatures } \\
\hline & $1990-2000^{*}$ & $2000-2015^{* *}$ & $2020-40$ & $2040-60$ & $2060-80$ & $2080-2100$ \\
\hline \multicolumn{7}{|l|}{ A2 Scenario } \\
\hline$\overline{\# \text { of affected peo }}$ & & 21.4 & 59.1 & 65.7 & 72.2 & 76.9 \\
\hline $\begin{array}{l}\text { As a share of population } \\
\text { B1 Scenario }\end{array}$ & & $0.42 \%$ & $1.17 \%$ & $1.30 \%$ & $1.42 \%$ & $1.52 \%$ \\
\hline$\overline{\# \text { of affected people (million) }}$ & & 21.0 & 58.2 & 69.3 & 58.1 & 53.8 \\
\hline As a share of population & & $0.42 \%$ & $1.15 \%$ & $1.37 \%$ & $1.15 \%$ & $1.06 \%$ \\
\hline
\end{tabular}

Notes: The table shows the average expected total internal migration rates. ${ }^{*}$ Column (1) shows expected internal migration rates during 1990-2000 and implied number of migrations during 2000-2010 given the level of population in the year 2000 . **Column (2) reports expected internal migration rates and implied number of migrations during 2000-2015 given the actual change in temperatures during the period 2000-2015. Columns (3)-(6) are those based on projected temperature changes given by the World Bank. The total number of migrants is computed based on the expected migration rates and the total population in each country group in 2000 obtained from the WDI. See the text for details. 


\section{Table A12: Expected Rural Out-Migration Rates}

\begin{tabular}{|c|c|c|c|c|c|c|}
\hline \multicolumn{7}{|c|}{ Panel A: Poor countries } \\
\hline & (1) & $(2)$ & (3) & $(4)$ & $(5)$ & (6) \\
\hline & 1990-2000* & $2000-2015^{* *}$ & $2020-40$ & 2040-60 & $2060-80$ & $2080-2100$ \\
\hline \multicolumn{7}{|l|}{ A2 Scenario } \\
\hline Total internal migration & $1.92 \%$ & $1.87 \%$ & $1.78 \%$ & $1.63 \%$ & $1.48 \%$ & $1.37 \%$ \\
\hline \# of migrants (million) & 61.6 & 60.1 & 57.3 & 52.6 & 47.7 & 44.2 \\
\hline $\begin{array}{l}\text { Rate of change from } 2000 \\
\text { B1 Scenario }\end{array}$ & & $-2.5 \%$ & $-7.1 \%$ & $-14.7 \%$ & $-22.6 \%$ & $-28.2 \%$ \\
\hline Total internal migration rates & $1.92 \%$ & $1.88 \%$ & $1.80 \%$ & $1.56 \%$ & $1.80 \%$ & $1.89 \%$ \\
\hline \# of migrants (millio & 61.6 & 60.3 & 58.0 & 50.3 & 58.1 & 60.9 \\
\hline Rate of change from 2000 & & $-2.1 \%$ & $-5.8 \%$ & $-18.4 \%$ & $-5.8 \%$ & $-1.1 \%$ \\
\hline \multicolumn{7}{|c|}{ Panel B: Lower-middle income countries } \\
\hline & $1990-2000^{*}$ & $2000-2015^{* *}$ & $2020-40$ & $2040-60$ & $2060-80$ & $2080-2100$ \\
\hline \multicolumn{7}{|l|}{ A2 Scenario } \\
\hline Total internal migration rates & $1.49 \%$ & $1.50 \%$ & $1.55 \%$ & $1.56 \%$ & $1.57 \%$ & $1.57 \%$ \\
\hline \# of migrants (million) & 11.28 & 11.36 & 11.72 & 11.80 & 11.88 & 11.93 \\
\hline $\begin{array}{l}\text { Rate of change from } 2000 \\
\text { B1 Scenario }\end{array}$ & & $0.7 \%$ & $3.9 \%$ & $4.6 \%$ & $5.3 \%$ & $5.7 \%$ \\
\hline nal migration rates & $1.49 \%$ & $1.50 \%$ & $1.54 \%$ & $1.56 \%$ & $1.55 \%$ & $1.54 \%$ \\
\hline$\#$ of $\mathrm{m}$ & 11.28 & 11.36 & 11.71 & 11.84 & 11.72 & 11.67 \\
\hline Rate of change from & & $0.7 \%$ & $3.7 \%$ & $5.0 \%$ & $3.9 \%$ & $3.5 \%$ \\
\hline \multicolumn{7}{|c|}{ Panel C: Upper-middle income countries } \\
\hline & 1990-2000* & $2000-2015^{* *}$ & $2020-40$ & $2040-60$ & $2060-80$ & $2080-2100$ \\
\hline \multicolumn{7}{|l|}{ A2 Scenario } \\
\hline$\overline{\text { Total internal migration rates }}$ & $1.22 \%$ & $1.26 \%$ & $1.29 \%$ & $1.35 \%$ & $1.41 \%$ & $1.44 \%$ \\
\hline \# of migrants $(\mathrm{m}$ & 13.3 & 13.8 & 14.1 & 14.8 & 15.4 & 15.8 \\
\hline $\begin{array}{l}\text { Rate of change from } 2000 \\
\text { B1 Scenario }\end{array}$ & & $3.6 \%$ & $6.4 \%$ & $11.1 \%$ & $15.6 \%$ & $18.7 \%$ \\
\hline al migration rates & $1.22 \%$ & $1.26 \%$ & $1.29 \%$ & $1.39 \%$ & $1.29 \%$ & $1.24 \%$ \\
\hline$\#$ of $\mathrm{m}$ & 13.3 & 13.7 & 14.1 & 15.2 & 14.1 & 13.6 \\
\hline Rate of change from 2000 & & $3.3 \%$ & $5.7 \%$ & $14.1 \%$ & $5.7 \%$ & $2.2 \%$ \\
\hline \multicolumn{7}{|c|}{ Panel D: Number of people affected by rising temperatures } \\
\hline & 1990-2000* & $2000-2015^{* *}$ & $2020-40$ & $2040-60$ & $2060-80$ & $2080-2100$ \\
\hline \multicolumn{7}{|l|}{ A2 Scenario } \\
\hline \# of affected pe & & 2.1 & 5.7 & 11.0 & 16.6 & 20.5 \\
\hline $\begin{array}{l}\text { As a share of population } \\
\text { B1 Scenario }\end{array}$ & & $0.04 \%$ & $0.11 \%$ & $0.22 \%$ & $0.33 \%$ & $0.40 \%$ \\
\hline$\overline{\# \text { of affected people (million) }}$ & & 1.8 & 4.8 & 13.8 & 4.8 & 1.4 \\
\hline As a share of population & & $0.04 \%$ & $0.09 \%$ & $0.27 \%$ & $0.09 \%$ & $0.03 \%$ \\
\hline
\end{tabular}

Notes: The table shows the average expected rural out-migration rates. ${ }^{*}$ Column (1) shows expected internal migration rates during 1990-2000 and implied number of migrations during 2000-2010 given the level of population in the year 2000 . **Column (2) reports expected internal migration rates and implied number of migrations during 2000-2015 given the actual change in temperatures during the period 2000-2015. Columns (3)-(6) are those based on projected temperature changes given by the World Bank. The total number of migrants is computed based on the expected migration rates and the total population in each country group in 2000 obtained from the WDI. See the text for details. 